\title{
DYNAMIC SIMULATION OF POLYESTER MOORING LINES
}

\author{
A Thesis \\ by \\ MIN SUK KIM \\ Submitted to the Office of Graduate Studies of \\ Texas A\&M University \\ in partial fulfillment of the requirements for the degree of \\ MASTER OF SCIENCE
}

May 2004

Major Subject: Ocean Engineering 


\title{
DYNAMIC SIMULATION OF POLYESTER MOORING LINES
}

\author{
A Thesis \\ by \\ MIN SUK KIM \\ Submitted to Texas A\&M University \\ in partial fulfillment of the requirements \\ for the degree of \\ MASTER OF SCIENCE
}

Approved as to style and content by:

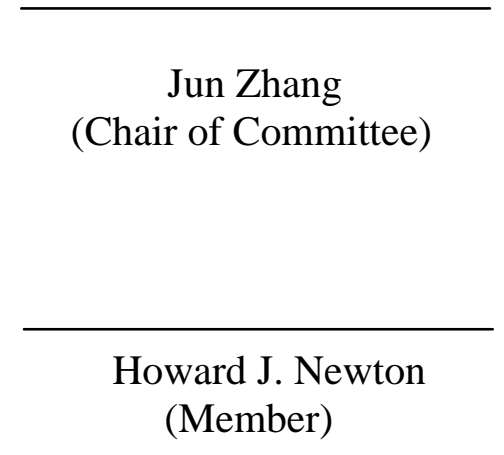

\begin{tabular}{c}
\hline $\begin{array}{c}\text { Moo H. Kim } \\
\text { (Member) }\end{array}$ \\
\hline $\begin{array}{c}\text { Paul Roschke } \\
\text { (Head of Department) }\end{array}$
\end{tabular}

May 2004

Major Subject: Ocean Engineering 


\author{
ABSTRACT \\ Dynamic Simulation of Polyester Mooring Lines. \\ (May 2004) \\ Min Suk Kim, B.S., Inha University \\ Chair of Advisory Committee: Dr. Jun Zhang
}

A numerical scheme, known as CABLE3D, originally developed for the simulation of dynamics of steel chain-wire mooring lines is extended to allow for the large elongation in a mooring line, the dependence of the modulus on tension, and energy dissipation of a polyester rope under mean and cyclic loads. The modified CABLE3D is then integrated into a numerical package, known as COUPLE6D, for computing the interaction between a floating structure and its hybrid polyester mooring system. The Deepstar Spar is chosen in this study to represent the floating structure.

By considering large elongation in polyester ropes in numerical simulation, the static offset curve of a polyester mooring system is softer than that calculated under the assumption of small elongation. That is, about $10 \%$ reduction in restoring force at the mean offset position of the Spar under the impact of 100-year hurricane storm. The effects of the mean loads on the modulus of polyester ropes are much greater than those of the dynamic loads. Hence, the former is more important in the simulation of the response of floating structures. The energy dissipation in polyester ropes under cyclic loading does not play significant roles in the responses of the Spar and tensions in a 
polyester mooring system. The above findings, although observed based on the numerical simulation of a particular floating structure, namely Spar, may have implications to other floating offshore structures moored by a polyester mooring system.

Two systems are simulated in two different met-ocean conditions: hurricane and loop current condition. To study the properties of polyester, numerical simulation were conducted in three ways. Those are related to the modulus based on mean load, mean and dynamic loads, and structural damping respectively. Through the simulation, statistics of motions of the hull and tension in the mooring lines are compared with those of a conventional steel mooring system. 


\section{ACKNOWLEDGEMENTS}

I would like to express my gratitude to my advisor, Dr. Jun Zhang, for first motivating my interest in this research and for providing me his continuous support, guidance, advice, and encouragement during the time I worked with him.

I would like to thank Dr. Moo H. Kim and Dr. Howard J. Newton for serving as my committee members and for their review of my thesis and their valuable advice. I would also like to thank other faculty members and students in the Ocean Engineering Department for their help.

I am thankful to Mr. Yu Ding for sharing his knowledge in simulation skills and coupled dynamic analysis.

I am grateful to the Offshore Technology Research Center for the financial support. 


\section{TABLE OF CONTENTS}

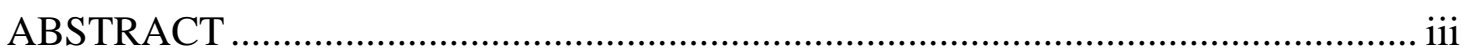

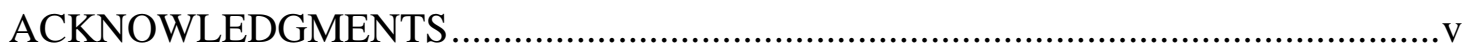

TABLE OF CONTENTS .......................................................................... vi

LIST OF FIGURES ......................................................................................... viii

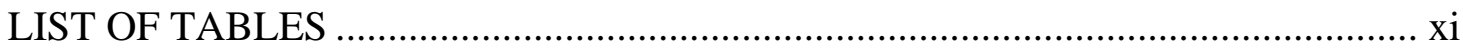

CHAPTER

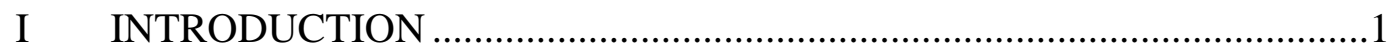

1.1 Current trend of oil and gas industries.............................................1

1.2 A target structure for this research................................................1

1.3 Background of a coupled dynamic analysis ....................................2

1.4 Design criterion of a polyester rope...................................................

1.5 Objective and scope of present study...............................................6

II DYNAMICS OF SLENDER RODS ................................................

2.1 Introduction..........................................................................

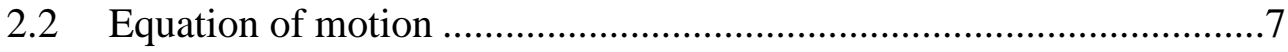

III THEORY OF COUPLED DYNAMIC ANALYSIS ...............................11

3.1 Introduction........................................................................11

3.2 6-DOF Nonlinear motion equation of a rigid body ..........................11

3.3 Coupled dynamic anlaysis ...........................................................16

IV NONLINEAR PROPERTIES OF POLYESTER ......................................20

4.1 Nonlinear stress-strain behavior of polyester .................................20

4.2 Formula for the modulus of a polyester rope..................................23

V NUMERICAL MODELING OF INTERACTION BETWEEN A SPAR AND ITS MOORING SYSTEM …...................................................25 
5.1 Main characteristics of a SPAR and its mooring system ..................25

5.2 Static stiffness curve ...............................................................28

5.2.1 Static offset curve of steel mooring system..................28

5.2.2 Static offset curve of a hybrid polyester mooring system.......28

5.2.3 Iterative process for computing the modulus

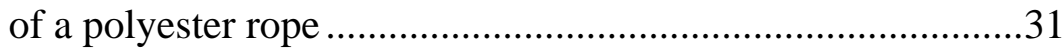

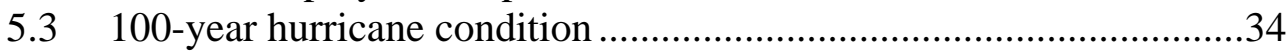

5.3.1 Configuration of the mooring system and met-ocean condition......................................34

5.3.2 Iterative process for computing the modulus as a function of dynamic tension............................................35

$5.4 \quad 50$-year loop current condition....................................................40

5.4.1 Met-ocean condition.......................................40

5.4.2 Modeling the modulus based on mean tension and dynamic tension................................................................42

VI NUMERICAL RESULTS AND DISCUSSION .....................................43

6.1 Introduction.........................................................................43

6.2 Numerical limitation of small extensible rod theory

for a polyester rope....................................................................44

6.3 Theory of structural damping considering energy dissipation............48

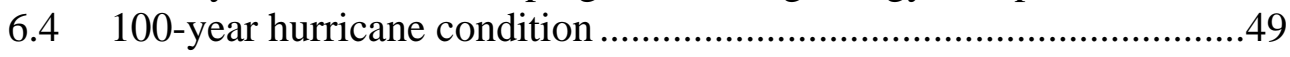

6.4.1 Steel mooring system simulated based on the formulation of large or small elongation...................49

6.4.2 Simulation results of a hybrid polyester mooring system.......52

6.4.3 Comparison of the polyester mooring sytem to the steel mooring system ...................................................57

$6.5 \quad 50$-year loop current condition....................................................64

6.5.1 Simulation results of a hybrid polyester mooring system.....64

6.5.2 Comparison of the polyester mooring system to the steel mooring system ..................................................69

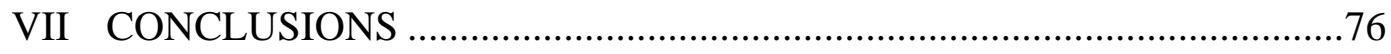

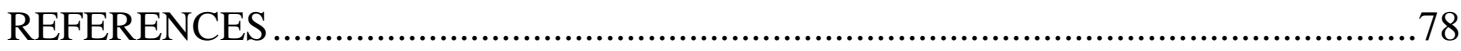

APPENDIX A ISSUES RELATED TO THE SAFETY FACTOR OF POLYESTER ROPE ...............................................................81

VITA 


\section{LIST OF FIGURES}

FIGURE

1 Coordinate system for rigid body motions

2 Coordinate system for structure and mooring system 17

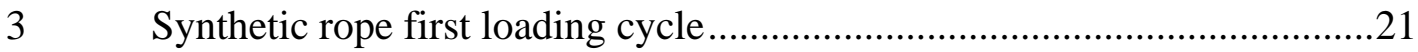

$4 \quad$ Stable hysteresis loops

$5 \quad$ Static offset curve of a mooring system computed using the numerical codes based on small and large elongation respectively .........................29

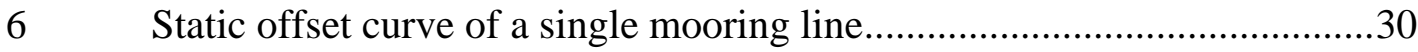

7 Comparison of the extensible and inextensible rod theory for polyester....30

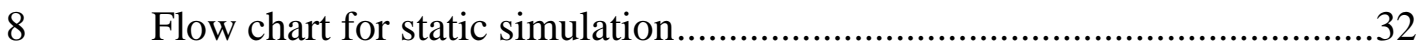

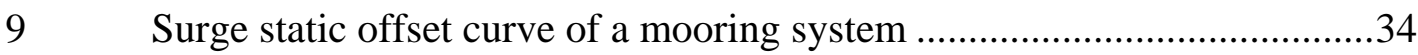

10 Configuration of SPAR in 100-year storm condition.................................35

11 Time series and spectrum $\left(m^{2} \times s\right)$ of wave elevation .............................36

12 Tension at the upper end of the polyester rope in line 1

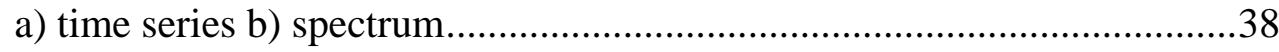

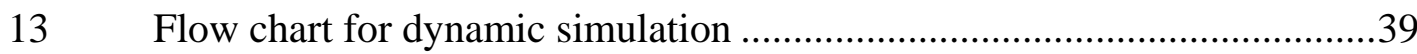

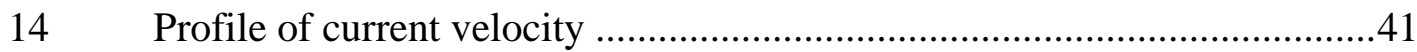

15 Configuration of SPAR in loop current condition .................................41

16 Results in line 1 using small extensible rod theory for polyester rope .......44

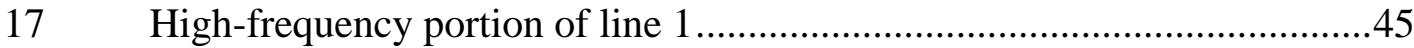

18 Spectrum of line 1 tension of polyester with small elongation theory ........45

19 Longitudinal bar under free vibration: a) two free ends b) equivalent bar with half length and one end fixed ..............................46 
FIGURE $\quad$ Page

20 Natural frequency of the first mode of taut polyester ropes......................47

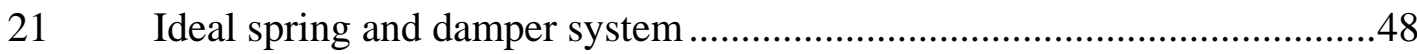

22 Surge motions of steel chain-wire mooring systems in hurricane condition..............................................50

23 Sway motions of steel chain-wire mooring systems

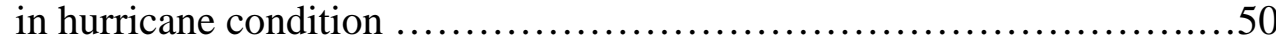

24 Heave motions of steel chain-wire mooring systems

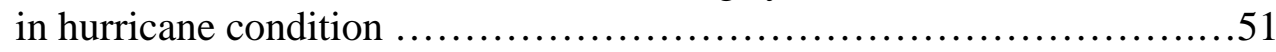

25 Line 1 tensions of steel chain-wire ropes in hurricane condition...........51

26 Line 8 tensions of steel chain-wire ropes in hurricane condition...........51

27 Surge motions in hurricane condition as a function of $a$ ) time and $b$ ) frequency.............................53

28 Sway motions in hurricane condition as a function of a) time and b) frequency

29 Heave motions in hurricane condition as a function of a) time and $b$ ) frequency ..............................55

30 Tension of hybrid polyester line 1 in hurricane condition .........................56

31 Tension of hybrid polyester line 8 in hurricane condition ........................56

32 Surge motions of chain-wire and polyester mooring system in hurricane condition as a function of a) time and b) frequency .59

33 Sway motions of chain-wire and polyester mooring system in hurricane condition as a function of a) time and b) frequency

$34 \quad$ Heave motions of chain-wire and polyester mooring system in hurricane condition as a function of a) time and b) frequency

35 Line 1 tensions of chain-wire and polyester mooring system in hurricane condition as a function of a) time and b) frequency 
$36 \quad$ Line 8 tensions of chain-wire and polyester mooring system in hurricane condition as a function of a) time and b) frequency

37 Surge motions of hybrid polyester mooring systems in loop current condition as a function of a) time and b) frequency........65

38 Sway motions of hybrid polyester mooring systems in loop current condition as a function of a) time and b) frequency........66

39 Heave motions of hybrid polyester mooring systems in loop current condition as a function of a) time and b) frequency........67

40 Tension of hybrid polyester line 8 in loop current condition .....................68

41 Tension of hybrid polyester line 1 in loop current condition ....................68

42 Surge motions of chain-wire and polyester mooring system in loop current condition as a function of a) time and b) frequency ...........71

43 Sway motions of chain-wire and polyester mooring system in loop current condition as a function of a) time and b) frequency

$44 \quad$ Heave motions of chain-wire and polyester mooring system in loop current condition as a function of a) time and b) frequency ...........73

45 Line 8 tensions of chain-wire and polyester mooring system in loop current condition as a function of a) time and b) frequency ...........74

$46 \quad$ Line 1 tensions of chain-wire and polyester mooring system in loop current condition as a function of a) time and b) frequency ...........75 


\section{LIST OF TABLES}

TABLE Page

1 Values of the constants in (4.2) for two types of small diameter rope........24

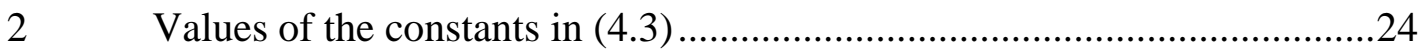

3 Configuration of two mooring systems ...........................................26

$4 \quad$ The main characteristics of the SPAR ...............................................27

$5 \quad$ Properties of the selected Marlow Superline...........................................27

$6 \quad$ Moduli of individual polyester ropes in the hybrid

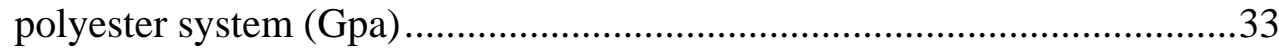

$7 \quad$ Modulus of the ropes when only mean load is applied (Gpa)...................37

8 Modulus after considering both mean and dynamic loads (Gpa)...............40

$9 \quad$ Modulus considering mean load only and mean and dynamic loads ..........42

10 Statistics of motions and tensions of steel mooring systems .....................52

11 Statistics of motions and tensions of polyester mooring systems ..............57

12 Statistics of the coupled analysis of steel and polyester mooring systems .................................................................63

13 Statistics of motions and tensions of polyester mooring systems

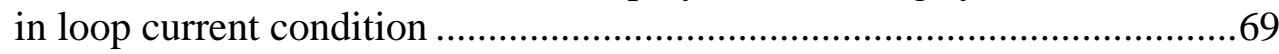

14 Statistics of steel and polyester mooring systems ….............................75 


\section{CHAPTER I}

\section{INTRODUCTION}

\subsection{Current trend of oil and gas industries}

In recent years, the offshore industry has been forced to explore deep water beyond 3000ft for oil and gas production. Because a conventional steel catenary mooring system has higher in-water weight and a larger foot print, it becomes inefficient and costly in deep water. Consequently, design consideration for deepwater development has been leaned to polyester mooring systems.

The remarkable advantages of a polyester rope are the high ratio of strength to weight of polyester and small footprint. Because of the lightweight of a polyester rope, smaller line pretensions are required to maintain an acceptable angle at the fairlead and thus can reduce the load on a floating structure significantly.

\subsection{A target structure for this research}

Innovative floating structures, such as a Spar, FPSO (Floating Production Storage and Offloading), and semi-submersible are attractive concepts for an ultra deep water production platform. In this research, a Classical Spar platform has been considered as a theme floating structure for the simulations of interactions with a polyester mooring system.

This dissertation follows the style and format of the Ocean Engineering. 
A Classical Spar platform is a large circular cylinder with constant cross section and with a draft of approximately over 600ft. The idea behind this concept, or rather what is justifying the use of this enormous hull, is that because of the large draft, the heave and pitch motion response of a spar platform is small enough to permit installation of rigid risers.

Another advantage of a Spar platform is that its natural surge frequency is far away the peak frequency of the dominant wave energy. However, wave, current, and wind loads can excite large amplitude low-frequency resonant motion of a SPAR platform and tension responses in mooring lines, most notably due to second order low-frequency effects. The contribution of these low-frequency loads to the motions and tensions plays an important role in the platform design. Thus, dynamic analysis based on a reliable technique should be used for analyzing a Spar production platform.

\subsection{Background of a coupled dynamic analysis}

An integrated floating structure consists of a mooring system, riser system and a floating platform. When the integrated system is in motion, its three components (mooring, risers and platform) dynamically interact with each other. In deep water, their interactions are significant hence their motions and forces should be analyzed together, which is known as Coupled dynamics analysis.

A traditional and simplified way of solving the dynamics of floating systems is to employ an uncoupled method, which ignores all or part of the dynamic interactions between a platform and its mooring lines and risers. As the water depth of offshore fields 
is getting deeper, mooring lines and risers become longer and heavier and uncoupled analysis methods may lead to inaccurate results. Thus, a coupled dynamic analysis of the floating platform systems is more necessary with increasing water depth and in a coupled analysis the motion equations of the hull and dynamic equations of a mooring/tendon/riser system are solved simultaneously.

A well-known method to compute wave potential forces on a floating structure (hull) is based on a wave diffraction/radiation theory truncated at second order in wave steepness. The potential is solved numerically using a Boundary Element Method (BEM) in the frequency domain. Among the numerical codes belonging to this method, WAMIT (1999) is one widely used by the offshore industry. Forces obtained using these codes include wave exciting force, radiation damping force (or potential damping force), and added mass force. Since the results given by WAMIT type codes are in the frequency domain, all forces applied on the hull in the time domain are calculated using the FFT and convolution techniques.

For the hulls composed of slender members, such as Spars and TLPs (Tension Leg Platforms), an alternative method to compute wave potential forces is based on the Morison equation. Accurate wave kinematics is crucial to render accurate wave loads in the use of the Morison equation. Wave kinematics can be computed using many different wave models, such as second-order wave theory, Wheeler Stretching, linear extrapolation and Hybrid Wave Models (HWM). Hybrid Wave Models are accurate at least up to second order in wave steepness and use two different perturbation schemes (conventional wave perturbation and phase modulation perturbation) to reach fast 
convergence of a truncated perturbation solution for a wave field of a broad-banded wave spectrum. They were proved to be very accurate through the comparison with both field and laboratory measurements (Ye, 1994, Zhang et al. 1996, 1997).

A coupled dynamic analysis is usually much more accurate than a quasi-static approach in predicting the motions of a hull and tensions in mooring lines. However, it is also computationally intensive, which hinders its application as a common design tool. A simulation of a moored floating structure for duration three hours (prototype scale) may take much longer time to perform using a couple analyses. In practice, a mooringline/riser system involves many mooring lines and risers. Therefore, the CPU time consumed for computing mooring-line and riser dynamics is considerably large and efficiency of numerical codes becomes very important.

A coupled dynamic analysis program called COUPLE6D, which is applicable to floating structures, was developed and a code for cable dynamics, called CABLE3D, was modified by including more efficient numerical scheme and expanded to allow for a relatively large extension in a cable (Chen, 2002). COUPLE6D has two options for computing wave potential forces, namely second-order diffraction/radiation theory or Morison equation using the HWMs to compute nonlinear wave kinematics. It also has two options for modeling mooring/tendon/riser system, namely, quasi-static and coupled dynamic approach. Recently, COUPLE6D was extended to include current load, wind load and VIV (Vortex Induced Vibration) effects (Ding et al. 2003). 


\subsection{Design criterion of a polyester rope}

To have a design standard of polyester rope, American Petroleum Institute (API), DeepStar (a joint industry consortium), and American bureau of Shipping (ABS) made effort to develop a design criterion and standard. They consolidated existing design guides, research data, and industry operation experience and made a new Recommended Practice (API RP 2SM, 1999). This design standard discusses several key issues, such as safety factor, test data in fatigue experiments, rope stiffness range, a series of creep rupture tests, minimum tension, and test cycles. Although the API presents the initial standard that can be put into the practice of mooring line design, there are still needs for more experience, and collection of more test data. In their publication, they also addressed the current difficulties. Most test data were for small specimen (yarn), and very few test data are available for real large synthetic ropes. Also they mentioned that short service experience of polyester ropes in permanent moorings, unknown failure mechanism (axial compression fatigue), absence of proper analytical model which can represent axial stiffness of ropes, and there is no proven inspection technique to assess internal damage. They presented the ranges of rope stiffness as being bounded by an upper stiffness level and a lower stiffness level, which were termed 'Storm stiffness' and ‘Post-Installed stiffness' (pre-tensioning installation) respectively. A properly validated analytical model of the rope stiffness will yield more accurate prediction about line tension and offset of structure.

Although an empirical formula has been developed (Del Vecchio, 1992), which will be used to model the modulus in this study, the variation of polyester rope stiffness 
with mean tension, load range (load amplitude) and load history needs to be implemented in numerical simulation of dynamics of a mooring system. Study of polyester rope stiffness variation under different load condition (dynamic environmental load condition, not a fixed load of the material test machine) is very rare. If additional information was available for this issue, it may help to reinforce the design criteria about polyester mooring applications.

\subsection{Objective and scope of present study}

Because the properties of synthetic ropes are very unique, very little knowledge is available for the design of synthetic mooring lines. In this study, we developed a method to use an empirical formula (Del Vecchio, 1992) to model the modulus of a polyester rope based on its mean and dynamic loads and then used it to simulate dynamic interaction between a classical SPAR and a hybrid polyester mooring system in the time domain. The statistics of motions of the hull and tension in the mooring lines are compared with those related to a conventional steel chain mooring system. Hopefully, the comparison may enrich our knowledge for future design of synthetic mooring lines. 


\section{CHAPTER II}

\section{DYNAMICS OF SLENDER RODS}

\subsection{Introduction}

Many offshore structures consist of slender rods or cables. Examples are pipelines, risers and mooring lines. The computation and understanding of dynamics of these structures require knowledge of nonlinearities arising from large deformation. In a classical theory of rods, the behavior of long bars is described in terms of the position of the centerline of the bar. Description of the motion equation of long bars in this study follows that presented by Nordgren (1974), Garrett (1982), Paulling and Webster (1986), Ma and Webster (1994) and Chen (2002).

\subsection{Equation of motion}

Assuming no torque and applied external moment, one can derive the linear momentum conservation equation with respect to a position vector $\vec{r}(s, t)$ that is a function of arc length (s) and time $(t)$.

$$
\begin{gathered}
-\left(B \mathbf{r}^{\prime \prime}\right)^{\prime \prime}+\left(\lambda \mathbf{r}^{\prime}\right)^{\prime}+\mathbf{q}=\rho \ddot{\mathbf{r}} \\
\lambda=T-B \kappa^{2}
\end{gathered}
$$

where $\boldsymbol{r}(s, t)$ is a position vector of $s$, the deformed arc length along the rod, and time $t, B$ is the bending rigidity, $\lambda$ is Lagrange multiplier, $\mathbf{q}$ is the distributed external force per unit length, $\rho$ is the mass per unit length, $T(s, t)=\mathbf{r}^{\prime} \cdot \mathbf{F}$ is the local tension and 
$\kappa^{2}=-\mathbf{r}^{\prime} \cdot \mathbf{r}^{\prime \prime \prime}, \boldsymbol{\kappa}$ is the local curvature of the rod. Prime and dot denote spatial derivative and time derivative, respectively.

If the rod is assumed to be inextensible, the following condition must be satisfied.

$$
\mathbf{r}^{\prime} \cdot \mathbf{r}^{\prime}=1
$$

The external forces $q$ applied on a rod consist of gravity forces, hydrostatic and hydrodynamic forces.

$$
\begin{aligned}
\mathbf{q}=\left(\rho_{f} A_{f}-\right. & \left.\rho_{i} A_{i}-\rho_{t} A_{t}\right) g \mathbf{e}_{y}+\rho_{f} A_{f}\left(\mathbf{I}+C_{M n} \mathbf{N}+C_{M t} \mathbf{T}\right) \mathbf{a}_{f} \\
& +\frac{1}{2} \rho_{f} D_{f} C_{D n} \mathbf{N}\left(\mathbf{v}_{f}-\dot{\mathbf{r}}\right)\left|\mathbf{N}\left(\mathbf{v}_{f}-\dot{\mathbf{r}}\right)\right| \\
& +\frac{1}{2} \rho_{f} D_{f} C_{D t} \mathbf{T}\left(\mathbf{v}_{f}-\dot{\mathbf{r}}\right)\left|\mathbf{T}\left(\mathbf{v}_{f}-\dot{\mathbf{r}}\right)\right|
\end{aligned}
$$

In the above equations:

$\rho_{f}(s)=$ the mass density of the sea water,

$\rho_{i}(s)=$ the mass density of the inside fluid,

$\rho_{t}(\mathrm{~s})=$ the mass density of the tube,

$D_{f}(s)=$ the diameter of the rod,

$A_{f}(s)=$ the outer cross-section area of the rod,

$A_{i}(s)=$ the inner cross-section area of the rod,

$A_{t}(s)=$ the structural cross-section area of the rod,

$\mathbf{v}_{f}=$ the velocity of the sea water (current and wave),

$\mathbf{a}_{f}=$ the acceleration of the sea water (current and wave), 
$C_{M n}=$ normal added-mass coefficient,

$C_{M t}=$ tangential added-mass coefficient,

$C_{D n}=$ normal drag coefficient,

$C_{D t}=$ tangential drag coefficient,

$\mathbf{T}, \mathbf{N}=$ transfer matrices,

$\mathbf{I}$ = identity matrix,

where the subscripts $f, i$ and $t$ denote the sea water, the fluid inside the tube and the tube itself. $\mathbf{T}$ and $\mathbf{N}$ are defined by:

$$
\begin{aligned}
& \mathbf{T}=\mathbf{r}^{\prime T} \mathbf{r}^{\prime} \\
& \mathbf{N}=\mathbf{I}-\mathbf{T}
\end{aligned}
$$

Under the assumption of very small elongation, the related simulation can result in large errors when a mooring line undergoes large elongation. Large elongation is experienced in a mooring line inserted by a spring used in wave basin tests or a prototype mooring line made of synthetic rope. If a cable has large elongation, the governing equation for the motion of a cable is described below. Let $\tilde{\lambda}=\frac{T}{1+\varepsilon}$;

$$
\left(\tilde{\lambda} \mathbf{r}^{\prime}\right)^{\prime}+\mathbf{q}=\rho \ddot{\mathbf{r}}
$$

and $\mathbf{r}$ must satisfy a stretching constrain equation for large elongation:

$$
\mathbf{r}^{\prime} \cdot \mathbf{r}^{\prime}=(1+\varepsilon)^{2}
$$


Additionally, $\varepsilon$ can be expressed as,

$$
\varepsilon=\frac{T}{E A}=\frac{\tilde{\lambda}}{E A-\tilde{\lambda}}
$$

Be defining,

$$
\tilde{\varepsilon}=\frac{\tilde{\lambda}}{E A}
$$

the constraint equation becomes:

$$
\mathbf{r}^{\prime} \cdot \mathbf{r}^{\prime}(1-\widetilde{\varepsilon})^{2}=1
$$




\section{CHAPTER III}

\section{THEORY OF COUPLED DYNAMIC ANALYSIS}

\subsection{Introduction}

In this chapter, nonlinear motion equations of a rigid body (platform) and a mooring system related by imposing proper boundary conditions at connection points between them. The descriptions given below follow the work by Paulling and Webster (1986), Lee (1995) and Chen (2002).

\subsection{6-DOF Nonlinear motion equations of a rigid body}

The rigid body motion equations with respect to the center of gravity ( $g$, more precisely, center of mass) were derived before (for example, Paulling and Webster, 1986; Lee, 1995) and their brief summarization is given below. Two coordinate systems are employed in the derivation of motion equations of a floating rigid body. Coordinate system ôxyyz is a space-fixed coordinate system, while oxyz is the body-fixed coordinate system moving with the body. The origin $o$ can be the center of gravity $(g)$ or any point fixed on the body. The body-fixed coordinate oxyz coincides with $\hat{o} \hat{x} \hat{y} \hat{z}$ when the body is at its initial position (see Fig. 1). A third coordinates $O X Y Z$ which is a spaced-fixed coordinate system with the $O X Y$ plan lying on the free surface and $Z$-axis positive upward is also introduced as a reference coordinate system. Incoming waves are given in this space-fixed reference coordinate system. 


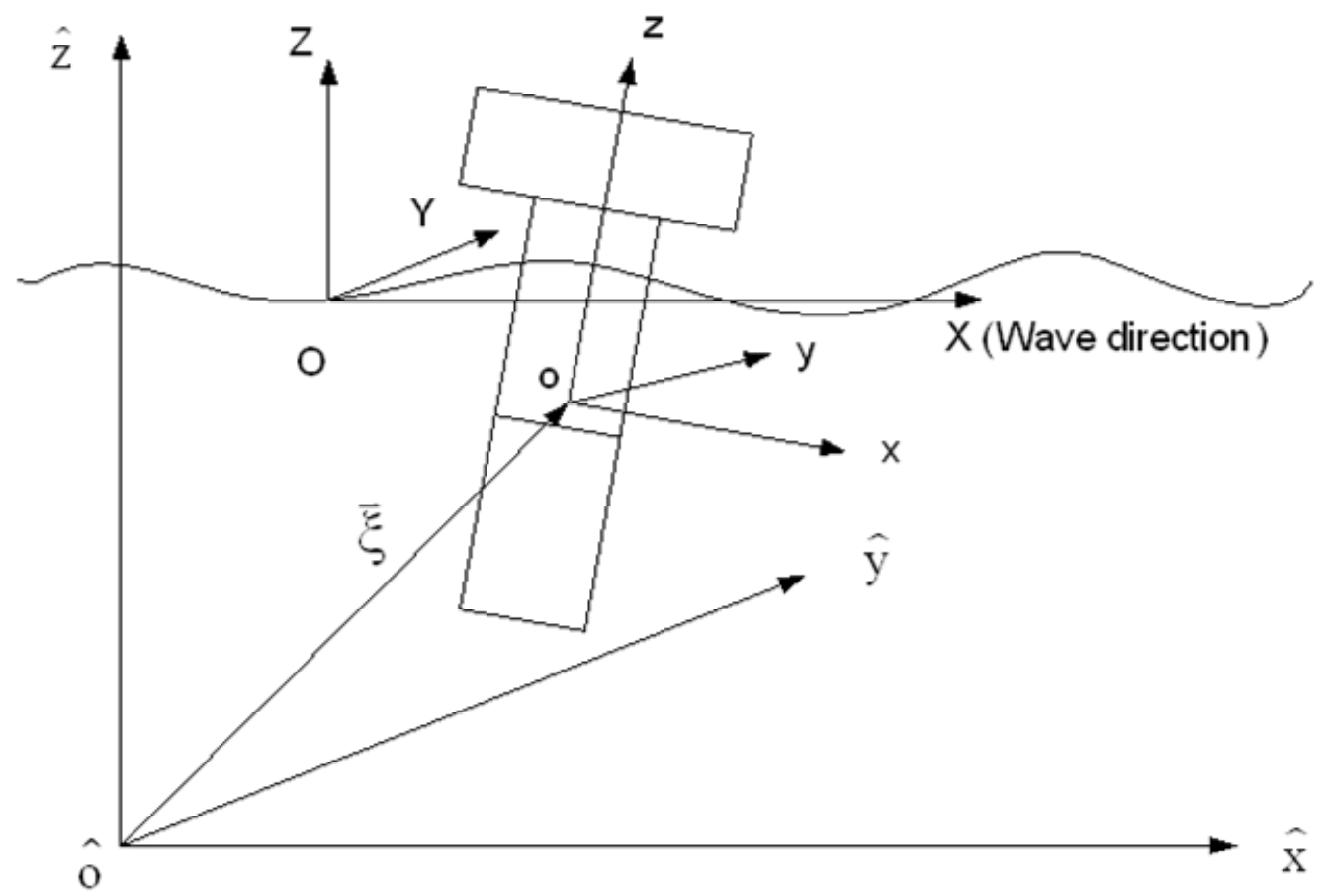

Fig. 1. Coordinate system for rigid body motions

Newton's second law may be written in terms of the rate of change of linear and angular momentum, respectively, as:

$$
\begin{aligned}
\frac{d \hat{\mathbf{L}}}{d t} & =\hat{\mathbf{F}} \\
\frac{d \mathbf{H}_{g}}{d t} & =\mathbf{M}_{g}
\end{aligned}
$$

where $\hat{\mathbf{L}}$ is the linear momentum, $\mathbf{H}_{g}$ the angular momentum with respect to $g$, $\hat{\mathbf{F}}$ the applied forces and $\mathbf{M}_{g}$ the applied moments with respect to $g$. $\hat{\mathbf{L}}$ is expressed as:

$$
\hat{\mathbf{L}}=m \hat{\mathbf{v}}_{g}
$$


where $m$ is the mass of the rigid body, $\hat{\mathbf{v}}_{g}$ is the velocity of the center of gravity.

It is convenient to express $\mathbf{H}_{g}$ in the body-fixed coordinate system as

$$
\mathbf{H}_{g}=\mathbf{I}_{g} \boldsymbol{\omega}
$$

where $\mathbf{I}_{g}$ is the moment of inertia matrix with respect to $g$ expressed in the body-fixed coordinate system oxyz. Vector $\boldsymbol{\omega}$ is the angular velocity also expressed in the bodyfixed coordinate system oxyz. The relationship between $\boldsymbol{\omega}$ and the derivatives of the Euler angles is given by:

$$
\boldsymbol{\omega}=\mathbf{B} \frac{d \boldsymbol{\alpha}}{d t}
$$

where $\boldsymbol{\alpha}=\left(\alpha_{1}, \alpha_{2} \alpha_{3}\right)^{t}$ are the Euler angles in the roll-pitch-yaw sequence.

$$
\mathbf{B}=\left[\begin{array}{ccc}
\cos \alpha_{3} \cos \alpha_{2} & \sin \alpha_{3} & 0 \\
-\sin \alpha_{3} \cos \alpha_{2} & \cos \alpha_{3} & 0 \\
\sin \alpha_{2} & 0 & 1
\end{array}\right]
$$

The relationship between $\frac{d \omega}{d t}$ and the second derivatives of the Euler angles is given by:

$$
\frac{d \boldsymbol{\omega}}{d t}=\mathbf{B} \frac{d^{2} \boldsymbol{\alpha}}{d t^{2}}+\boldsymbol{\alpha}_{q}
$$


where

$$
\boldsymbol{\alpha}_{q}=\mathbf{Q} \frac{d \boldsymbol{\alpha}}{d t}=\left[\begin{array}{ccc}
-\cos \alpha_{3} \sin \alpha_{2} \alpha_{2 t}-\sin \alpha_{3} \cos \alpha_{2} \alpha_{3 t} & \cos \alpha_{3} \alpha_{3 t} & 0 \\
\sin \alpha_{3} \sin \alpha_{2} \alpha_{2 t}-\cos \alpha_{3} \cos \alpha_{2} \alpha_{3 t} & -\sin \alpha_{3} \alpha_{3 t} & 0 \\
\cos \alpha_{2} \alpha_{2 t} & 0 & 0
\end{array}\right]\left\{\begin{array}{l}
\alpha_{1 t} \\
\alpha_{2 t} \\
\alpha_{3 t}
\end{array}\right\}
$$

Then the translational and rotational motion equations are respectively given by:

$$
\begin{gathered}
m \hat{\mathbf{a}}_{g}=\hat{\mathbf{F}} \\
\mathbf{I}_{g} \frac{d \boldsymbol{\omega}}{d t}+\boldsymbol{\omega} \times \mathbf{I}_{g} \boldsymbol{\omega}=\mathbf{M}_{g}
\end{gathered}
$$

where $\hat{\mathbf{a}}_{g}$ is the acceleration at the center of gravity $g$. Moment $\mathbf{M}_{g}$ is also defined with respect to the body-fixed coordinate system.

Furthermore, more general motion equations with respect to $o$ are derived. The acceleration at the center of gravity $g$ expressed in the $\hat{o} x \hat{y} \hat{z}$ coordinates is:

$$
\hat{\mathbf{a}}_{g}=\hat{\mathbf{a}}_{o}+\mathbf{T}^{t}\left(\frac{d \boldsymbol{\omega}}{d t} \times \mathbf{r}_{g}+\boldsymbol{\omega} \times\left(\boldsymbol{\omega} \times \mathbf{r}_{g}\right)\right)
$$

The moment in the body-fixed coordinate system with respect to $g$ is:

$$
\mathbf{M}_{g}=\mathbf{M}_{o}-\mathbf{r}_{g} \times \mathbf{T} \hat{\mathbf{F}}
$$

Substituting equations (3.11) and (3.12) into equations (3.9) and (3.10), and 
expressing $\hat{\mathbf{a}}_{o}$ as $\frac{d^{2} \boldsymbol{\xi}}{d t^{2}}$, the translational motion equations of a rigid body expressed in the $\hat{o} \hat{x} \hat{y} \hat{z}$ (spaced-fixed) coordinate system and the rotational motion equations expressed in the oxyz (body-fixed) coordinate system with respect to $o$ are:

$$
\begin{gathered}
m \frac{d^{2} \boldsymbol{\xi}}{d t^{2}}+m \mathbf{T}^{t}\left(\frac{d \boldsymbol{\omega}}{d t} \times \mathbf{r}_{g}\right)+m \mathbf{T}^{t}\left(\boldsymbol{\omega} \times\left(\boldsymbol{\omega} \times \mathbf{r}_{g}\right)\right)=\hat{\mathbf{F}} \\
\mathbf{I}_{o} \frac{d \boldsymbol{\omega}}{d t}+\boldsymbol{\omega} \times \mathbf{I}_{o} \boldsymbol{\omega}+m \mathbf{r}_{g} \times\left(\mathbf{T} \frac{d^{2} \boldsymbol{\xi}}{d t^{2}}\right)=\mathbf{M}_{o}
\end{gathered}
$$

where

superscript $t$ represents transpose of a matrix,

$\hat{\mathbf{a}}_{o}=\frac{d^{2} \boldsymbol{\xi}}{d t^{2}}$, is the acceleration at point $o$ of the body expressed in $\hat{o} \hat{x} \hat{y} \hat{z}$,

$\xi=\left(\xi_{1}, \xi_{2}, \xi_{3}\right)^{\mathrm{t}}$, is the displacement at point $o$ of the body expressed in $\hat{o} \hat{x} \hat{y} \hat{z}$,

$\boldsymbol{\omega}=\left(\omega_{1}, \omega_{2}, \omega_{3}\right)^{t}$, is the angular velocity expressed in oxyz,

$\mathbf{r}_{g}=\left(x_{g}, y_{g}, z_{g}\right)^{t}$, is the vector of the center of gravity (mass) of the body expressed in oxyz,

$\mathbf{I}_{o}$ is the moment of inertia of the body with respect to o expressed in oxyz,

$\hat{\mathbf{F}}$ is the total forces applied on the body expressed in $\hat{o} \hat{x} \hat{y} \hat{z}$,

$\mathbf{M}_{o}$ is the total moments with respect to $o$ the origin of the oxyz coordinates; and $\mathbf{T}$ is a transfer matrix between the body-fixed coordinate system and the spacefixed coordinate system expressed as: 


$$
\begin{aligned}
& \mathbf{T}= \\
& {\left[\begin{array}{ccc}
\cos \alpha_{3} \cos \alpha_{2} & \sin \alpha_{3} \cos \alpha_{1}+\cos \alpha_{3} \sin \alpha_{2} \sin \alpha_{1} & \sin \alpha_{3} \sin \alpha_{1}-\cos \alpha_{3} \sin \alpha_{2} \cos \alpha_{1} \\
-\sin \alpha_{3} \cos \alpha_{2} & \cos \alpha_{3} \cos \alpha_{1}-\sin \alpha_{3} \sin \alpha_{2} \sin \alpha_{1} & \cos \alpha_{3} \sin \alpha_{1}+\sin \alpha_{3} \sin \alpha_{2} \cos \alpha_{1} \\
\sin \alpha_{2} & -\cos \alpha_{2} \sin \alpha_{1} & \cos \alpha_{2} \cos \alpha_{1}
\end{array}\right]}
\end{aligned}
$$

$\mathbf{T}$ is an orthogonal matrix with the property that $\mathbf{T}^{t}=\mathbf{T}^{-1}$.

The relationship between space-fixed coordinates $\hat{\mathbf{x}}=(\hat{x}, \hat{y}, \hat{z})^{t}$ and body-fixed coordinates $\mathbf{x}=(x, y, z)^{t}$ is:

$$
\hat{\mathbf{x}}=\xi+\mathbf{T}^{t} \mathbf{x}
$$

\subsection{Coupled dynamic analysis}

Motion equations of the hull and dynamic equations of its mooring/tendon/riser system are integrated by imposing appropriate boundary conditions at their connection points (fairleads or porches). $O^{\prime} X^{\prime} Y^{\prime} Z^{\prime}$ is a space-fixed coordinate system for slender structures (mooring lines, tendons, risers), with origin at the still water surface and $\mathrm{Y}^{\prime}$ axis positive upward. $O X Y Z$ is a space-fixed coordinate system for the hull, with origin at the still water surface and $Z$ axis positive upward. $O^{\prime}$ and $O$ are coincident. oxyz is a body-fixed coordinate system moving with the body (see Fig. 2.). 

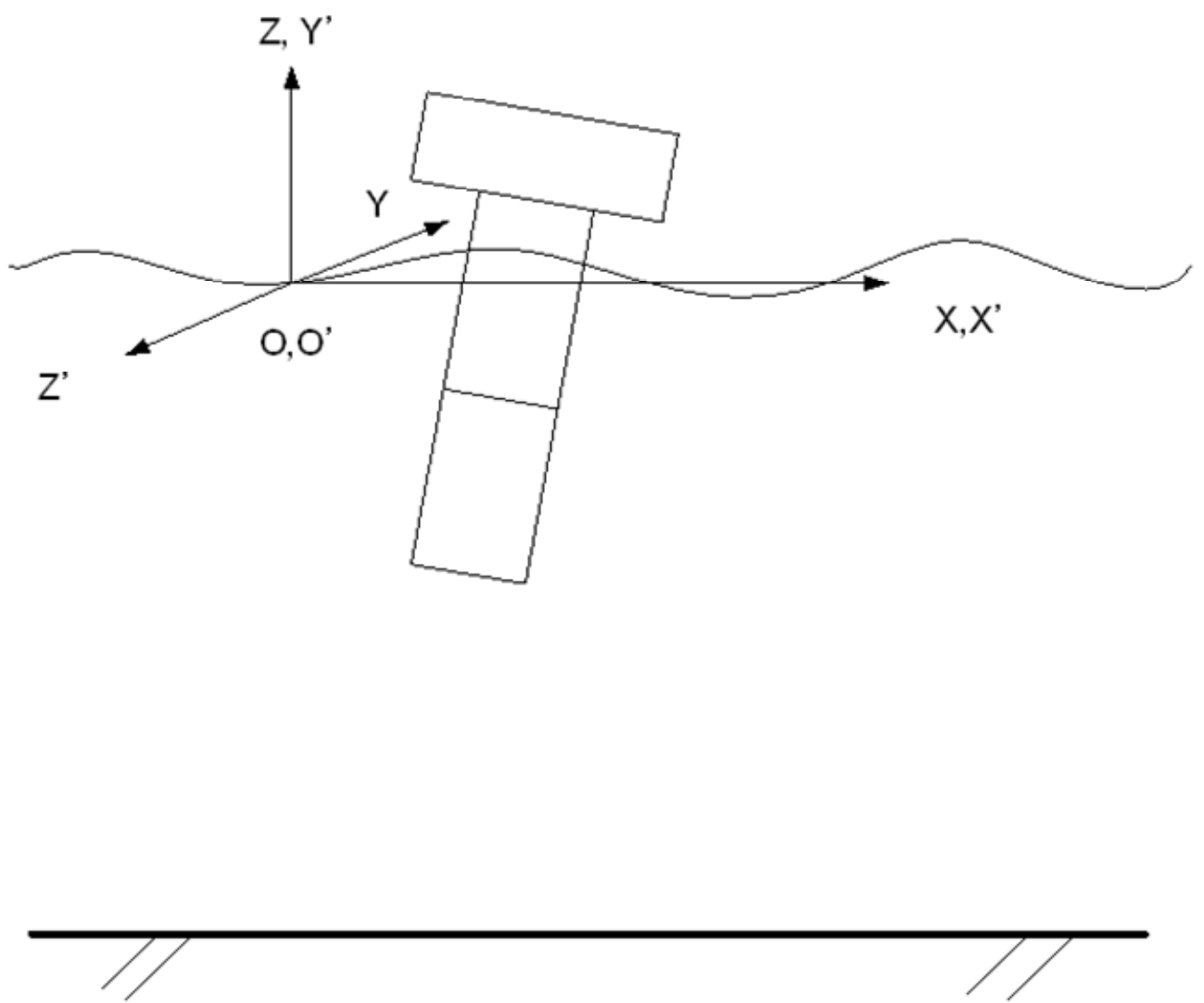

Fig. 2. Coordinate system for structure and mooring system

The coordinate of the connection point on the hull as expressed in body-fixed coordinate system is $\boldsymbol{x}_{c l}$. The coordinate of the connection point of lth mooring line as expressed in $O^{\prime} X^{\prime} Y^{\prime} Z^{\prime}$ is $\boldsymbol{r}_{0 l}$. The relationship between them is:

$$
\mathbf{r}_{0 l}=\mathbf{L}^{t}\left(\mathbf{T}^{t} \mathbf{x}_{c l}+\mathbf{X}_{\hat{o}}+\xi\right)
$$

where $\mathbf{L}$ is the transfer matrix between $O X Y Z$ and $O^{\prime} X^{\prime} Y^{\prime} Z^{\prime}$ : 


$$
\begin{aligned}
& \left\{\begin{array}{l}
\boldsymbol{X} \\
\boldsymbol{Y} \\
\boldsymbol{Z}
\end{array}\right\}=\boldsymbol{L}\left\{\begin{array}{l}
\boldsymbol{X}^{\prime} \\
\boldsymbol{Y}^{\prime} \\
\boldsymbol{Z}^{\prime}
\end{array}\right\} \\
& \boldsymbol{L}=\left\{\begin{array}{ccc}
1 & 0 & 0 \\
0 & 0 & -1 \\
0 & 1 & 0
\end{array}\right\}
\end{aligned}
$$

Since the fairlead (or porch) is at $s=0$, then the generalized forces and moments applied on at the fairlead or porch of $l$ th mooring line/tendon/riser is:

$$
\begin{gathered}
\mathbf{f}_{1}=-\left\{\tilde{\lambda} \mathbf{r}^{\prime}(0)-\left(B \mathbf{r}^{\prime \prime}\right)^{\prime}(0)\right\}=-\mathbf{F}(0) \\
\mathbf{f}_{2}=-\frac{1}{L} B \mathbf{r}^{\prime \prime}(0)
\end{gathered}
$$

For hinged boundary conditions, no moment is transferred. Hence,

$$
\mathbf{f}_{2}=0
$$

and forces and moments applied on the hull at $l$ th fairlead are,

$$
\begin{gathered}
\mathbf{F}_{l}=\mathbf{F}(0)=-\mathbf{f}_{1}=-\left(f_{11}, f_{12}, f_{13}\right)_{l} \\
\tilde{\mathbf{M}}_{l}=0
\end{gathered}
$$

If the mooring/tendon/riser system consists of $L$ individual mooring lines/tendons/risers, the mooring/tendon/riser system forces applied on the hull are the 
summation of forces and moments of each mooring line/tendon/riser applied on the structure at the fairlead or porch. The forces and moments of the mooring system applied on the hull can be expressed as:

$$
\begin{gathered}
\mathbf{F}_{M}=\sum_{l=1}^{L}\left(\mathbf{L F} \mathbf{F}_{l}\right) \\
\mathbf{M}_{M}=\sum_{l=1}^{L}\left[\mathbf{r}_{c l} \times\left(\mathbf{T L F}_{l}\right)+\mathbf{T L} \tilde{\mathbf{M}}_{l}\right]
\end{gathered}
$$

where $\mathbf{L}$ is a transfer matrix between the spaced-fixed coordinates for the mooring /tendon/riser system and the hull. It should be noted that $\mathbf{F}_{M}$ is expressed in the spacefixed coordinate system $\hat{o} \hat{x} \hat{z} \hat{z}$, and $\mathbf{M}_{M}$ is expressed in the body-fixed coordinate system oxyz. When hinged boundary conditions are applied, $\tilde{\mathbf{M}}_{l}=0$. 


\section{CHAPTER IV}

\section{NONLINEAR PROPERTIES OF POLYESTER}

\subsection{Nonlinear stress-strain behavior of polyester}

The nonlinear behavior of polyester rope is difficult to ascertain because it is determined by many factors, such as rope construction, rope material, type of load, and load history. In many cases, characteristics of specific ropes must be experimentally established prior to implementation as mooring line components. Because mooring line is under cyclic loads from wave force and varying currents, a study of the stress-strain behavior of synthetic fiber rope under cyclic loads is helpful in formulating a realistic model of the mooring line response to time varying loads.

Under cyclic loads from a zero stress condition to a certain maximum stress, $\sigma$, and then down again to a zero stress condition, a typical stress-strain curve of a polyester rope is sketched in Fig. 3.

This curve shows a certain amount of residual strain at the end of this first cycle. This phenomena result in a phase difference between the stress and strain. If the rope is stressed through the same cycle a number of times, several hysteresis loops will be obtained. The residual strain increase with each cycle, however, as shown in Fig. 4, the increase become less and less as the number of cycles grows (Berteaux, 1976). 


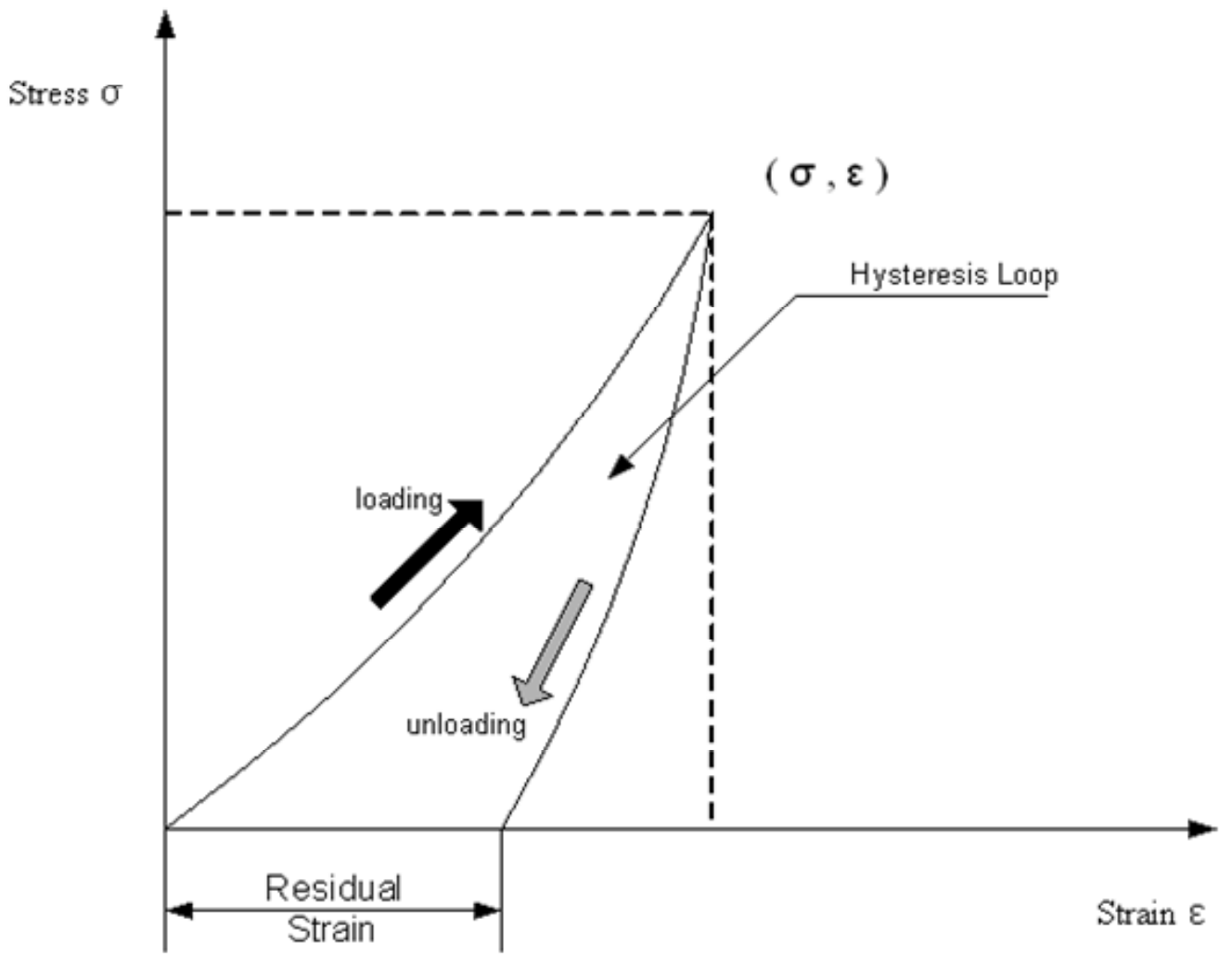

Fig. 3. Synthetic rope first loading cycle

Furthermore, the last hysteresis loops have a tendency to superimpose each other. This suggests the possibility of approximating the elastic response of the rope after a large number of cycles by a "permanent” residual strain and a "stable” hysteresis loop. This fact supports the establishment of the relation to strain as a function of applied stress (or force). In other words, a single function can be used to uniquely describe them and this function is the center line of the stable hysteresis loop that presents the average response of the rope to cyclic loads. 


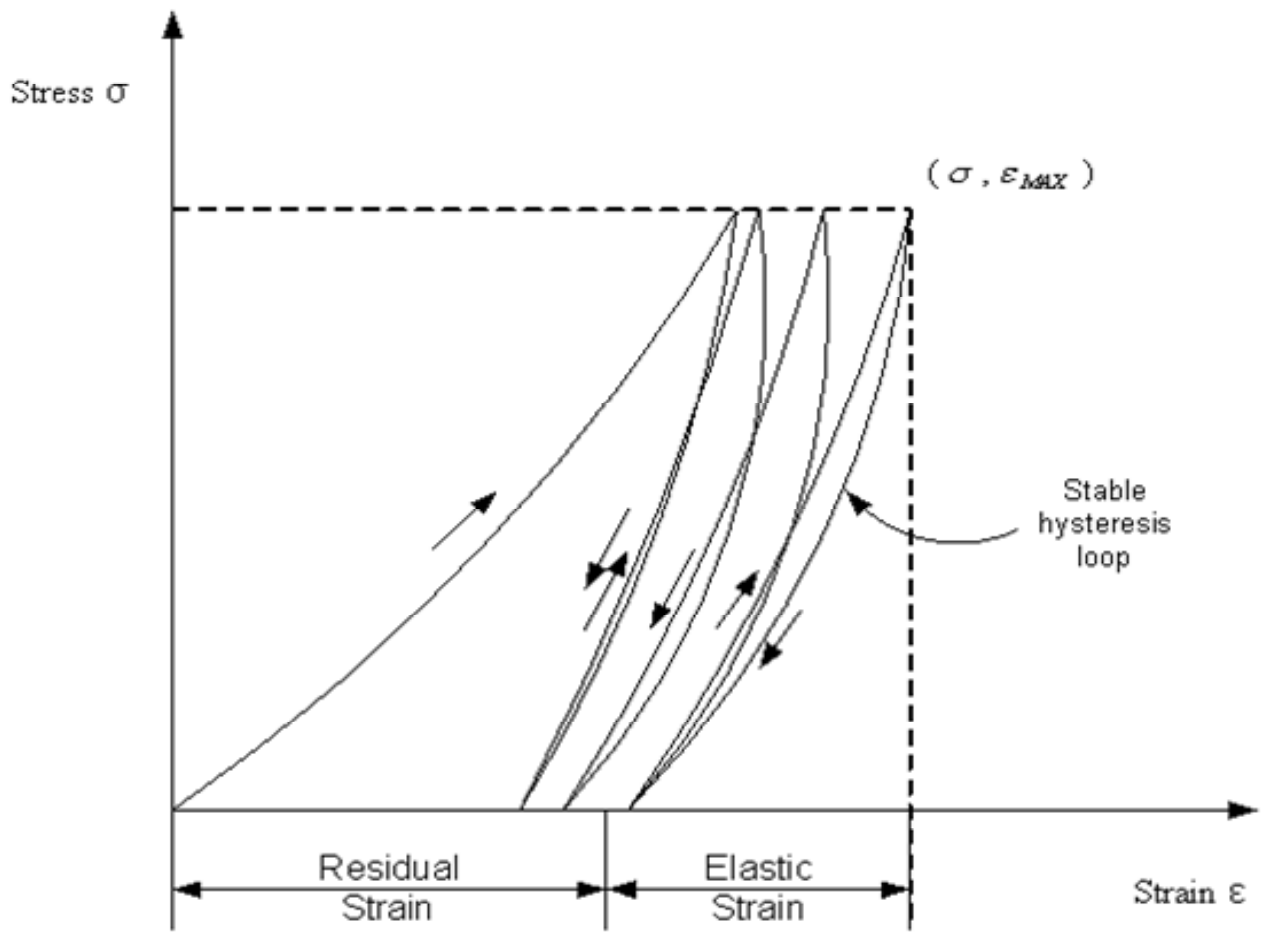

Fig. 4. Stable hysteresis loops

The modulus relates the stress to strain, representing the slope of the stress-strain diagram.

$$
E=\frac{\partial \sigma}{\partial \varepsilon}
$$

Therefore, a nonlinear modulus can be estimated experimentally as a function of stress. In this study, we use the empirical formula of modulus to simulate the interaction of SAPR and its polyester mooring system. 


\subsection{Formula for the modulus of a polyester rope}

The strain in a polyester rope does not have linear relation with its tension. Instead, their relation shows significant time dependent behavior, such as creep and hysteresis. Direct simulation of the dynamics of a polyester rope is extremely complicated. To simplify numerical simulation of a SPAR interacting its polyester mooring system, an empirical formulation is used to model the Young's modulus of a polyester rope. Experimental studies concerning the modulus of a polyester rope indicated the main parameters influencing the modulus of a polyester rope are the mean and dynamic load, and temperature. Del Vecchio (1992) proposed the following formula for determining the modulus of a rope at constant temperature.

$$
\frac{E}{\rho}=\alpha+\beta L_{m}-\gamma L_{a}-\delta \log (T),
$$

where $E / \rho$ is the specific modulus of elasticity in N/tex $\left(1\right.$ tex $\left.=10^{-6} \mathrm{~kg} / \mathrm{m}\right), \quad \rho$ the density of polyester, $L_{m}$ the ratio of mean load to the minimum breaking load in percentage, $L_{a}$ the ratio of the amplitude of dynamic load to the minimum breaking load in percentage, and $T$ the average period of dynamic load in second.

The constants, $\alpha, \beta, \gamma$, and $\delta$, depend on the specifics of a rope and have the same unit as $E$ / $\rho$. For example, their values for two different polyester ropes are given in Table 1, Marlow Superline has a parallel sub-rope construction, with fourteen 3-strand sub-ropes, made by Marlow Ropes in the UK and the other has a parallel strand construction, with 34 strands, made by Brascorda in Brazil. 
Table 1 Values of the constants in (4.2) for two types of small diameter rope

\begin{tabular}{|c|c|c|c|c|c|}
\hline Rope type & Diameter & $\alpha$ & $\beta$ & $\gamma$ & $\delta$ \\
\hline Marlow Superline & $14.7 \mathrm{~mm}$ & 10.409 & 0.152 & 0.194 & 0.437 \\
\hline Brascorda parallel & $11.5 \mathrm{~mm}$ & 12.058 & 0.152 & 0.201 & 0.473 \\
\hline
\end{tabular}

Further examination indicated that the modulus depends mainly on the mean load and the amplitude of dynamic load and its dependence on the period of dynamic load is rather weak and may be neglected (Fernandes et al. 1998). Satisfactory agreement between this formula and the experimental results was also observed by Fernandes et al. (1998). The same formula but in a slightly different form was presented by Bosman and Hooker (1999) based on their experimental study.

$$
E=\alpha+\beta L_{m}-\gamma L_{a}-\delta \log (T)
$$

where the notations are the same as those described in (4.2) except the unit for $E$ is Gpa. The related constants in (4.3) are summarized in Table 2.

Table 2 Values of the constants in (4.3)

\begin{tabular}{|c|c|c|c|c|c|}
\hline Rope type & Diameter & $\alpha$ & $\beta$ & $\gamma$ & $\delta$ \\
\hline Marlow Superline & $17 \mathrm{~mm}$ & 13.37 & 0.174 & 0 & 0 \\
\hline
\end{tabular}




\section{CHAPTER V}

\section{NUMERICAL MODELING OF INTERACTION BETWEEN A SPAR AND ITS MOORING SYSTEM}

\subsection{Main characteristics of a SPAR and its mooring system}

To test and demonstrate the usefulness of the extended numerical code for polyester mooring lines, a deep-water floating structure positioned by a mooring system is chosen for numerical simulation. The characteristics of chain mooring lines, the hull, water depth, and environment conditions were chosen according to DeepStar project (1999). The water depth is $914.4 \mathrm{~m}$. The original mooring system of the DeepStar SPAR consists of fourteen mooring lines and each line involves a long steel wire cable at the middle and two steel chains at each end.

Based on Deepstar steel chain mooring model, the characteristics of hybrid polyester mooring lines were chosen such that the simulated surge static offset curve is as close as possible to that of the steel chain mooring system ${ }^{*}$. In this study, we replaced the steel cable by a Superline polyester rope of a nominal diameter $23.2 \mathrm{~cm}$ and left the steel chains unchanged. The main characteristics of the hybrid polyester mooring and original steel mooring system are compared in Table 3. The main characteristics of the hull are listed in Table 4. The main properties of the Superline polyester rope and related

\footnotetext{
${ }^{*}$ The match between a hybrid polyester and steel mooring system does not imply an optimal design for the hybrid polyester mooring system. However, the match of the static offset curve of the hybrid polyester mooring system with that of the steel semi-taut mooring system allows a fair comparison of the motions of the SPAR positioned respectively by these two mooring system.
} 
empirical constants used in numerical simulation are given in Table 5. The configurations of a hybrid polyester and steel mooring system are the same except that the length of polyester ropes is shorter than that of replaced steel cable and thus the footprint of the hybrid polyester mooring system is smaller.

Table 3 Configuration of two mooring systems

\begin{tabular}{|c|c|c|c|}
\hline \multicolumn{2}{|c|}{ Mooring type } & Steel semi tout & Polyester tout \\
\hline \multicolumn{2}{|c|}{ Number of mooring lines } & 14 & 14 \\
\hline \multirow{6}{*}{$\begin{array}{l}\text { Mooring } \\
\text { Line } \\
\text { Composition }\end{array}$} & Platform & $76.2 \mathrm{~m} \times 13.34 \mathrm{~cm} \mathrm{~K} 4$ & $76.2 \mathrm{~m} \times 13.34 \mathrm{~cm} \mathrm{~K} 4$ \\
\hline & section & Studless Chain & Studless Chain \\
\hline & Riser & $975.36 \mathrm{~m} \times 15.65 \mathrm{~cm}$ & $800.36 \mathrm{~m} \times 23.2 \mathrm{~cm}$ \\
\hline & section & Sheathed Wire & Superline Polyester \\
\hline & Ground & $76.2 \mathrm{~m} \times 13.34 \mathrm{~cm} \mathrm{~K} 4$ & $76.2 \mathrm{~m} \times 13.34 \mathrm{~cm} \mathrm{~K} 4$ \\
\hline & section & Studless Chain & Studless Chain \\
\hline \multicolumn{2}{|l|}{ Pretension } & $3025 \mathrm{KN}$ & $2200 \mathrm{KN}$ \\
\hline
\end{tabular}

Equation (4.3) is used to compute the modulus of polyester ropes but their constants $(\alpha, \beta$ and $\gamma)$ were converted based on the corresponding ones suggested by Fernandes et al. (1998).

The diameter of the polyester rope was chosen to provide sufficient breaking strength. It is noticed the diameter of the polyester rope is much greater than those used in the experiments of Fernandes et al. (1998). Hence, these constants may not be accurate for large diameter ropes and are intended for demonstrating our numerical method only. 
Table 4 The main characteristics of the SPAR

\begin{tabular}{|c|c|}
\hline Hull & \\
\hline Displacement $^{*}$ & $53600 \mathrm{~m}$. ton \\
\hline Total displacement $^{\dagger}$ & $220640 \mathrm{~m}$. ton \\
\hline Diameter & $122 \mathrm{ft}$ \\
\hline Length & $705 \mathrm{ft}$ \\
\hline Draft & $650 \mathrm{ft}$ \\
\hline Hard tank depth & $220 \mathrm{ft}$ \\
\hline KB (from bottom of SPAR) & $540 \mathrm{ft}$ \\
\hline KG (from bottom of SPAR) & $462 \mathrm{ft}$ \\
\hline KG (based on total displacement) & $314 \mathrm{ft}$ \\
\hline Radius of gyration & Pitch=221ft, yaw $=28.5 \mathrm{ft}$ \\
\hline Drag force coefficient & 1.16 \\
\hline Wind force coefficient & $0.0558\left(\mathrm{kips} /(\mathrm{ft} / \mathrm{sec})^{2}\right.$ ) \\
\hline Center of wind pressure & $722 \mathrm{ft} \mathrm{ABL}$ \\
\hline
\end{tabular}

Table 5 Properties of the selected Marlow Superline

\begin{tabular}{|c|c|}
\hline Minimum Breaking Strength & 1500 tonnes \\
\hline Nominal Diameter & $0.232 \mathrm{~m}$ \\
\hline Mass per unit in Air & $34.5 \mathrm{Kg} / \mathrm{m}$ \\
\hline Mass per unit in Sea Water & $8.7 \mathrm{Kg} / \mathrm{m}$ \\
\hline$\alpha$ & 14.469 \\
\hline$\beta$ & 0.2113 \\
\hline$\gamma$ & 0.2697 \\
\hline
\end{tabular}

* Displacement or net buoyancy includes hull, topsides, mooring, and hard tanks.

${ }^{\dagger}$ Total Displacement includes hull, topsides, mooring, hard tanks, and water in soft tanks and moonpool. 


\subsection{Static stiffness curve}

\subsubsection{Static offset curve of steel mooring system}

To demonstrate the effects of elongation of steel mooring lines, two different surge offset curves were obtained using numerical codes based on the formulations large elongation and small elongation respectively ${ }^{*}$. They are plotted in Fig. 5. The offset curve computed using the code based on small elongation assumption shows slightly larger restoring force than that computed using large elongation code but the magnitude of difference is relatively insignificant. The pretension in a hybrid polyester mooring line was applied so that the static offset curve of the polyester mooring system resembles that of the original steel mooring system. The static offset curve of the polyester line is compared with that of the original steel mooring line in Fig. 6.

\subsubsection{Static offset curve of a hybrid polyester mooring system}

Although the effects of elongation of steel chains are relatively small, the effects of large elongation in a polyester mooring line on the offset curve are expected to be significant. To demonstrate these effects, static offset curves of the hybrid polyester mooring systems were computed using the two codes based on the formulation of small and large elongation respectively and are compared in Fig. 7.

\footnotetext{
* The code based the formulation of small elongation virtually neglects the elongation of mooring lines
} 


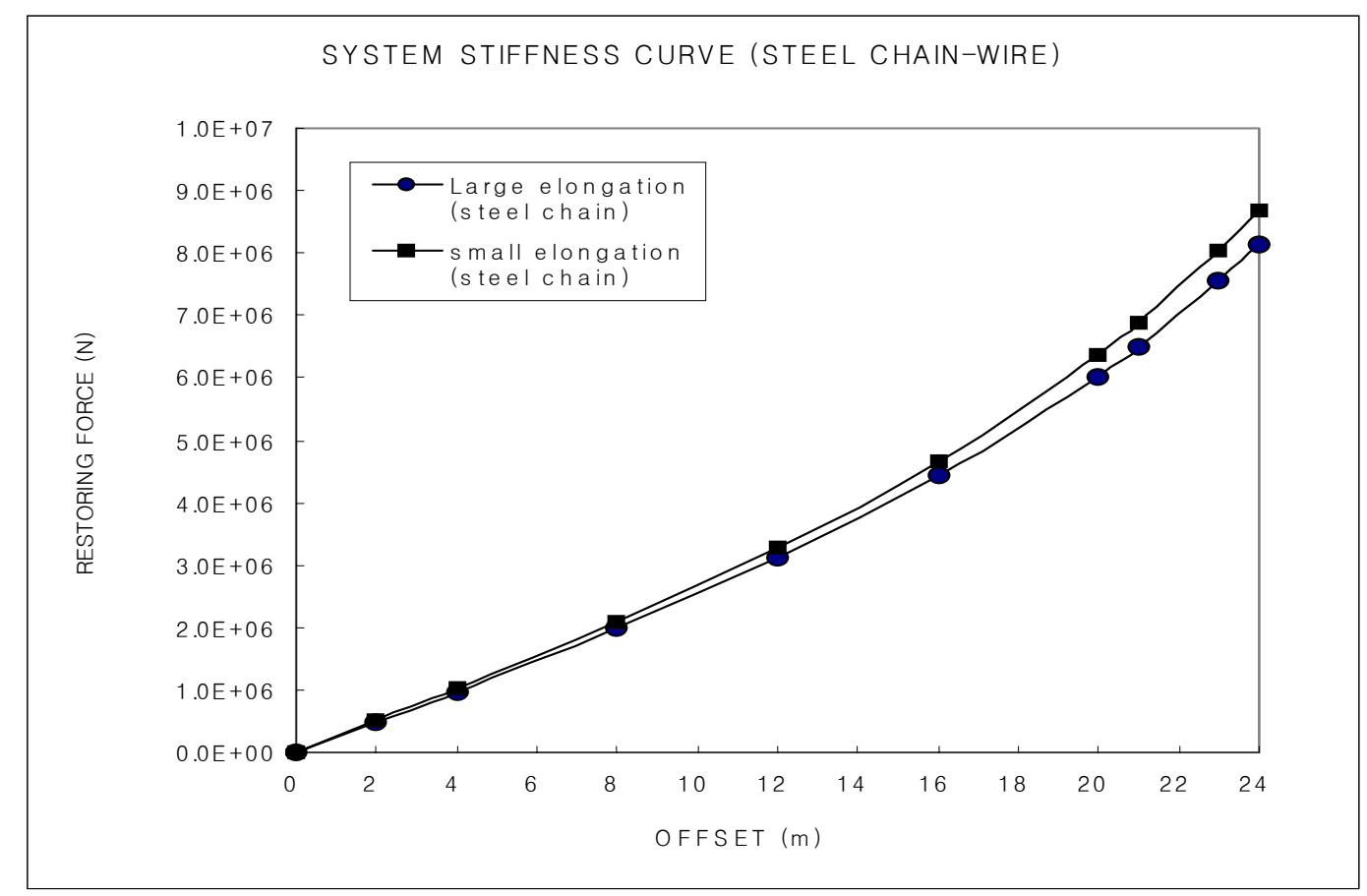

Fig. 5. Static offset curve of a steel mooring system computed using the numerical codes based on small and large elongation respectively

The offset curve predicted by the small elongation code is stiffer than that predicted by the large elongation code, which is consistent with the comparison observed in Fig. 5, but the difference in Fig. 7 is much greater. Because a polyester mooring line has relatively large elongation, the code based on the formulation of large elongation should be used to simulate polyester ropes. 


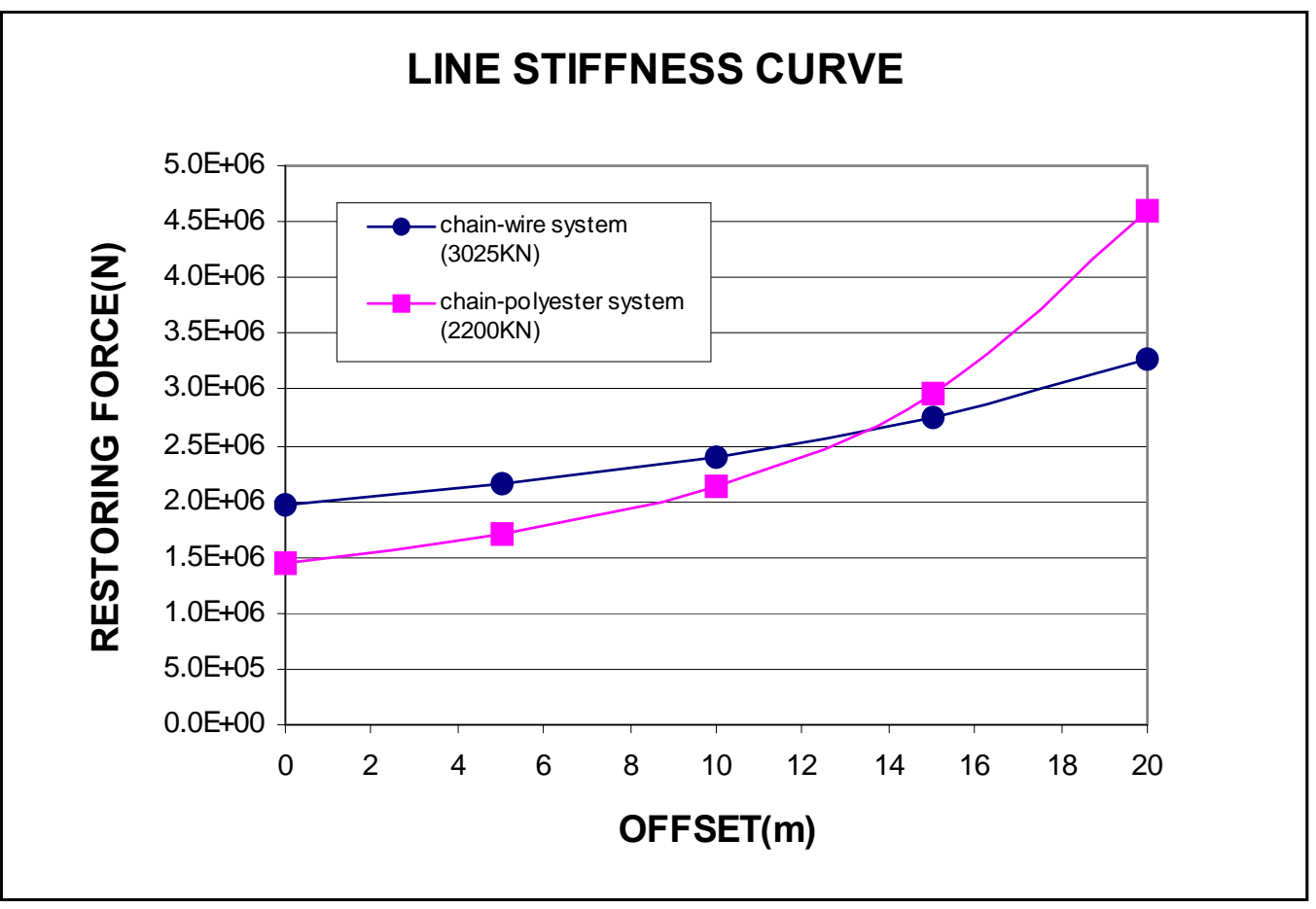

Fig. 6. Static offset curve of a single mooring line

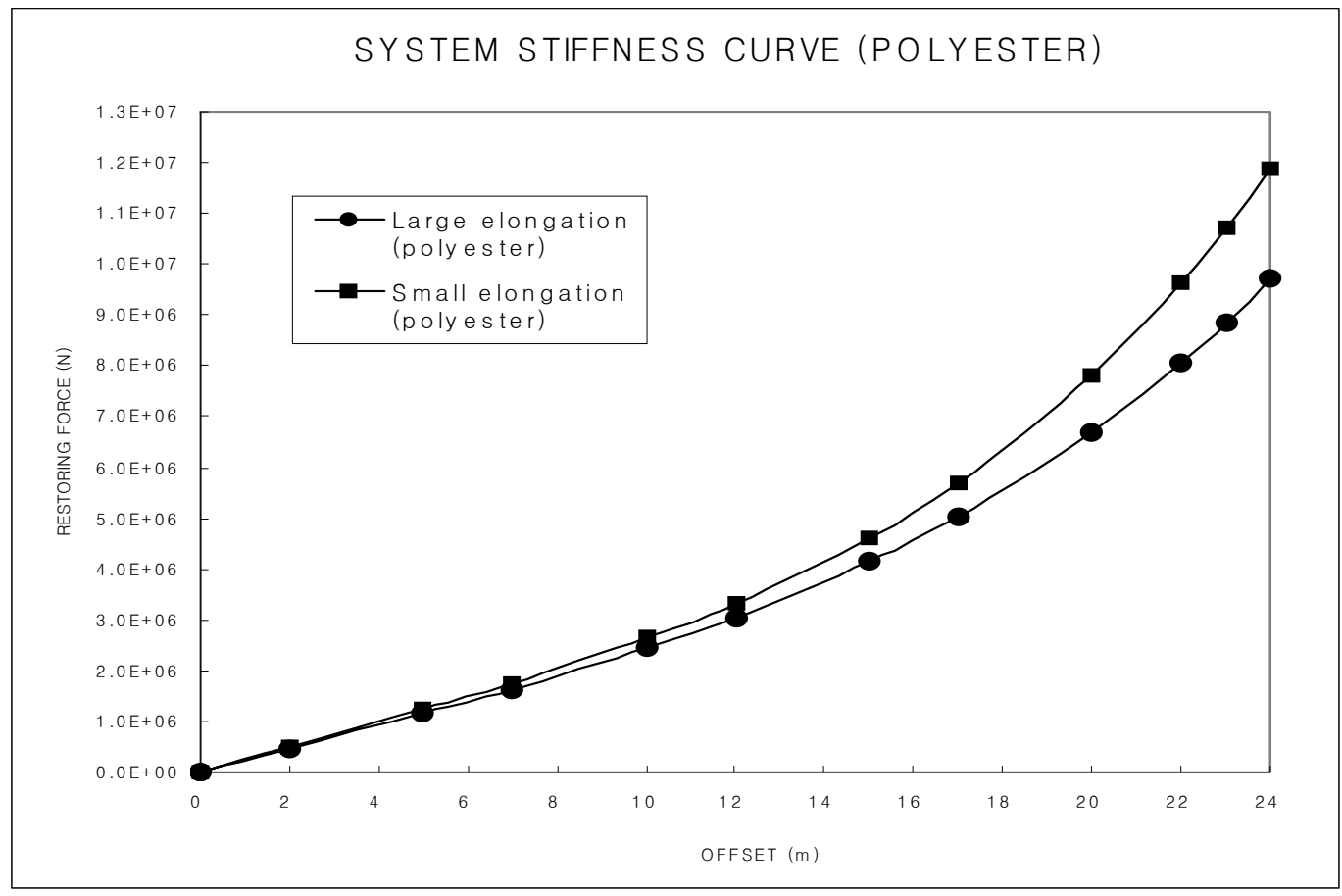

Fig. 7. Comparison of the extensible and inextensible rod theory for polyester 


\subsubsection{Iterative process for computing the modulus of a polyester rope}

It is known that the modulus of a polyester rope depends on the mean load. Therefore, to derive a static offset curve, the modulus of a polyester rope is computed and updated in accordance with the offset. When its fairlead is placed at a given offset, the tension in a polyester rope is static and thus the dynamic load is equal to zero. Because the modulus of a polyester rope is related to the static tension in the rope, the modulus cannot be determined in advance when the offset is given. Hence, it is approximately calculated through an iterative process. At a given offset, we first use the value of the modulus determined at a previous closest offset as an approximation to compute the restoring force at the fairlead of a mooring line and the tension at the upper end of the polyester rope. Knowing the tension, we up-date the modulus according to (4.3) and then re-calculate the restoring force and tension. If the difference between the values of the modulus obtained in two consecutive iterations is smaller than a prescribed error tolerance, then the computation advances for the next offset position. A flowchart describing the process for computing modulus depending on the mean tension is sketched in Fig. 8. Little iteration is needed to reach a convergent value for the modulus. In calculating the static offset curve of a polyester mooring system, the iteration process is similar to that described above except the modulus of each individual rope is different. For an example, the modulus as a function of the tension of individual mooring lines and offset in the mooring system are given in Table 6 . It is noticed that line 1 is the upstream direction which has the biggest tension at the upper end, and thus the biggest modulus. 


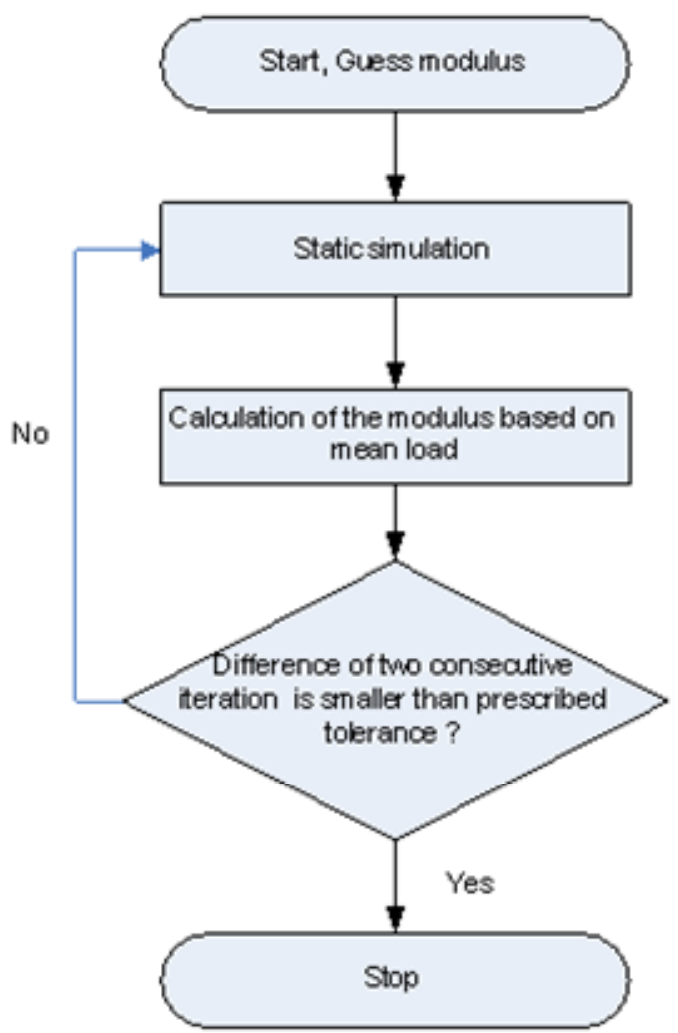

Fig. 8. Flow chart for static simulation

Finally, the surge offset curve of the polyester mooring system is compared with that of the original steel mooring system in Fig. 9. It is observed that the restoring force provided by the polyester mooring system is slightly smaller when the surge offset is below $15 \mathrm{~m}$ and slightly greater when the offset above $15 \mathrm{~m}$. This is expected because the modulus of a polyester rope increases with the increase in tension. 
Table 6 Moduli of individual polyester ropes in the hybrid polyester system (Gpa)

\begin{tabular}{|c|c|c|c|c|c|c|}
\hline & \multicolumn{6}{|c|}{ Offset of the polyester system $(\mathrm{m})$} \\
\hline Line Number & $1 \mathrm{~m}$ & $5 \mathrm{~m}$ & $10 \mathrm{~m}$ & $15 \mathrm{~m}$ & $20 \mathrm{~m}$ & $25 \mathrm{~m}$ \\
\hline 1 & $1.74 \mathrm{E}+01$ & $1.77 \mathrm{E}+01$ & $1.82 \mathrm{E}+01$ & $1.90 \mathrm{E}+01$ & $2.06 \mathrm{E}+01$ & $2.35 \mathrm{E}+01$ \\
\hline 2 & $1.74 \mathrm{E}+01$ & $1.77 \mathrm{E}+01$ & $1.81 \mathrm{E}+01$ & $1.87 \mathrm{E}+01$ & $1.99 \mathrm{E}+01$ & $2.19 \mathrm{E}+01$ \\
\hline 3 & $1.74 \mathrm{E}+01$ & $1.76 \mathrm{E}+01$ & $1.78 \mathrm{E}+01$ & $1.81 \mathrm{E}+01$ & $1.86 \mathrm{E}+01$ & $1.92 \mathrm{E}+01$ \\
\hline 4 & $1.74 \mathrm{E}+01$ & $1.74 \mathrm{E}+01$ & $1.75 \mathrm{E}+01$ & $1.76 \mathrm{E}+01$ & $1.77 \mathrm{E}+01$ & $1.78 \mathrm{E}+01$ \\
\hline 5 & $1.74 \mathrm{E}+01$ & $1.73 \mathrm{E}+01$ & $1.73 \mathrm{E}+01$ & $1.72 \mathrm{E}+01$ & $1.72 \mathrm{E}+01$ & $1.71 \mathrm{E}+01$ \\
\hline 6 & $1.73 \mathrm{E}+01$ & $1.72 \mathrm{E}+01$ & $1.71 \mathrm{E}+01$ & $1.70 \mathrm{E}+01$ & $1.69 \mathrm{E}+01$ & $1.68 \mathrm{E}+01$ \\
\hline 7 & $1.73 \mathrm{E}+01$ & $1.72 \mathrm{E}+01$ & $1.70 \mathrm{E}+01$ & $1.68 \mathrm{E}+01$ & $1.67 \mathrm{E}+01$ & $1.66 \mathrm{E}+01$ \\
\hline 8 & $1.73 \mathrm{E}+01$ & $1.71 \mathrm{E}+01$ & $1.69 \mathrm{E}+01$ & $1.68 \mathrm{E}+01$ & $1.67 \mathrm{E}+01$ & $1.66 \mathrm{E}+01$ \\
\hline 9 & $1.73 \mathrm{E}+01$ & $1.72 \mathrm{E}+01$ & $1.70 \mathrm{E}+01$ & $1.68 \mathrm{E}+01$ & $1.67 \mathrm{E}+01$ & $1.66 \mathrm{E}+01$ \\
\hline 10 & $1.73 \mathrm{E}+01$ & $1.72 \mathrm{E}+01$ & $1.71 \mathrm{E}+01$ & $1.70 \mathrm{E}+01$ & $1.69 \mathrm{E}+01$ & $1.68 \mathrm{E}+01$ \\
\hline 11 & $1.74 \mathrm{E}+01$ & $1.73 \mathrm{E}+01$ & $1.73 \mathrm{E}+01$ & $1.72 \mathrm{E}+01$ & $1.72 \mathrm{E}+01$ & $1.71 \mathrm{E}+01$ \\
\hline 12 & $1.74 \mathrm{E}+01$ & $1.74 \mathrm{E}+01$ & $1.75 \mathrm{E}+01$ & $1.76 \mathrm{E}+01$ & $1.77 \mathrm{E}+01$ & $1.78 \mathrm{E}+01$ \\
\hline 13 & $1.74 \mathrm{E}+01$ & $1.76 \mathrm{E}+01$ & $1.78 \mathrm{E}+01$ & $1.81 \mathrm{E}+01$ & $1.86 \mathrm{E}+01$ & $1.92 \mathrm{E}+01$ \\
\hline 14 & $1.74 \mathrm{E}+01$ & $1.77 \mathrm{E}+01$ & $1.81 \mathrm{E}+01$ & $1.87 \mathrm{E}+01$ & $1.99 \mathrm{E}+01$ & $2.19 \mathrm{E}+01$ \\
\hline & & & & & & \\
\hline & & & & & \\
\hline 14 & & & & & \\
\hline & & & & &
\end{tabular}




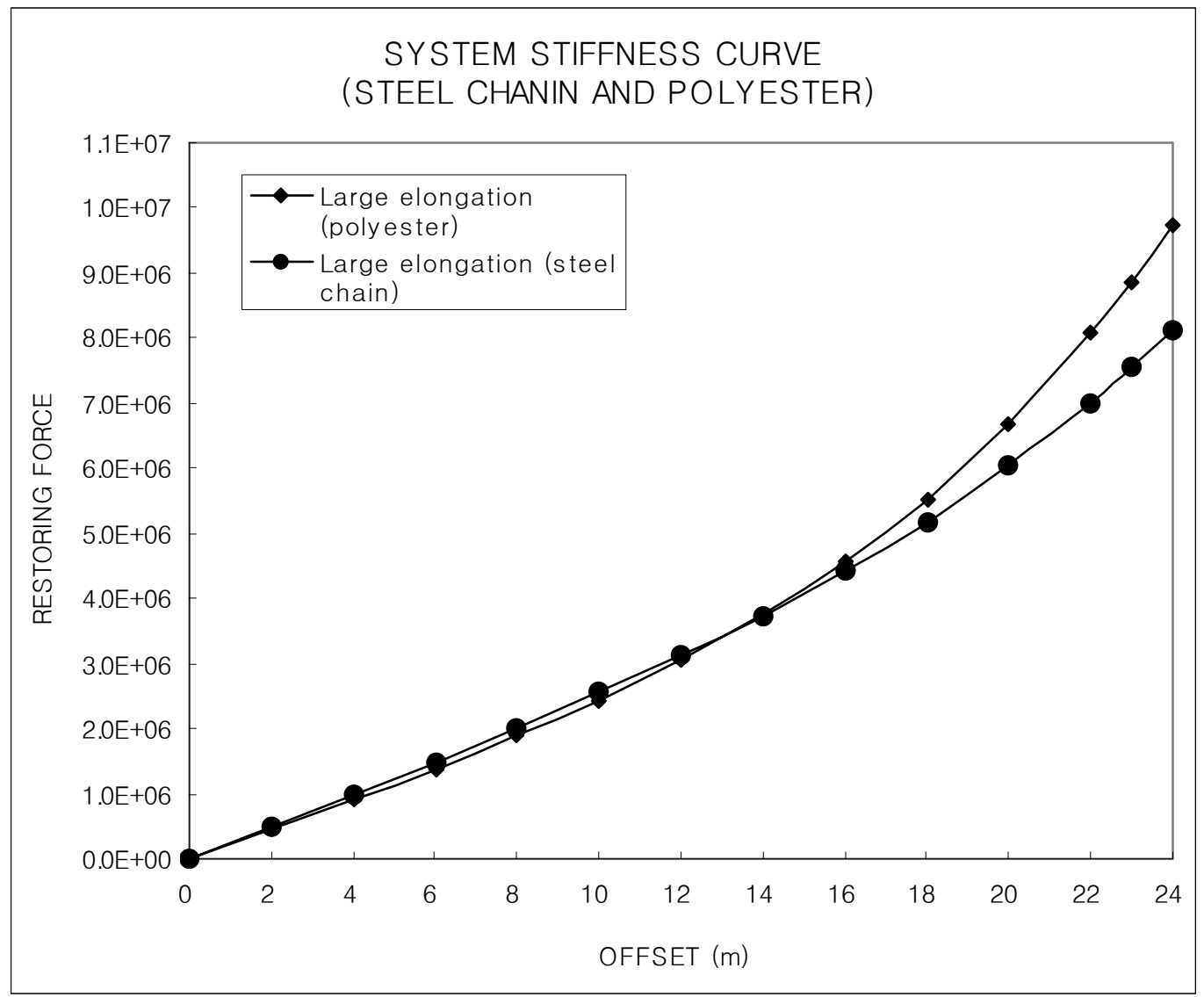

Fig. 9. Surge static offset curve of a mooring system

\subsection{0-year hurricane condition}

\subsubsection{Configuration of the mooring system and met-ocean condition}

Long-crested incident waves are generated following a JONSWAP spectrum $(\gamma=$ 2.5) of a significant wave height $12.2 \mathrm{~m}$ and peak period $14 \mathrm{~s}$. The wave environment was selected to represent a typical 100 -year storm in the Gulf of Mexico. The steady wind speed is $92 \mathrm{mph}$. The velocity of the current is steady but varies with water depth. The directions of waves, wind and current with respect to the mooring system are depicted in Fig. 10 and the time series and energy spectrum of wave elevation are 
presented in Fig. 11.

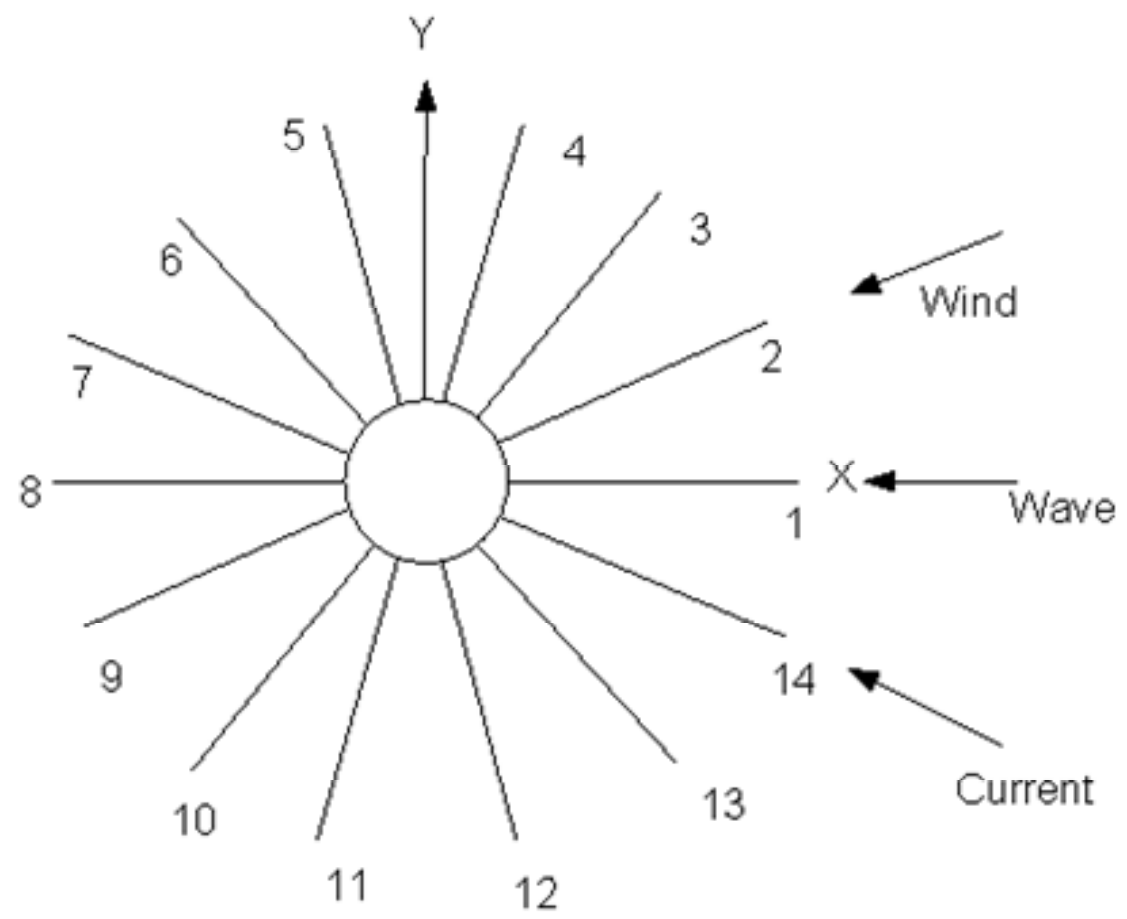

Fig. 10. Configuration of SPAR in 100-year storm condition

\subsubsection{Iterative process for computing the modulus as a function of dynamic tension}

In addition to their relatively large elongation, the key factor in simulating a polyester rope is to model the dependence of its modulus on the tension. Since the wet weight of a polyester rope is small, the change in tension along a polyester rope is expected to be insignificant and we may use the tension at its upper end to represent the tension along the whole rope. Knowing the load in the rope, the empirical formula given in (4.3) is employed to determine the modulus as a function of mean and dynamic tension. 

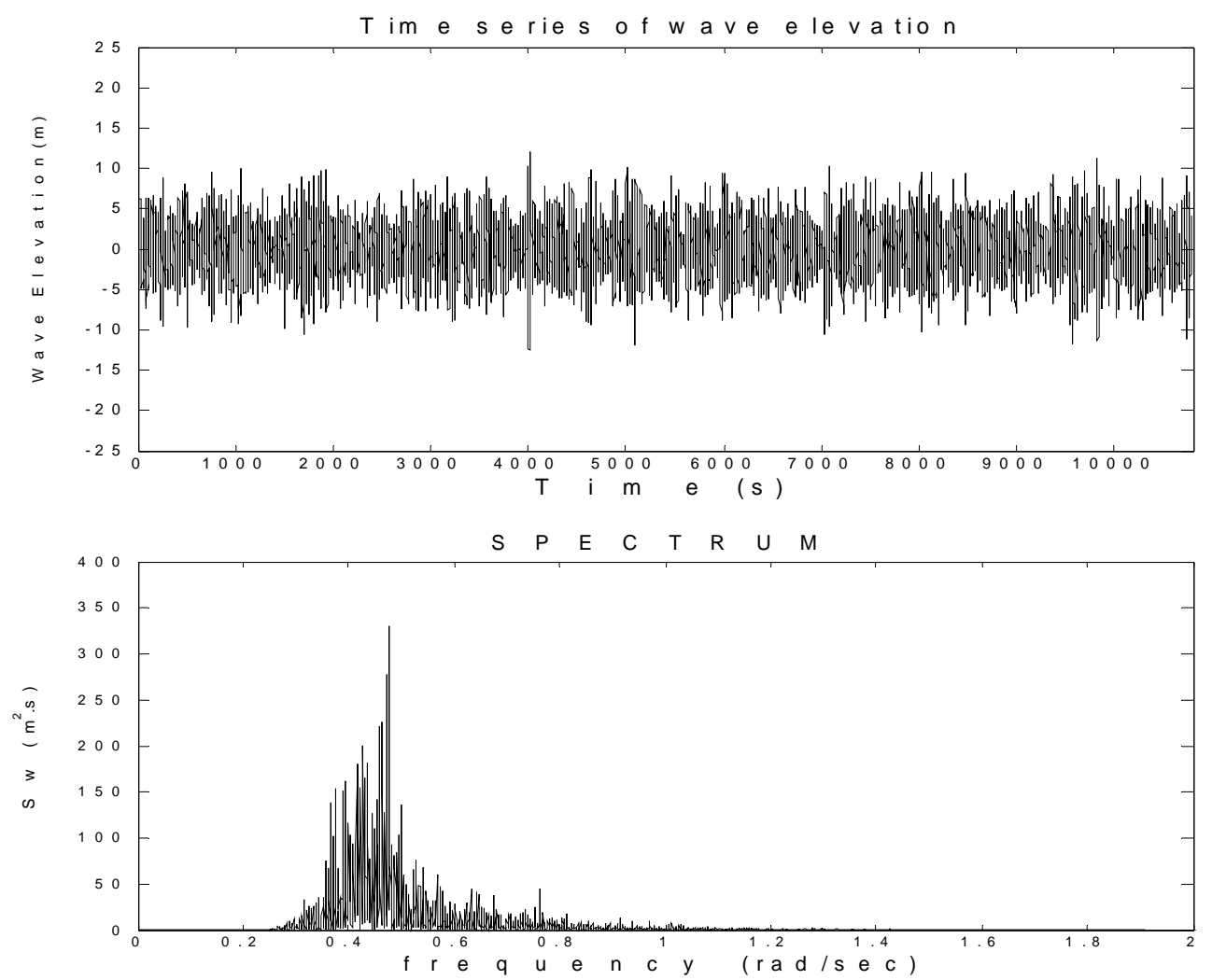

Fig. 11. Time series and spectrum $\left(\mathrm{m}^{2} \cdot \mathrm{s}\right)$ of wave elevation.

When the SPAR is under the impact of steep ocean waves, gusty wind and strong currents, polyester ropes used in the mooring system experiences not only the mean load but also irregular dynamic loads. In this case, the effects of dynamic loads on the modulus should be considered and we divide the process of computing the modulus into two steps. The first step is to determine the mean load on the SPAR and then in turn the mean tension in the polyester ropes. The mean load on the SPAR results from the steady current and wind, and second-order steady wave forces, which can be calculated given the met-ocean condition. Based on the mean load on the SPAR and following the same manner described in the static modeling, we determine the modulus in each individual polyester rope in the mooring system and the mean offset of the SPAR from its 
equilibrium position. The results of the modulus of individual polyester ropes are given in Table 7. It is noticed that only the mean load applied on the SPAR is considered in this step.

Table 7 Modulus of the ropes when only mean load is applied (Gpa)

\begin{tabular}{|c|c|c|c|}
\hline Line umber & 1st initial E & 2nd iterated E & 3rd iterated E \\
\hline 1 & 17.629 & 18.256 & 18.257 \\
\hline 2 & 17.629 & 18.136 & 18.137 \\
\hline 3 & 17.629 & 17.807 & 17.809 \\
\hline 4 & 17.629 & 17.455 & 17.455 \\
\hline 5 & 17.629 & 17.170 & 17.171 \\
\hline 6 & 17.629 & 16.975 & 16.976 \\
\hline 7 & 17.629 & 16.863 & 16.863 \\
\hline 8 & 17.629 & 16.821 & 16.822 \\
\hline 9 & 17.629 & 16.848 & 16.849 \\
\hline 10 & 17.629 & 16.944 & 16.946 \\
\hline 11 & 17.629 & 17.122 & 17.123 \\
\hline 12 & 17.629 & 17.388 & 17.388 \\
\hline 13 & 17.629 & 17.731 & 17.732 \\
\hline 14 & 17.629 & 18.079 & 18.079 \\
\hline & & & \\
\hline 14 & & & 179 \\
\hline
\end{tabular}

The next step is to determine the change in the modulus of each polyester rope due to dynamic loads. Similar to the process to determine the change in the modulus due to static loads, the dependence of modulus on dynamic tension is obtained through iteration. First, the modulus of each polyester rope given in the last column of Table 7 is used in simulating the interaction between the SPAR and its polyester mooring system given the 
met-ocean conditions. During the simulation, the modulus of each rope remains unchanged. The simulation renders the tension at the upper end of each rope as a function of time. As an example, the tension in the polyester rope of Line 1 as a function of time and its spectrum are plotted in Fig. 12.
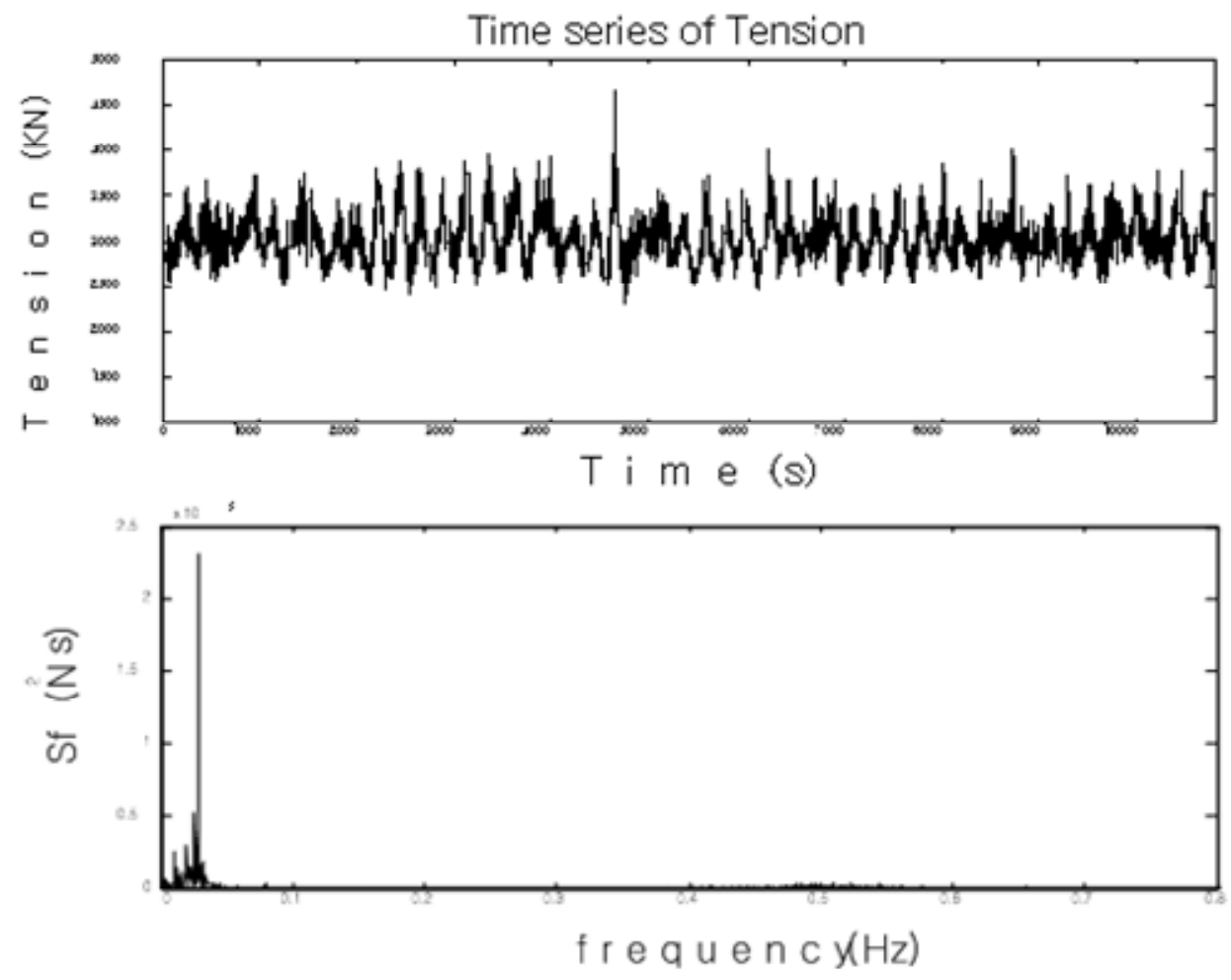

Fig. 12. Tension at the upper end of the polyester rope in line 1

a) time series b) spectrum

It is noticed that the tension of polyester rope spreads over a wide range in the frequency domain, quite different from a single component in the laboratory tests for calibrating the constant $\gamma$. Fortunately, almost all significant tension energy locates in a narrow low-frequency range, which is expected because of large amplitude of slow drift 
motions of the SPAR. In this study, low-frequency region is defined as $0-0.03(\mathrm{rad} / \mathrm{sec})$.

Applying a low-pass filter $(0.0-0.03 \mathrm{rad} / \mathrm{sec})$ on the tension-time series, we are able to obtain approximate average amplitude of dynamic load $\left(\mathrm{L}_{\mathrm{a}}\right)$ for each polyester rope. Based on the approximate dynamic load, we modify the modulus of each rope and re-simulate the interaction between the SPAR and its mooring system. The iteration continues until the relative difference between the modulus (of each polyester rope) computed in two consecutive iterations is smaller than a prescribed error tolerance. A flow chart describing the process of iteration is depicted in Fig. 13. The final results of the modulus after considering the mean and dynamic loads are given in Table 8 . The fourth column lists the modulus considering both mean and dynamic loads.

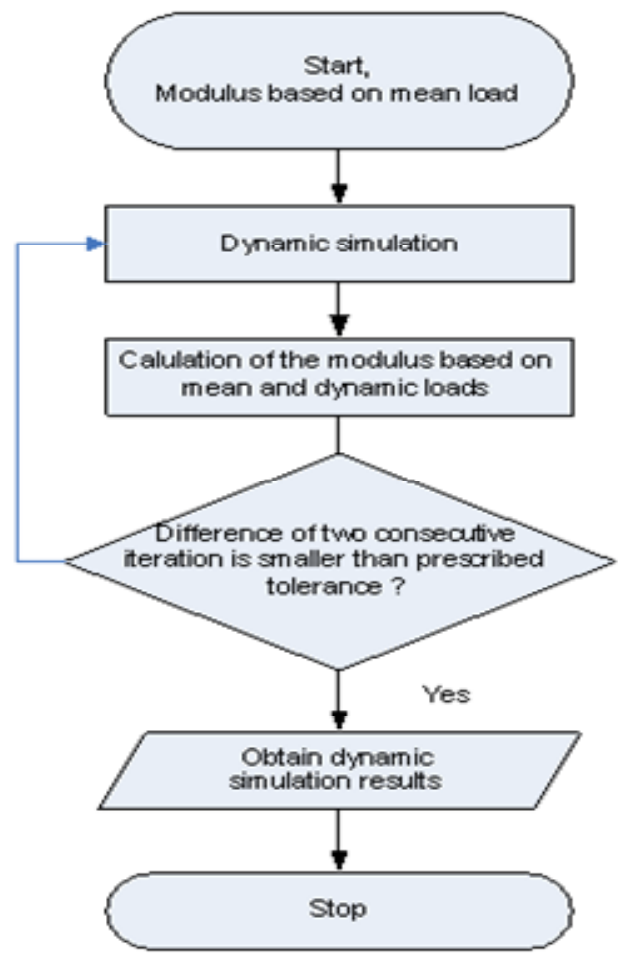

Fig. 13. Flow chart for dynamic simulation 
Table 8 Modulus after considering both mean and dynamic loads (Gpa)

\begin{tabular}{|c|c|c|c|}
\hline Line Number & $\mathrm{E}=\alpha+\beta \mathrm{Lm}$ & $\mathrm{La}$ (amplitude) & $\mathrm{E}=\alpha+\beta \mathrm{Lm}-\gamma \mathrm{La}$ \\
\hline 1 & 18.257 & 1.63 & 17.817 \\
\hline 2 & 18.137 & 1.98 & 17.604 \\
\hline 3 & 17.809 & 1.44 & 17.422 \\
\hline 4 & 17.455 & 0.82 & 17.234 \\
\hline 5 & 17.171 & 0.39 & 17.065 \\
\hline 6 & 16.976 & 0.16 & 16.935 \\
\hline 7 & 16.863 & 0.15 & 16.822 \\
\hline 8 & 16.822 & 0.26 & 16.752 \\
\hline 9 & 16.849 & 0.36 & 16.751 \\
\hline 10 & 16.946 & 0.43 & 16.830 \\
\hline 11 & 17.123 & 0.50 & 16.987 \\
\hline 12 & 17.388 & 0.52 & 17.247 \\
\hline 13 & 17.732 & 0.44 & 17.614 \\
\hline 14 & 18.079 & 0.80 & 17.864 \\
\hline
\end{tabular}

\subsection{0-year loop current condition}

\subsubsection{Met-ocean condition}

Under the impact of 100-year loop currents, the mean loads in the most loaded mooring line (line 8) already reaches more than $60 \%$ of the breaking strength of the largest polyester rope available on the website of the manufacture. Here, we chose a loop current of smaller velocity, and named it as 50-year loop current, to provide sufficient safety factor for the polyester ropes used in this study. Wave and wind spectrum in companion with a typical 100-year loop current condition were used in the case of 50year loop current. The significant wave height is $6.1 \mathrm{~m}$ and peak period is $11 \mathrm{~s}$. The steady wind speed is $50 \mathrm{mph}$. The velocity of the current is steady but varies with water 
depth, which is plotted in Fig. 14. The directions of waves, wind and current with respected to the mooring line system of are depicted in Fig. 15.

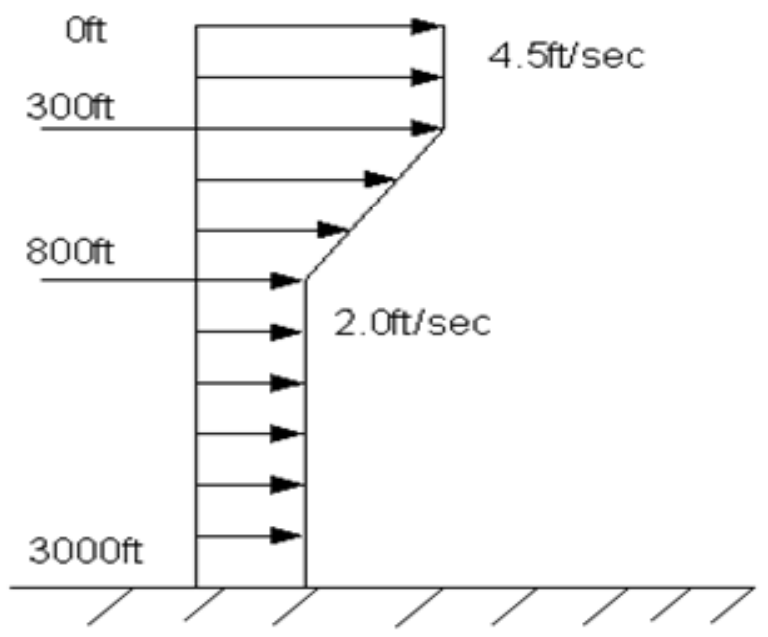

Fig. 14. Profile of current velocity

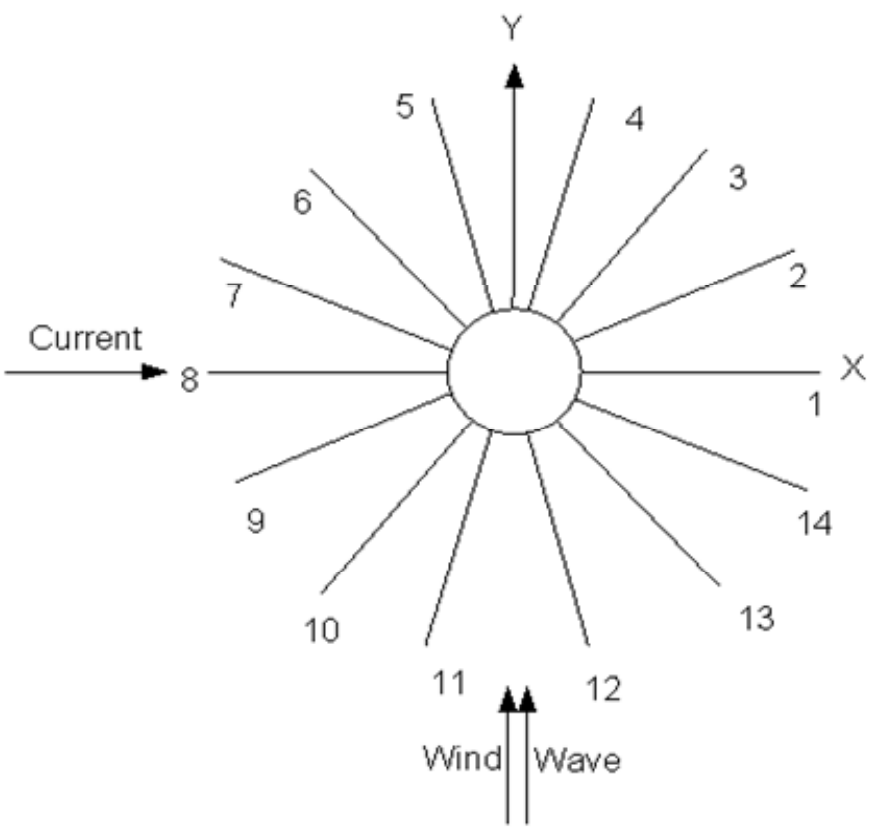

Fig. 15. Configuration of SPAR in loop current condition 


\subsubsection{Modeling the modulus based on mean tension and dynamic tension}

The main procedures are the same as 100-year storm condition except lowfrequency region is defined as $0-0.1(\mathrm{rad} / \mathrm{sec})$ which is the passing range of the low-pass filter. The final results of the modulus by the mean load only and considering both mean and dynamic loads are given in Table 9. In Table 9, the fourth column is the modulus considering mean tension only and the last column is the modulus considering both mean and dynamic tension. $\mathrm{L}_{\mathrm{m}}$ and $\mathrm{L}_{\mathrm{a}}$ are the ratios of the related tensions to breaking strength of a polyester rope and given in the percentage.

Table 9 Modulus considering mean load only and mean and dynamic loads

\begin{tabular}{|c|c|c|c|c|c|c|}
\hline $\begin{array}{c}\text { Line } \\
\#\end{array}$ & $\begin{array}{c}\text { Tension } \\
(\mathbf{N})\end{array}$ & $\begin{array}{c}\mathrm{Lm} \\
(\%)\end{array}$ & $\begin{array}{c}\mathrm{E}=(\boldsymbol{\alpha}+\boldsymbol{\beta} \mathbf{L m}) \\
(\mathbf{G p a})\end{array}$ & $\begin{array}{c}\text { mean amplitude } \\
(\mathbf{N})\end{array}$ & $\begin{array}{c}\text { La } \\
(\%)\end{array}$ & $\begin{array}{c}\mathrm{E}=(\boldsymbol{\alpha}+\boldsymbol{\beta} \mathbf{m} \quad-\quad \text { rLa }) \\
(\mathbf{G p a})\end{array}$ \\
\hline 1 & $1.4847 \mathrm{E}+06$ & 10.09 & 16.602 & $2.6086 \mathrm{E}+03$ & 0.02 & 16.597 \\
\hline 2 & $1.5042 \mathrm{E}+06$ & 10.23 & 16.630 & $1.1923 \mathrm{E}+04$ & 0.08 & 16.608 \\
\hline 3 & $1.5900 \mathrm{E}+06$ & 10.81 & 16.753 & $2.1251 \mathrm{E}+04$ & 0.14 & 16.714 \\
\hline 4 & $1.7566 \mathrm{E}+06$ & 11.94 & 16.992 & $3.3695 \mathrm{E}+04$ & 0.23 & 16.930 \\
\hline 5 & $2.0565 \mathrm{E}+06$ & 13.98 & 17.423 & $5.4450 \mathrm{E}+04$ & 0.37 & 17.323 \\
\hline 6 & $2.5883 \mathrm{E}+06$ & 17.60 & 18.187 & $8.5516 \mathrm{E}+04$ & 0.58 & 18.030 \\
\hline 7 & $3.4314 \mathrm{E}+06$ & 23.33 & 19.398 & $1.0327 \mathrm{E}+05$ & 0.70 & 19.209 \\
\hline 8 & $4.1221 \mathrm{E}+06$ & 28.02 & 20.390 & $4.4037 \mathrm{E}+04$ & 0.30 & 20.309 \\
\hline 9 & $3.7987 \mathrm{E}+06$ & 25.82 & 19.926 & $2.0936 \mathrm{E}+05$ & 1.42 & 19.542 \\
\hline 10 & $2.9071 \mathrm{E}+06$ & 19.76 & 18.645 & $2.0510 \mathrm{E}+05$ & 1.39 & 18.269 \\
\hline 11 & $2.2425 \mathrm{E}+06$ & 15.24 & 17.690 & $1.1043 \mathrm{E}+05$ & 0.75 & 17.488 \\
\hline 12 & $1.8611 \mathrm{E}+06$ & 12.65 & 17.142 & $5.3171 \mathrm{E}+04$ & 0.36 & 17.045 \\
\hline 13 & $1.6473 \mathrm{E}+06$ & 11.20 & 16.835 & $2.4813 \mathrm{E}+04$ & 0.17 & 16.790 \\
\hline 14 & $1.5318 \mathrm{E}+06$ & 10.41 & 16.669 & $9.9979 \mathrm{E}+03$ & 0.07 & 16.651 \\
\hline
\end{tabular}




\section{CHAPTER VI}

\section{NUMERICAL RESULTS AND DISCUSSION}

\subsection{Introduction}

Numerical simulations are made in the cases of 100-year storm condition and 50year loop current condition. Comparison of the corresponding simulations are made for several cases, namely, the consideration of small and large elongation in the computation, the comparison of polyester and chain-wire mooring systems, the dependence of modulus on mean load and dynamic load, and the effects of structural damping of the polyester rope on the numerical simulation. Given the met-ocean conditions and using the modulus of each polyester rope modified according to its mean and dynamic loads described in the previous chapters, we used COUPLE6D to simulate the motions of the SPAR interacting with the polyester mooring system in the time domain. For the purpose of comparison, we also made the corresponding simulation of the same SPAR interacting with the original steel mooring system. Each simulation was made for about three hour in prototype scale for obtaining meaningful statistics. The corresponding motion of the SPAR interacting respectively with the polyester and steel mooring system are compared statistically, and in time and frequency domain. 


\subsection{Numerical limitation of small extensible rod theory for a polyester rope}

Attempts to simulate polyester mooring system for 3 hour duration were failed in using CABLE3D based on the assumption of small elongation. During the simulation, high-frequency tension of ropes was generated and gradually increased. Finally this high-frequency tension led to a blowout in the simulation, especially in the polyester rope of the greatest tension. Since this frequency is much greater the wave frequency, the high-frequency tension component does not likely result from the motion of the SPAR. The tension in Line 1 became extremely large when the simulation lasted a few thousand seconds, which is plotted in Fig. 16. To show the high-frequency tension, a portion of tension history around 1780 s is enlarged in Fig. 17. The spectrum of tension plotted in Fig.18 indicates the high frequency vibration occurred around $2.8 \sim 2.9 \mathrm{~Hz}$ frequency range.

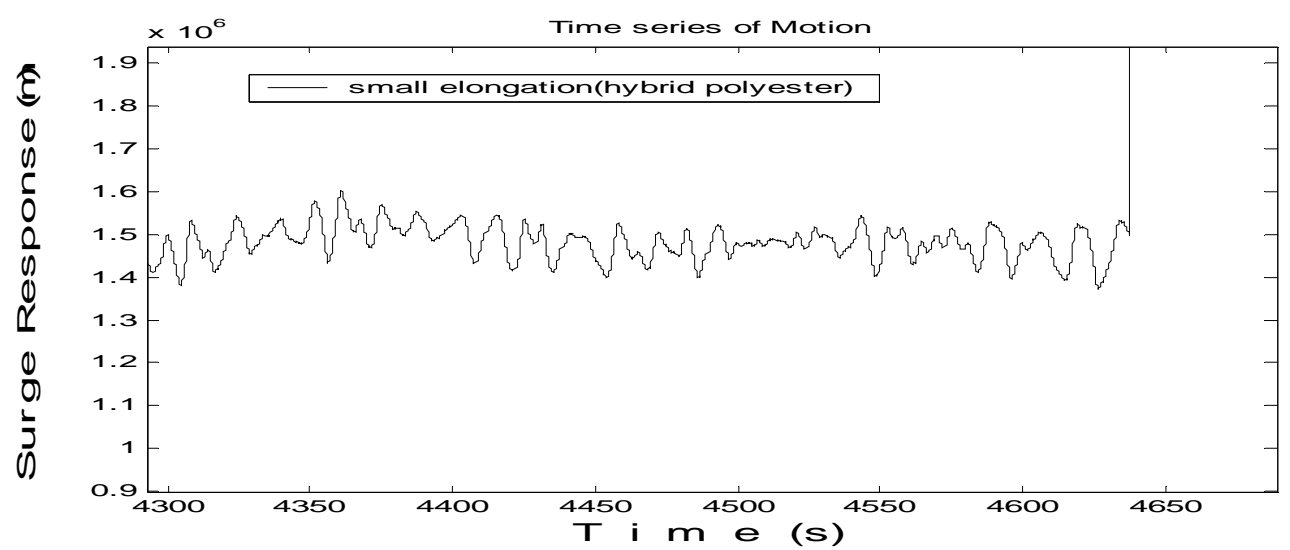

Fig. 16. Results in line 1 using small extensible rod theory for polyester rope 
Time series of Tension

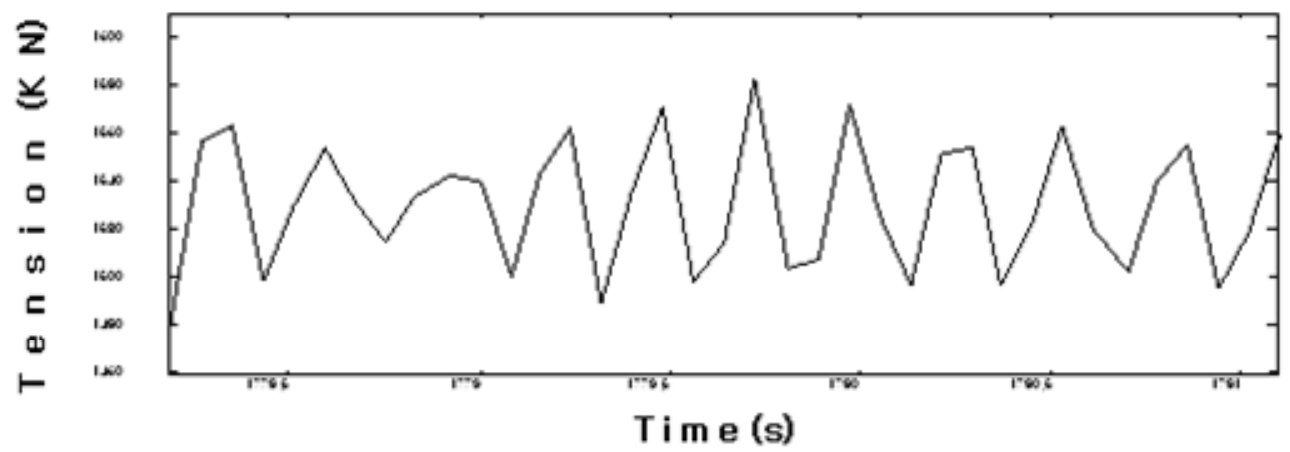

Fig. 17. High-frequency portion of line 1

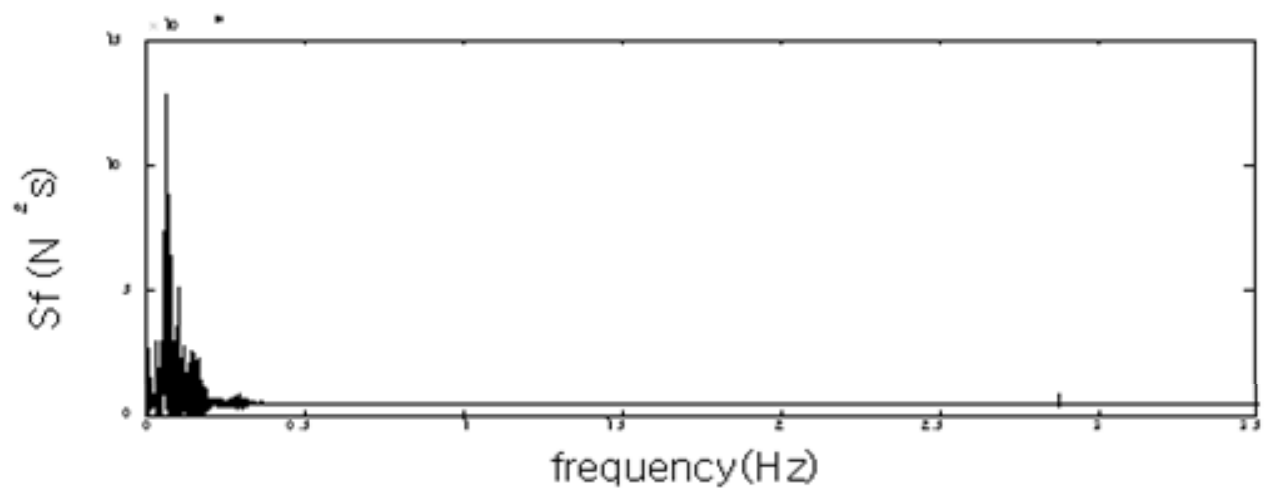

Fig. 18. Spectrum of line 1 tension of polyester with small elongation theory

Further examination of the cause for generating high-frequency tension revealed that it results from the resonance vibration of the polyester rope embedded in a hybrid polyester mooring line. It is shown by the fact that the frequency of resonant tension matches the natural frequency of the polyester rope.

Noticing that both ends of the polyester rope connect to steel chains, a taut polyester rope can be approximated as an elastic rod of two free ends. Since the wet weight of a polyester rope is insignificant, the gravity force applied on the rope can be neglected. By modeling it as a weightless elastic bar plotted in Fig. 19, the natural 
frequencies for the longitudinal vibration of the polyester rope can be approximately computed by

$$
\omega=(2 n-1) \frac{\pi}{L} \sqrt{\frac{E}{\rho}}, \quad n=1,2,3, \ldots
$$

a)
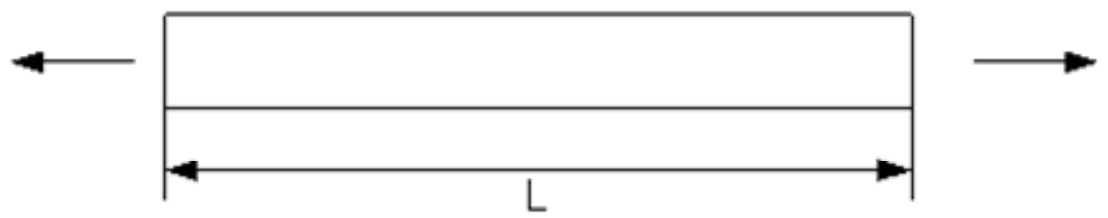

b)
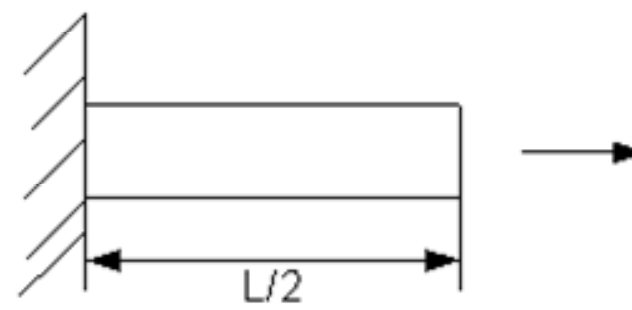

Fig. 19. Longitudinal bar under free vibration:

a) two free ends b) equivalent bar with half length and one end fixed

where $E$ is the modulus of the rope, $L$ the length, $\rho$ the density, and $n$ denotes the nth mode for the natural frequency (Meirovitch 1967).

The natural frequency for the first mode $(n=1)$ of the polyester ropes of lengths ranging from $700 \mathrm{~m}$ to $1300 \mathrm{~m}$ is computed using (6.1) and plotted in Fig. 20. The density of all ropes of different lengths remains the same, $\rho=1380 \mathrm{~kg} / \mathrm{m}^{3}$. For comparison, the corresponding frequency of the resonant tension observed in the numerical simulation is also plotted in Fig. 20. In all numerical simulations, a hybrid mooring line always consists of a polyester rope connecting to two steel chains. Although the length of a 
polyester rope changes from $700 \mathrm{~m}$ to $1300 \mathrm{~m}$, the lengths of the two end chains remain the same. Also in all simulations, the same SPAR is used. Fig. 20 shows that the frequency of the resonant tension occurring in numerical simulations depends on the length of the rope and to some extent on the size of the time step used in numerical simulations. The simulated frequency converges with the decrease in the size of time step and is in satisfactory agreement with the analytic natural frequency in the entire length range of polyester ropes. The problem of generating high-frequency tension in a hybrid polyester mooring line can be eliminated by using large elongation numerical code or including viscous damping of a polyester rope in the numerical simulations.

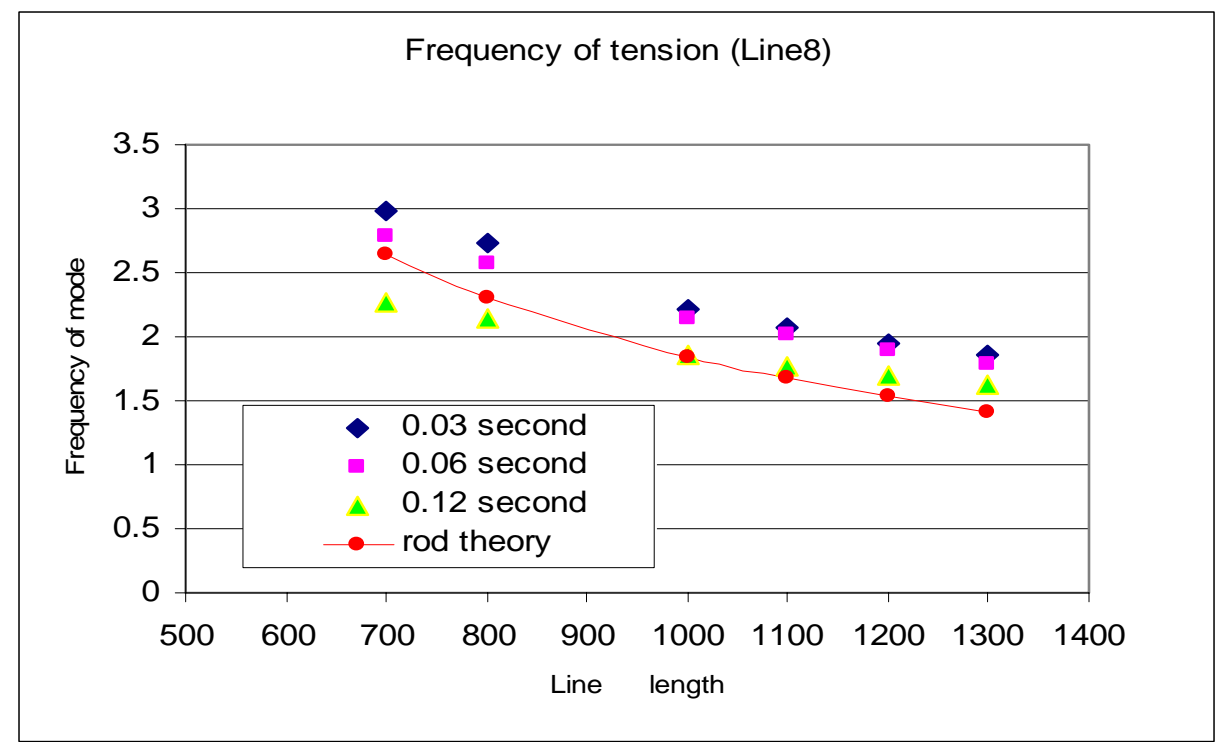

Fig. 20. Natural frequency of the first mode of taut polyester ropes. 


\subsection{Theory of structural damping considering energy dissipation}

Under a cyclical load, polyester ropes demonstrate inelastic behavior, that is, noncoincident relations between stress and strain in the cases of loading and unloading, known as hysteresis loop in a stress-strain diagram (see Fig. 3.). The energy dissipation contained in a hysteresis loop was considered in numerical schemes to estimate the contribution of structural damping effect on a coupled dynamic simulation. In applying a sinusoidal extension to a taut rope, a polyester rope can be approximately modeled by an ideal spring, in which stress is proportional to strain, and an ideal dashpot, in which stress proportional to rate of strain as follows (Morton, 1975).

$$
\sigma=E_{p} \varepsilon+\eta_{p} \frac{d \varepsilon}{d t}
$$

where $E_{p}$ is spring modulus, $\eta_{p}$ viscous coefficient of dashpot, $\sigma$ stress and $\varepsilon$ strain.

An ideal spring-damper system for modeling is described in Fig. 21.

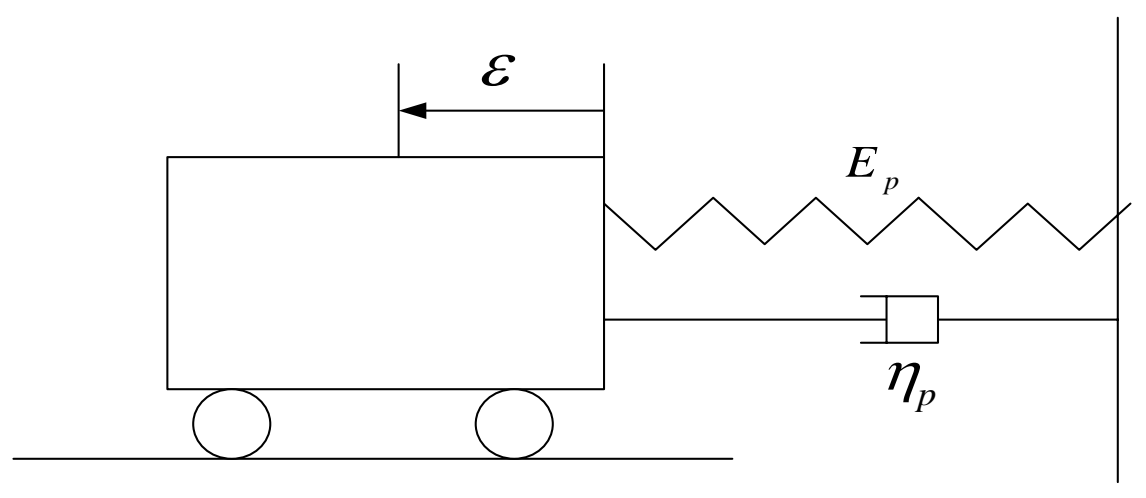

Fig. 21. Ideal spring and damper system 
When a polyester yarn is subjected to a cyclic loading, the stress and strain are not in phase. The strain lags behind the stress in time, and this phase shift is denoted by $\delta$ and $\tan \delta$ is the ratio of the out-of-phase stress to in-phase stress (Bosman, 1996).

$$
\tan \delta=\frac{\eta_{p} \omega}{E_{p}}
$$

where $\omega$ is angular frequency $(\mathrm{rad} / \mathrm{sec})$. A yarn with a high value of $\tan \delta$ has a high energy loss, using linear regression, the following empirical equation was derived based on data fitting and suggested for practical value of a polyester mooring system (Bosman, 1996).

$$
\tan \delta=-0.01+0.061 * \varepsilon_{\mathrm{a}}
$$

where $\varepsilon_{\mathrm{a}}$ is the amplitude of cyclic strain. In considering viscous structural damping effects in this study, we let $\tan \delta=0.02$ and obtain $\eta_{p}=5.3936 \times 10^{8}$.

\subsection{0-year hurricane condition}

\subsubsection{Steel mooring system simulated based on the formulation of large or small elongation}

In this section, numerical results of conventional steel chain-wire-chain mooring responses are predicted respectively using CABLE3D based on the formulation of large and small elongation. Even though steel has small elongation, marginal difference is 
observed between the results based on the two different formulations. This is expected because the elongation of steel mooring lines is relatively small. The calculated static offset curves of the mooring system were plotted in Fig. 5, showing slightly small stiffness based on the assumption of large elongation. The simulated motions and tensions of highest and smallest loaded line are compared in Figs. 22 - 26, and the statistics are summarized in Table 10. When a simulation based on the formulation of large elongation, the surge motion of a SPAR increased slightly and a heave motion decreased little but differences of motion are small, only about $0.1 \sim 0.5 \mathrm{~m}$. In general, satisfactory agreement is observed between the two corresponding simulations.

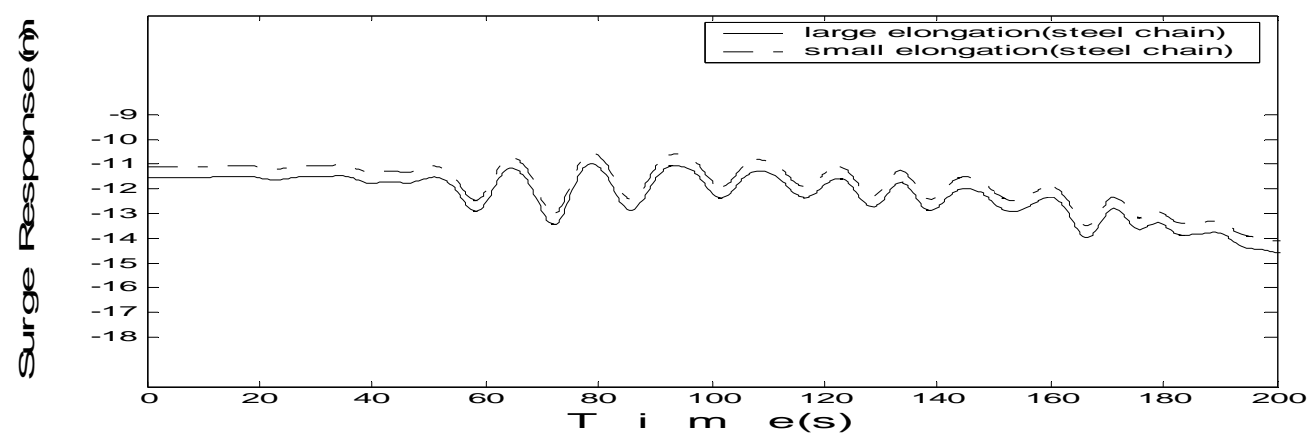

Fig. 22. Surge motions of steel chain-wire mooring systems in hurricane condition

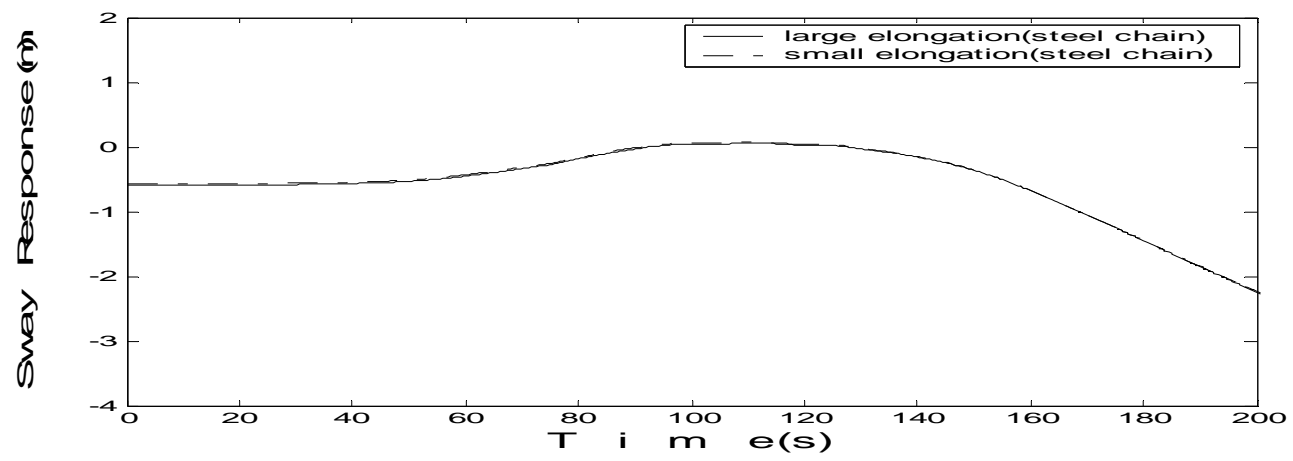

Fig. 23. Sway motions of steel chain-wire mooring systems in hurricane condition 


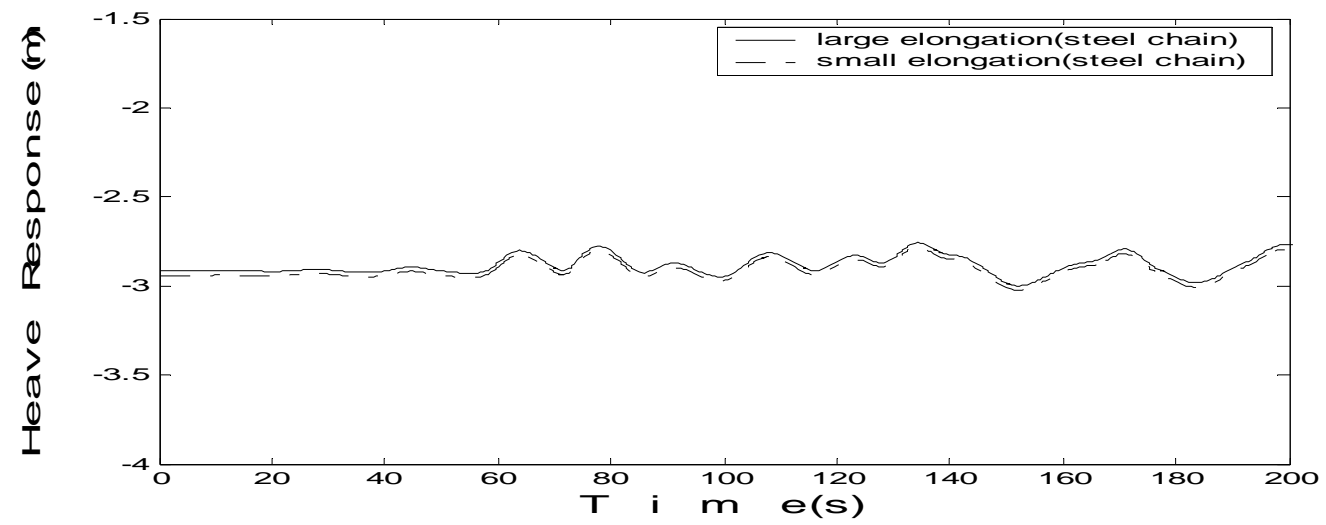

Fig. 24. Heave motions of steel chain-wire mooring systems in hurricane condition

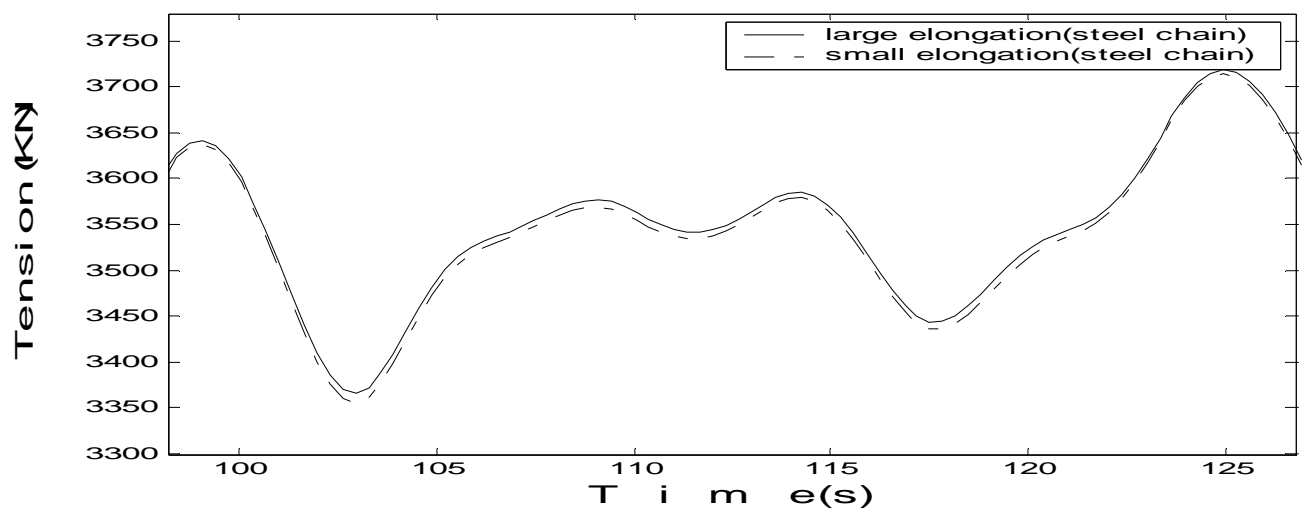

Fig. 25. Line 1 tensions of steel chain-wire ropes in hurricane condition

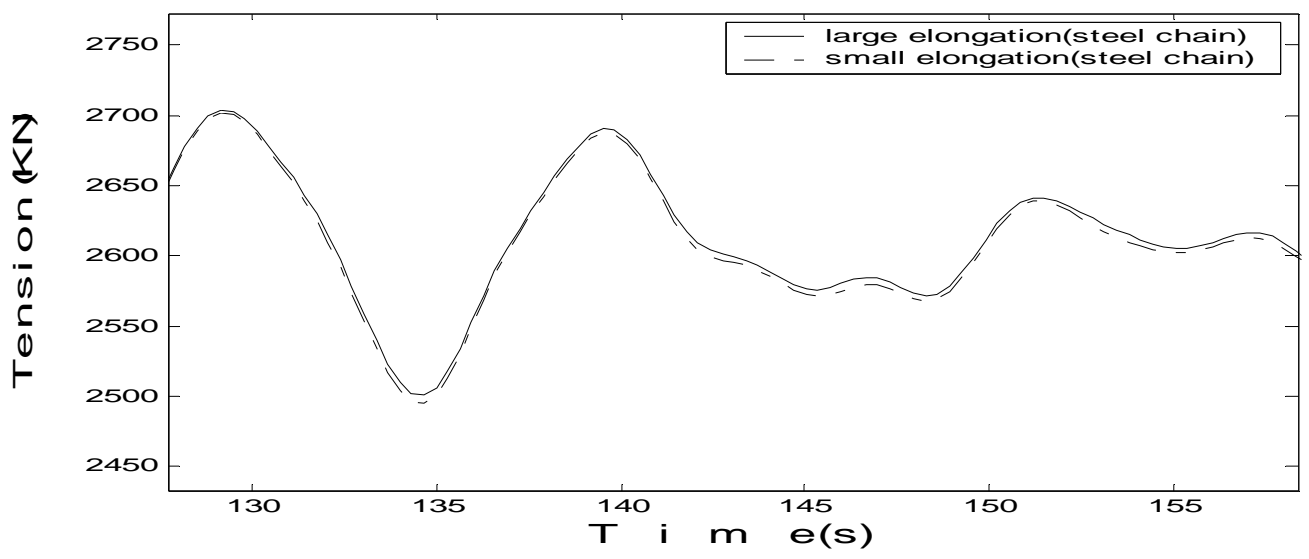

Fig. 26. Line 8 tensions of steel chain-wire ropes in hurricane condition 
Table 10 Statistics of motions and tensions of steel mooring systems

\begin{tabular}{|c|c|c|c|c|c|}
\hline Large elongation & Surge (m) & Sway (m) & Heave (m) & Line 1 Tension (KN) & Line 8 Tension (KN) \\
\hline Max & -8.4150 & 3.0019 & -2.2870 & $4.7916 \mathrm{E}+03$ & $2.8311 \mathrm{E}+03$ \\
\hline Min & -20.8424 & -5.0147 & -3.2476 & $3.1021 \mathrm{E}+03$ & $2.3196 \mathrm{E}+03$ \\
\hline Mean & -13.6238 & -0.9325 & -2.8765 & $3.6739 \mathrm{E}+03$ & $2.5797 \mathrm{E}+03$ \\
\hline Standard D. & 1.8871 & 1.8549 & 0.1239 & $1.9577 \mathrm{E}+02$ & $6.6439 \mathrm{E}+02$ \\
\hline Small elongation & Surge (m) & Sway (m) & Heave (m) & Line 1 Tension (KN) & Line 8 Tension (KN) \\
\hline Max & -7.7794 & 3.0792 & -2.3147 & $4.8301 \mathrm{E}+03$ & $2.8375 \mathrm{E}+03$ \\
\hline Min & -20.4231 & -5.0378 & -3.2704 & $3.0756 \mathrm{E}+03$ & $2.3105 \mathrm{E}+03$ \\
\hline Mean & -13.1131 & -0.8900 & -2.9012 & $3.6670 \mathrm{E}+03$ & $2.5767 \mathrm{E}+03$ \\
\hline Standard D. & 1.8960 & 1.9415 & 0.1228 & $2.0068 \mathrm{E}+03$ & $6.7633 \mathrm{E}+03$ \\
\hline
\end{tabular}

\subsubsection{Simulation results of a hybrid polyester mooring system}

Using CABLE3D based on the formulation of large elongation, numerical simulations of interaction between the SPAR and its polyester mooring system were conducted in three different ways. For polyester ropes, numerical computations were made for using the modulus, determined based on either mean force only or mean force and load amplitude both. The values of the different moduli were presented in Tables 9 and 10. The third column in Table 9 describes the moduli which were modified based on mean load and dynamic load amplitude using equation (4.3). The third one considers structural damping. Based on the results given by these three simulations, we may find whether or not the effect of dynamic loading and structural damping are important to the simulation of polyester ropes.

The results of three different simulations are plotted in Figs. 27 - 29 for the motion of the SPAR. Time series of tension in line 1 and line 8 are drawn in Figs. $30-31$. Statistics of motions of the SPAR and tensions at eh fairlead of mooring lines are 
summarized in Table 11. The comparison in these figures and table indicates the modification on the modulus due to dynamic loads does not play significant role on the interaction between the SPAR and its hybrid polyester mooring system. The effects of including the structural damping in polyester ropes are negligible.
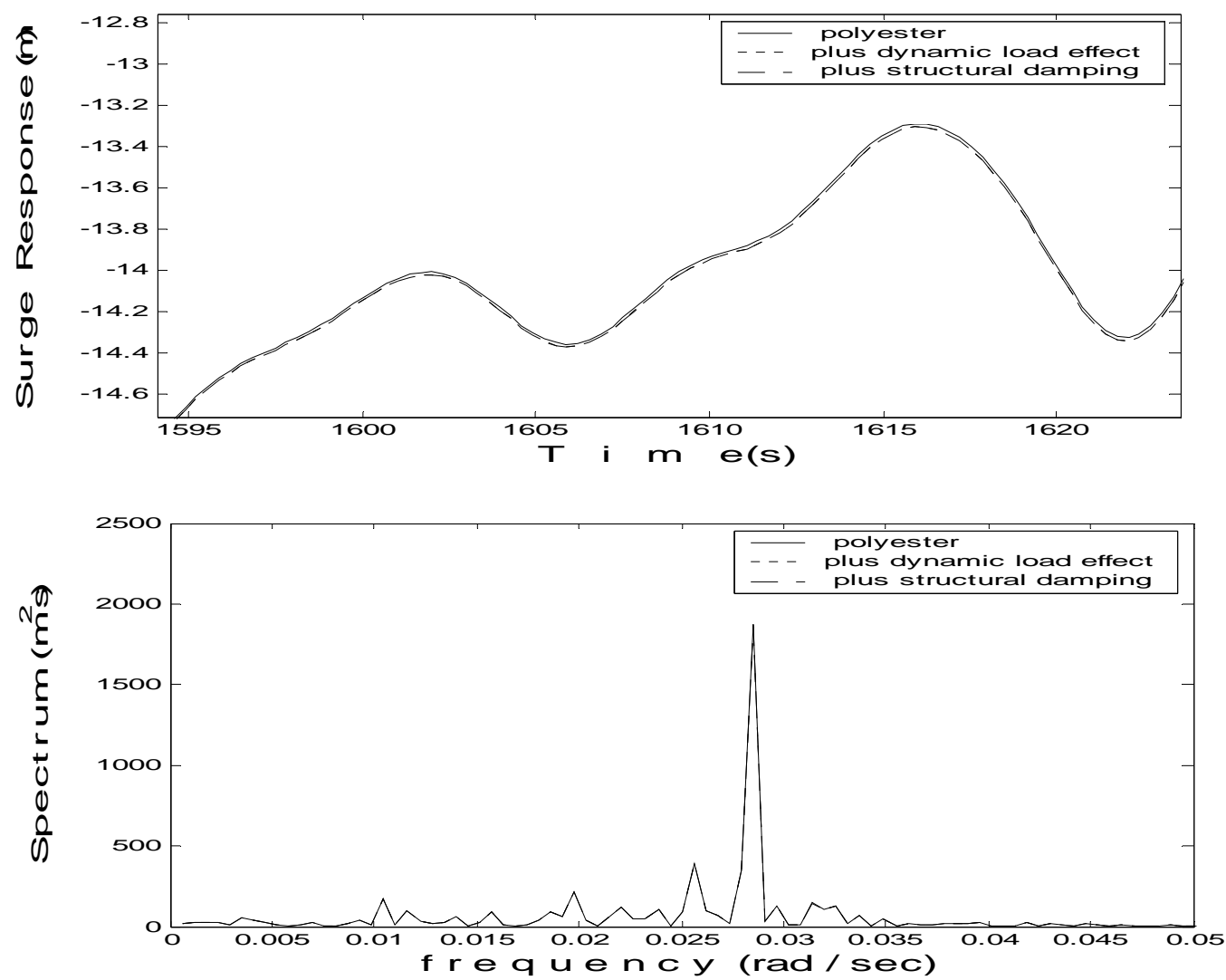

Fig. 27. Surge motions in hurricane condition as a function of a) time and b) frequency 

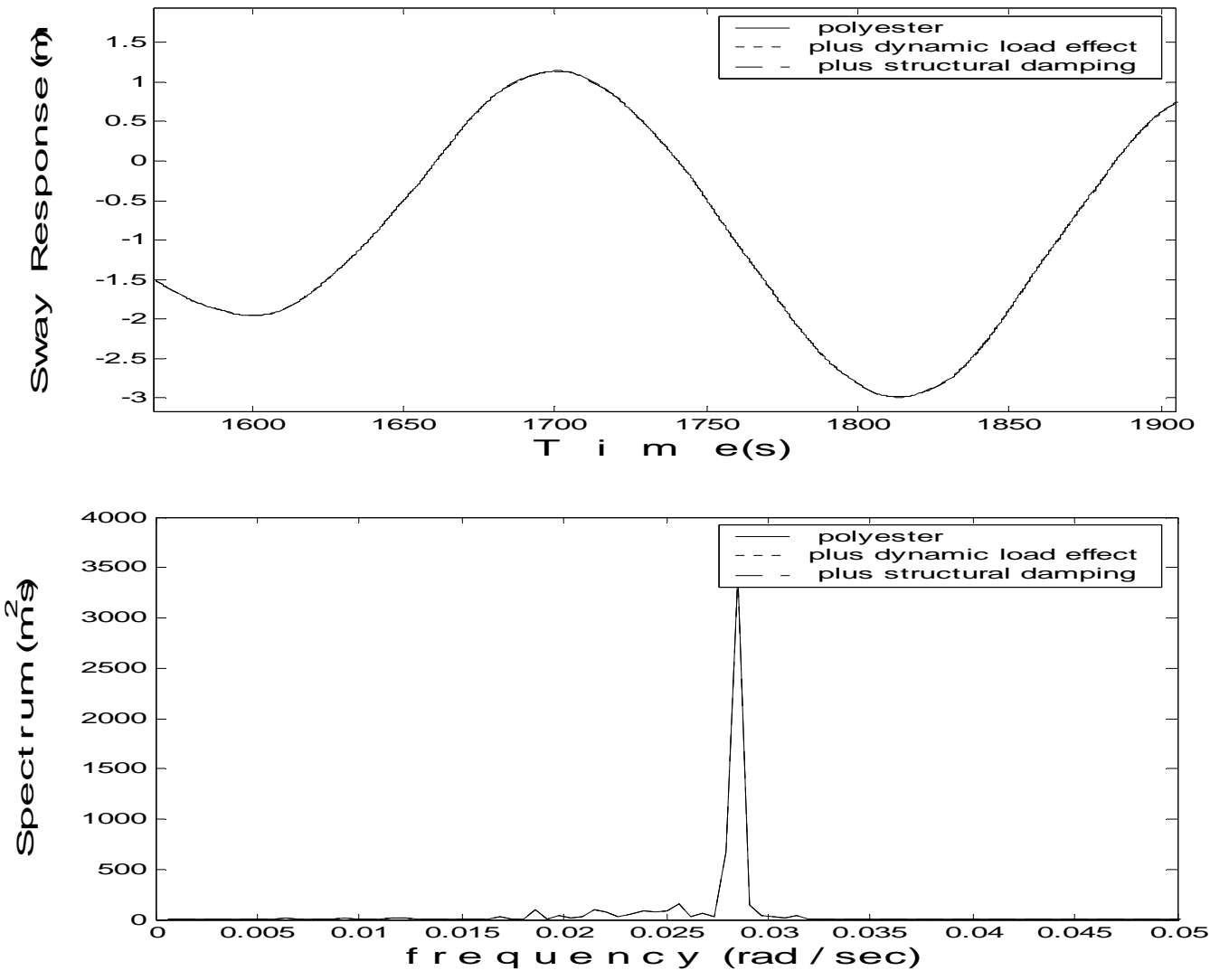

Fig. 28. Sway motions in hurricane condition as a function of a) time and b) frequency 

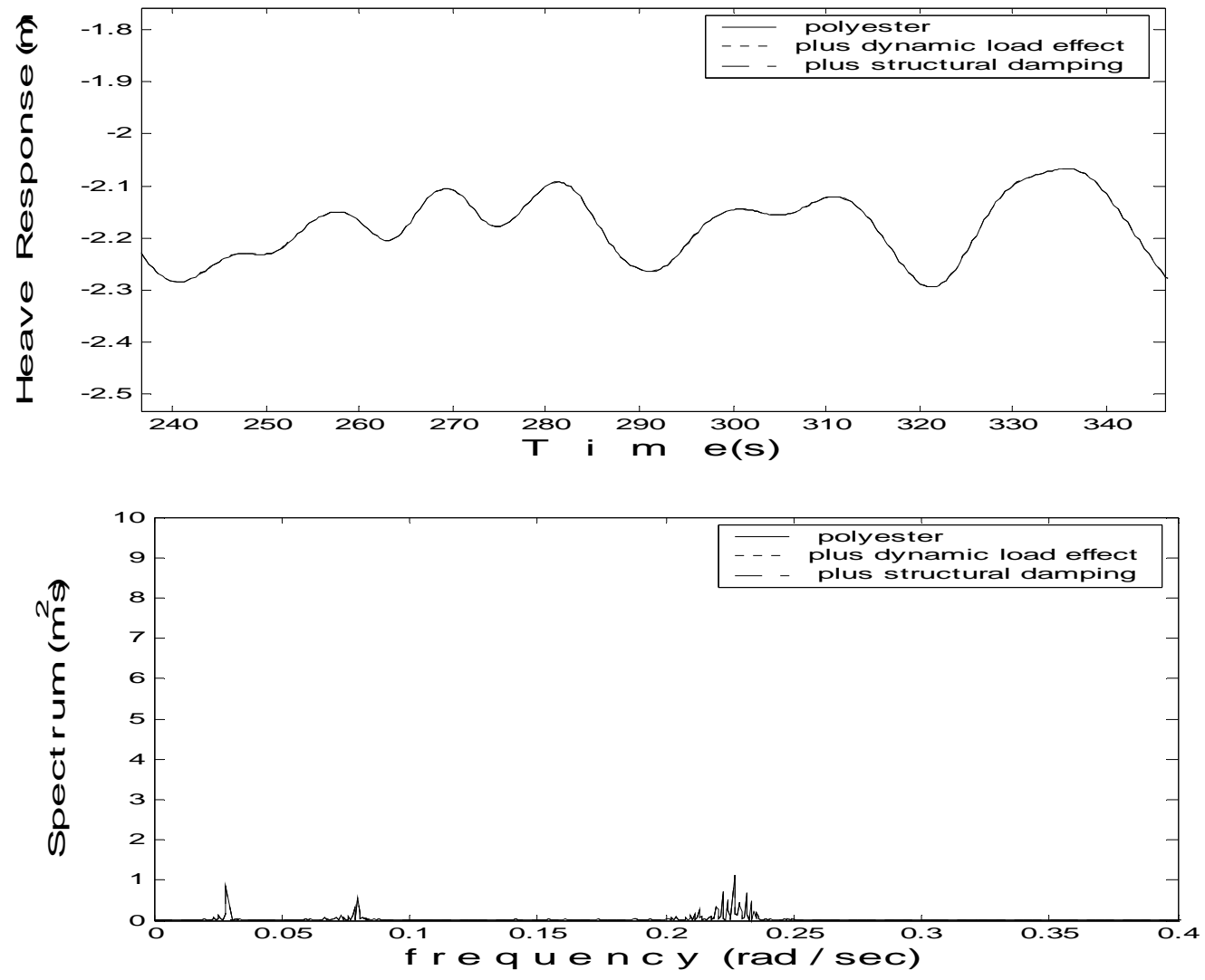

Fig. 29. Heave motions in hurricane condition as a function of a) time and b) frequency 


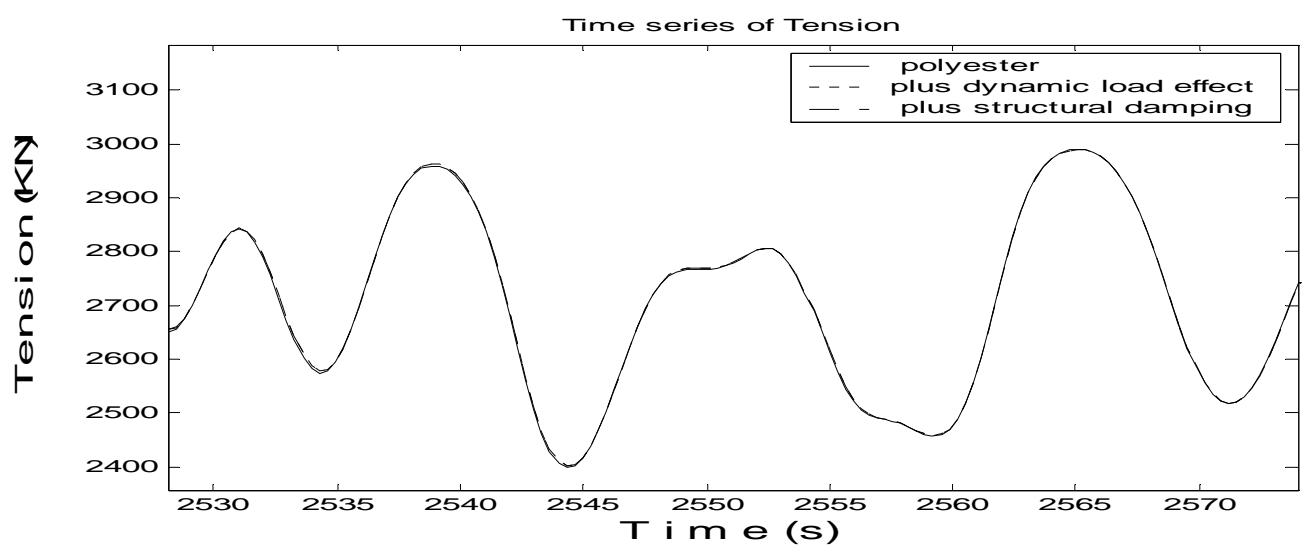

Fig. 30. Tension in hybrid polyester line 1 in hurricane condition

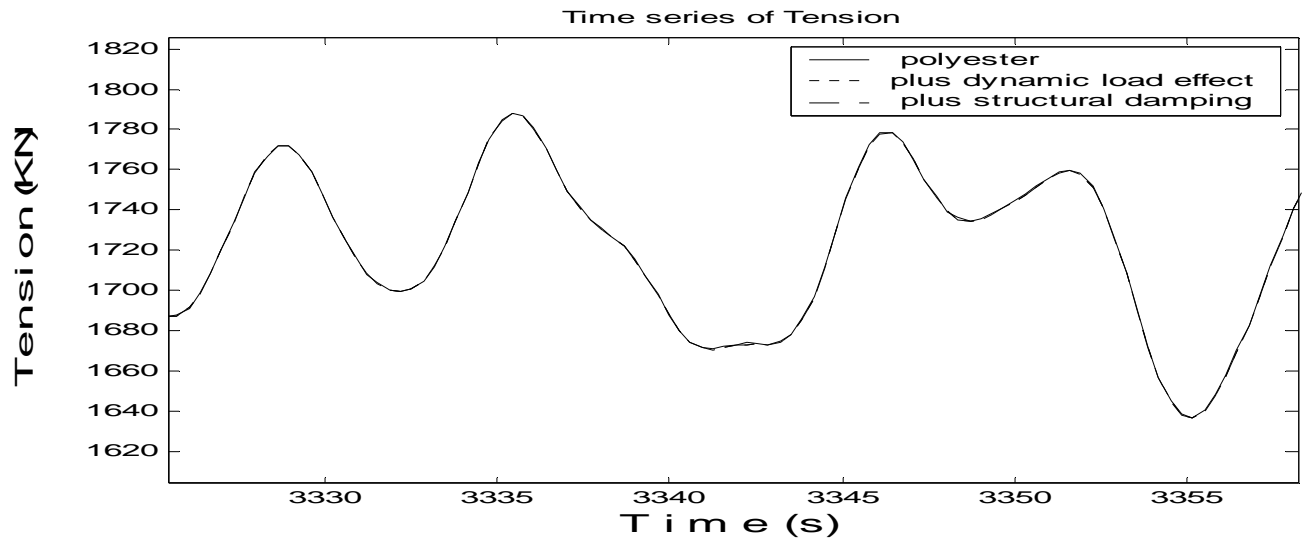

Fig. 31. Tension in hybrid polyester line 8 in hurricane condition 
Table 11 Statistics of motions and tensions of polyester mooring systems

\begin{tabular}{|c|c|c|c|c|c|}
\hline Mean load only & Surge (m) & Sway (m) & Heave (m) & Line 1 Tension (KN) & Line 8 Tension (KN) \\
\hline Max & -8.1094 & 3.0267 & -1.6381 & $4.6675 \mathrm{E}+03$ & $2.0036 \mathrm{E}+03$ \\
\hline Min & -21.5061 & -4.8430 & -2.4965 & $2.3089 \mathrm{E}+03$ & $1.5962 \mathrm{E}+03$ \\
\hline Mean & -13.8858 & -0.9235 & -2.1645 & $3.0367 \mathrm{E}+03$ & $1.7914 \mathrm{E}+03$ \\
\hline Standard D. & 1.8750 & 1.8178 & 0.1056 & $2.5100 \mathrm{E}+02$ & $4.9100 \mathrm{E}+01$ \\
\hline Both mean and dynamic load & Surge (m) & Sway (m) & Heave (m) & Line 1 Tension (KN) & Line 8 Tension (KN) \\
\hline Max & -8.1386 & 3.0214 & -1.6377 & $4.6452 \mathrm{E}+03$ & $2.0029 \mathrm{E}+03$ \\
\hline Min & -21.5171 & -4.8496 & -2.4960 & $2.3102 \mathrm{E}+03$ & $1.5961 \mathrm{E}+03$ \\
\hline Mean & -13.9043 & -0.9285 & -2.1643 & $3.0354 \mathrm{E}+03$ & $1.7911 \mathrm{E}+03$ \\
\hline Standard D. & 1.8744 & 1.8156 & 0.1056 & $2.4953 \mathrm{E}+02$ & $4.9084 \mathrm{E}+01$ \\
\hline $\begin{array}{l}\text { Both mean and dynamic load + } \\
\text { Structural damping }\end{array}$ & Surge (m) & Sway (m) & Heave (m) & Line 1 Tension (KN) & Line 8 Tension (KN) \\
\hline Max & -8.1387 & 3.0214 & -1.6376 & $4.6452 \mathrm{E}+03$ & $2.0030 \mathrm{E}+03$ \\
\hline Min & -21.5171 & -4.8496 & -2.4960 & $2.3101 \mathrm{E}+03$ & $1.5960 \mathrm{E}+03$ \\
\hline Mean & -13.9044 & -0.9285 & -2.1643 & $3.0354 \mathrm{E}+03$ & $1.7911 \mathrm{E}+03$ \\
\hline Standard D. & 1.8744 & 1.8156 & 0.1056 & $2.4953 \mathrm{E}+02$ & $4.9083 \mathrm{E}+01$ \\
\hline
\end{tabular}

\subsubsection{Comparison of the polyester mooring system to the steel mooring system}

In this section, we compare numerical simulations of the SPAR positioned respectively by a hybrid polyester mooring system and the corresponding steel chain mooring system. The time series and spectra of surge motion of the SPAR positioned respectively by these two mooring systems are plotted in Fig. 32. As shown in surge stiffness curve (see Fig. 9.), the polyester mooing system is softer than the steel mooring system below $15 \mathrm{~m}$ surge excursion. Therefore, static equilibrium position of the polyester system is further away from that of the steel mooring system.

The time series and spectra of sway motion of both systems are plotted in Fig. 33 . Because the sway motion of the SPAR is much smaller, the two spectra are almost 
identical. Time series and spectra of heave responses are compared in Fig. 34. The mean draw-down force of the polyester mooring system is much smaller than that of the steel mooring system, mainly because smaller pretension was applied. Therefore, the mean heave of the SPAR positioned by the hybrid polyester mooring system is closer to sea surface. It is confirmed that middle and low frequency motions play an important role in heave response as shown in the spectra. Although these responses were slightly reduced in the polyester mooring system, very low-frequency response was greater.

Line 1 has largest tension because it is in the upstream direction of currents. In Fig. 35, time series and spectra of tension in Line 1 of both mooring systems are plotted. As shown in the figure, the mean tension was significantly reduced in the polyester rope but very low-frequency components of the tension are bigger than those of steel lines. Finally, time series and spectra of tension in Line 8 which has a smallest tension were compared in Fig. 36. The mean tension was significantly reduced in polyester mooring, and so were very low-frequency components in Line 8. Statistics of numerical simulations are summarized in Table 12. 

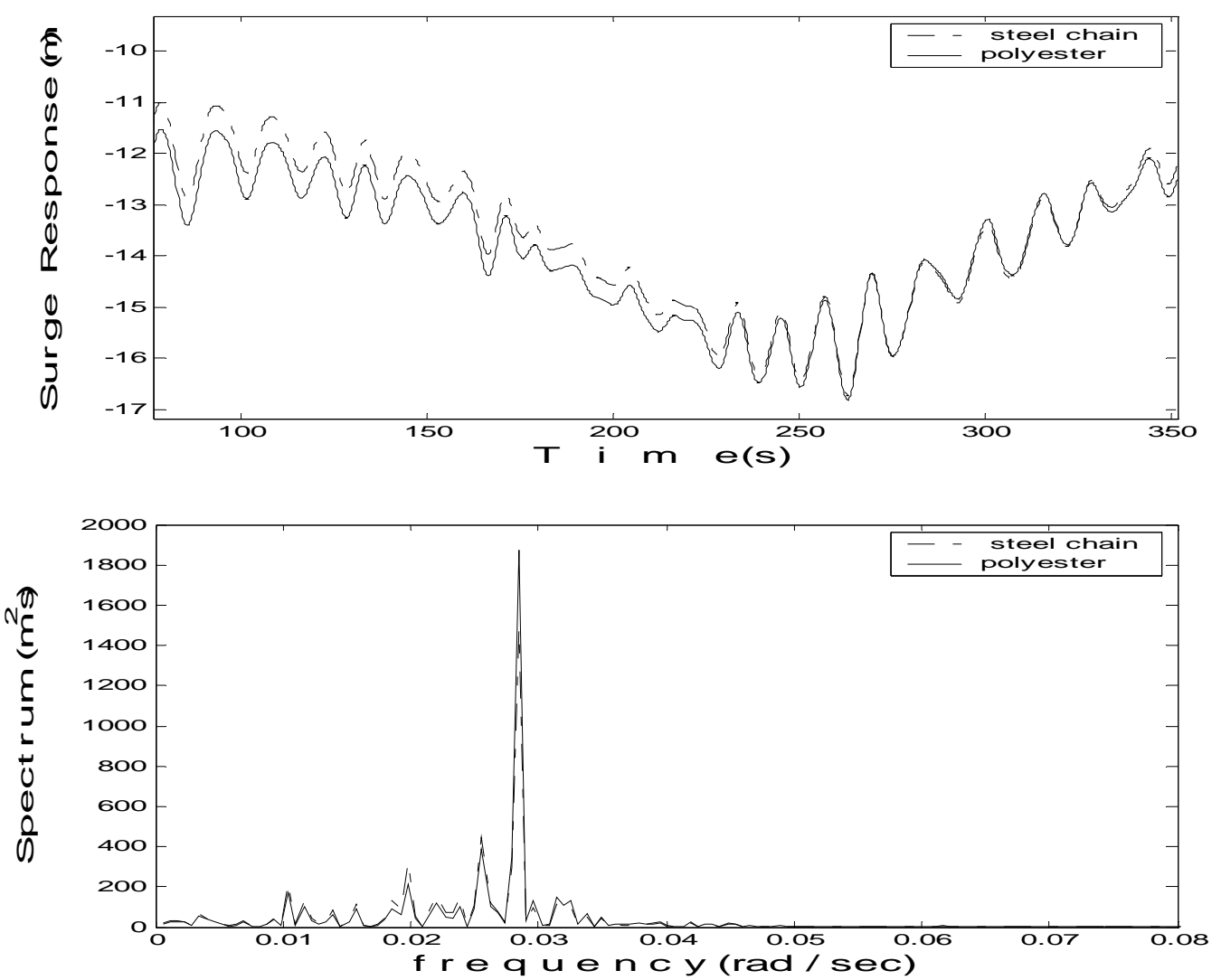

Fig. 32. Surge motions of chain-wire and polyester mooring system in hurricane condition as a function of a) time and b) frequency 

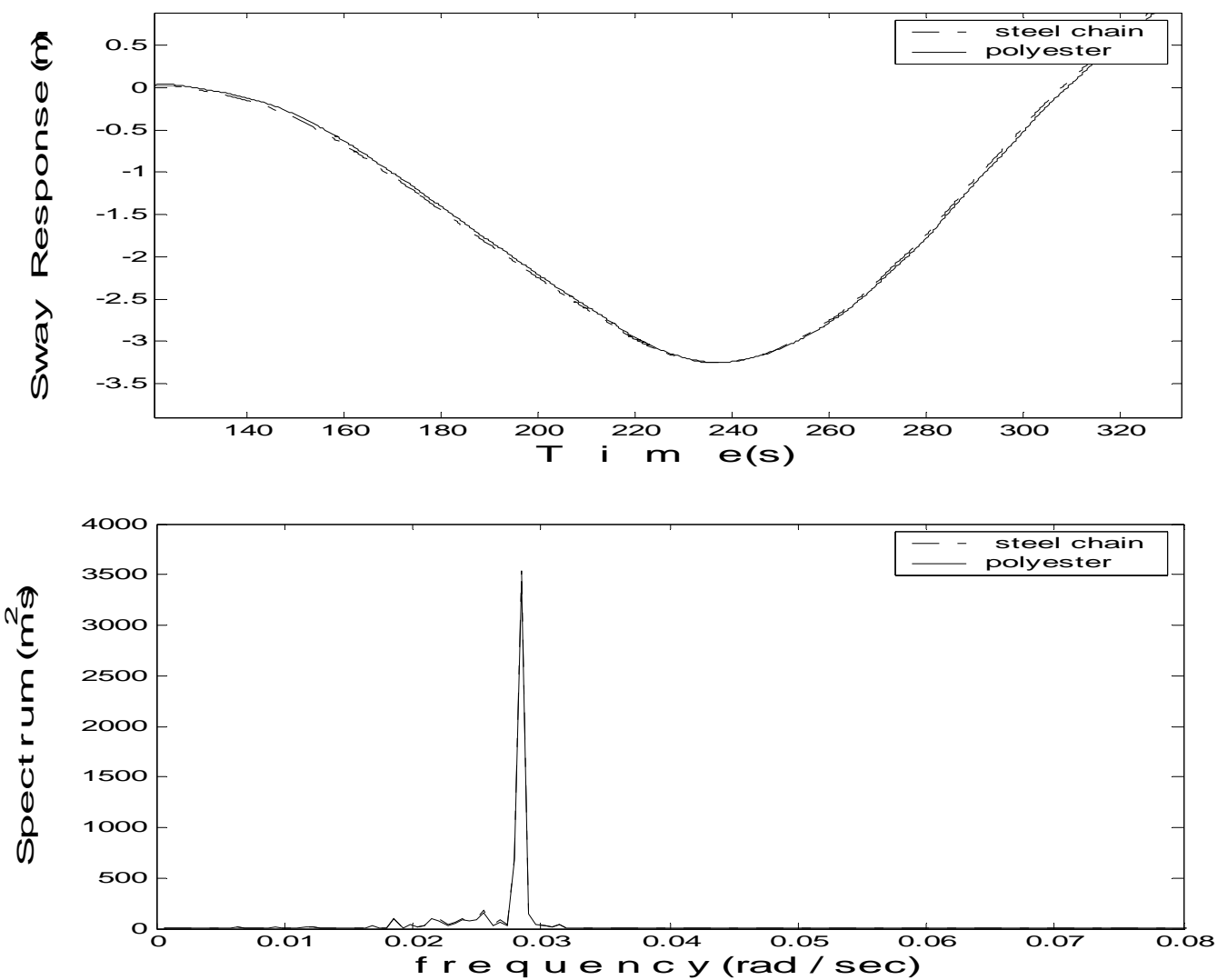

Fig. 33. Sway motions of chain-wire and polyester mooring system in hurricane condition as a function of a) time and b) frequency 

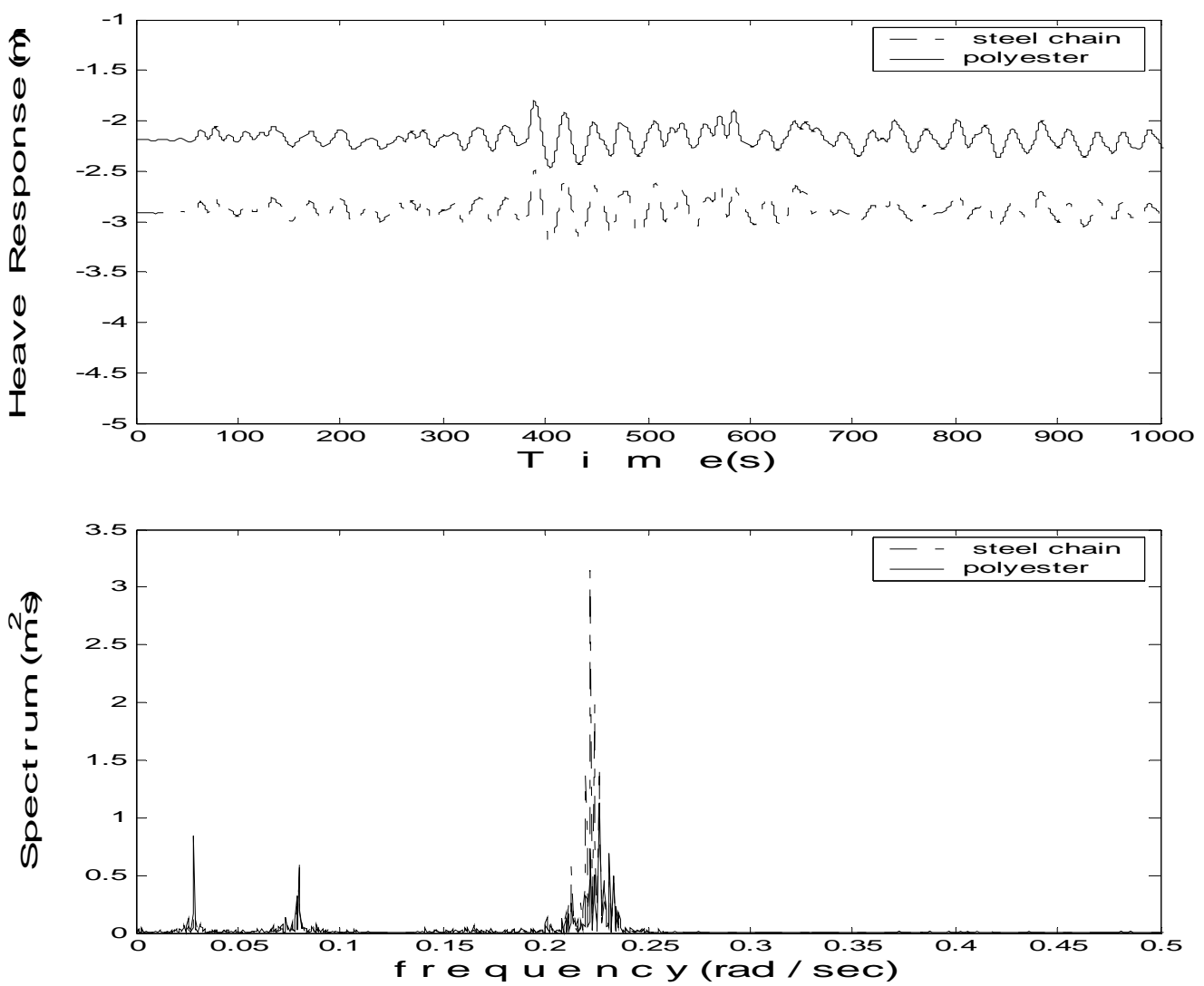

Fig. 34. Heave motions of chain-wire and polyester mooring system in hurricane condition as a function of a) time and b) frequency 

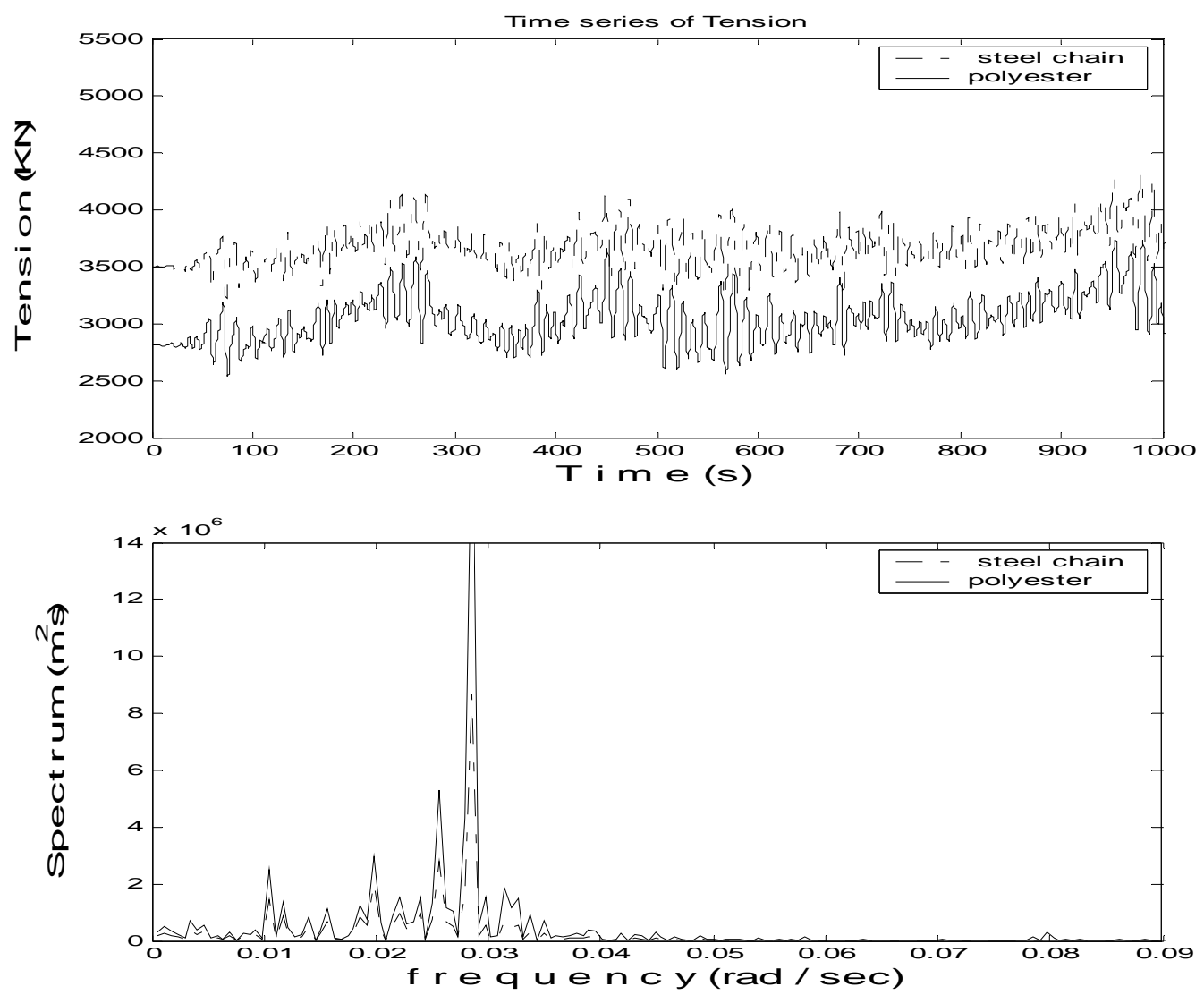

Fig. 35. Line 1 tensions of steel chain-wire and polyester mooring system in hurricane condition as a function of a) time and b) frequency 

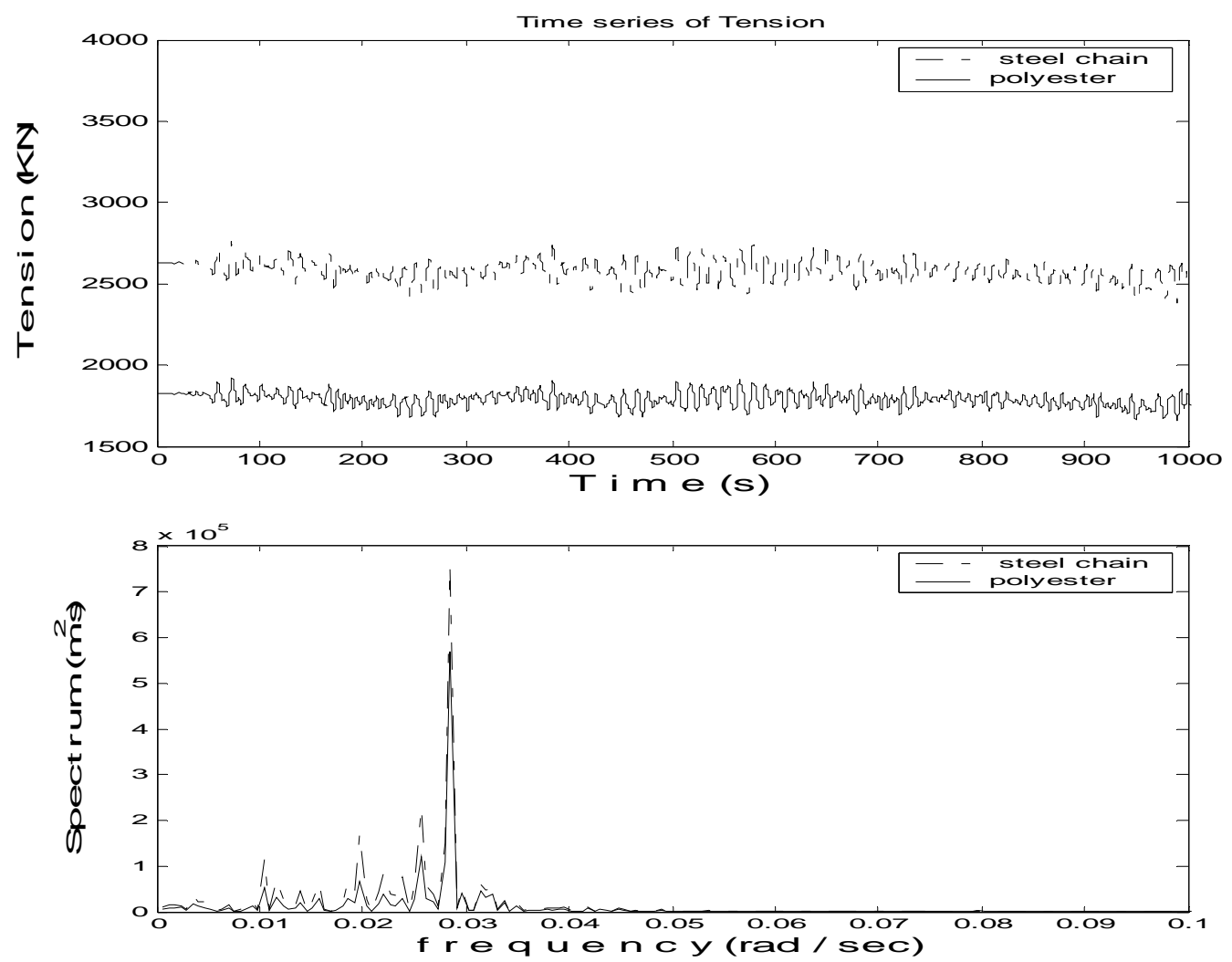

Fig. 36 Line 8 tensions of steel chain-wire and polyester mooring system in hurricane condition as a function of a) time and b) frequency

Table 12 Statistics of the coupled analysis of steel and polyester mooring systems

\begin{tabular}{|l|c|c|c|c|c|}
\hline Steel chain-wire & Surge (m) & Sway (m) & Heave (m) & Line 1 Tension(KN) & Line 8 Tension(KN) \\
\hline Max & -8.4150 & 3.0019 & -2.2870 & $4.7916 \mathrm{E}+03$ & $2.8311 \mathrm{E}+03$ \\
\hline Min & -20.8424 & -5.0147 & -3.2476 & $3.1021 \mathrm{E}+03$ & $2.3196 \mathrm{E}+03$ \\
\hline Mean & -13.6238 & -0.9325 & -2.8765 & $3.6739 \mathrm{E}+03$ & $2.5797 \mathrm{E}+03$ \\
\hline Standard D. & 1.8871 & 1.8549 & 0.1239 & $1.9577 \mathrm{E}+02$ & $6.6439 \mathrm{E}+01$ \\
\hline polyester & Surge (m) & Sway (m) & Heave (m) & Line 1 Tension (KN) & Line 8 Tension (KN) \\
\hline Max & -8.1094 & 3.0267 & -1.6381 & $4.6675 \mathrm{E}+03$ & $2.0036 \mathrm{E}+03$ \\
\hline Min & -21.5061 & -4.8430 & -2.4965 & $2.3089 \mathrm{E}+03$ & $1.5962 \mathrm{E}+03$ \\
\hline Mean & -13.8858 & -0.9235 & -2.1645 & $3.0367 \mathrm{E}+03$ & $1.7914 \mathrm{E}+03$ \\
\hline Standard D. & 1.8750 & 1.8178 & 0.1056 & $2.5100 \mathrm{E}+02$ & $4.9100 \mathrm{E}+01$ \\
\hline
\end{tabular}




\subsection{0-year loop current condition}

\subsubsection{Simulation results of a hybrid polyester mooring system}

As described as in section 6.4.2, numerical simulations of the polyester mooring system were conducted in three different ways: modulus based on mean loads only, modulus based on both mean and dynamic loads, and the inclusion of structural damping.

When the modulus includes the modification due to dynamic loads, surge motion slightly increases but sway and heave motions change a little. The structural damping does not make noticeable contribution to the results of simulations in the case of loop currents. The results of the three cases are plotted in Figs. $37-39$. Time series of tension in Lines 8 and 1 are drawn in Figs. 40 and 41. Statistics of motions of the SPAR and tensions in Line 8 and 1 are summarized in Table 13. Based on the comparison observed in these figures and table, we may also conclude that dynamic effects and structural damping effects do not significantly influence on the motion of the SPAR and the tension in mooring lines, and structural damping is negligible for coupled analysis of polyester ropes. 

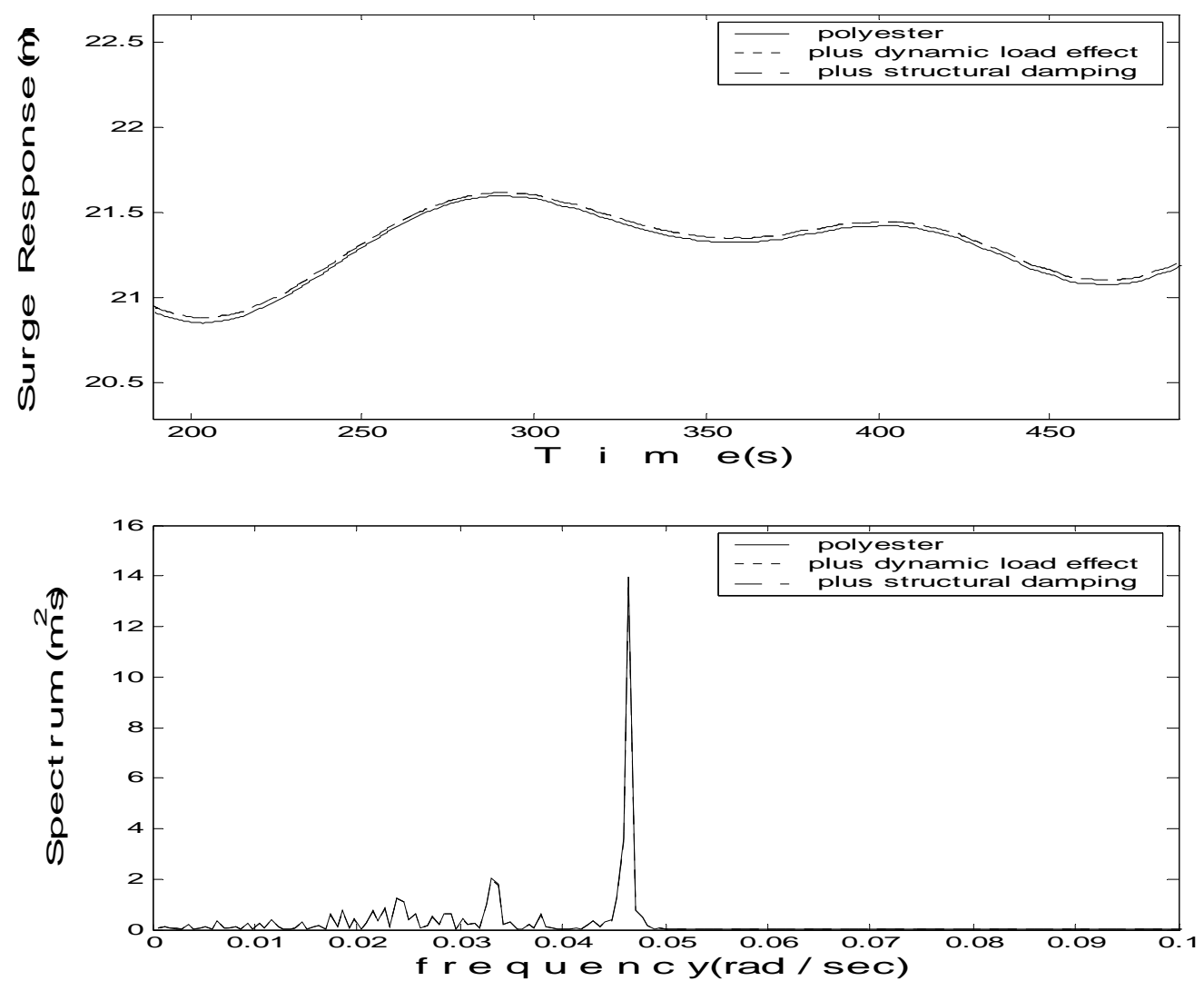

Fig. 37. Surge motions of hybrid polyester mooring systems in loop current condition as a function of a) time and b) frequency 

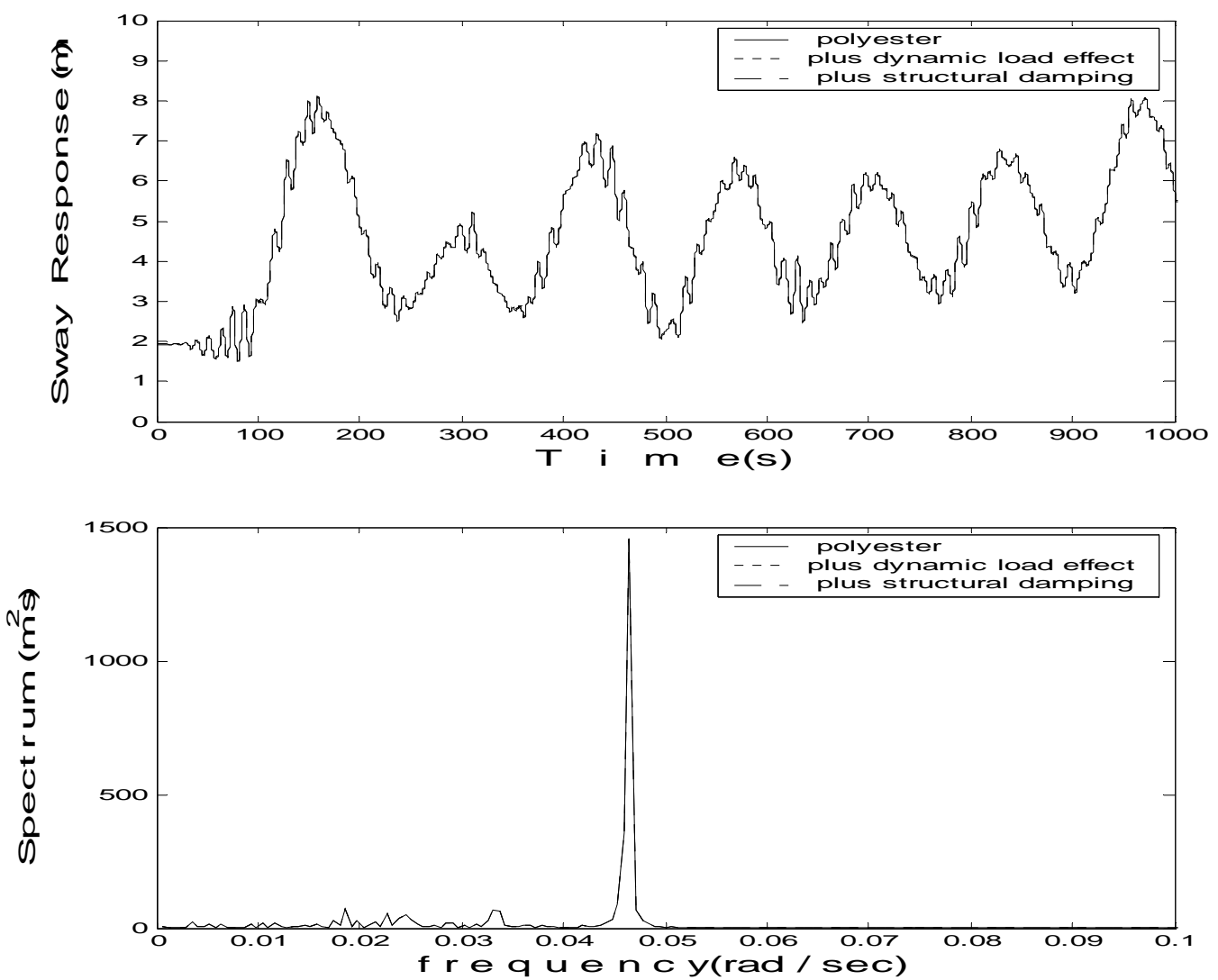

Fig. 38. Sway motions of hybrid polyester mooring systems in loop current condition as a function of a) time and b) frequency 

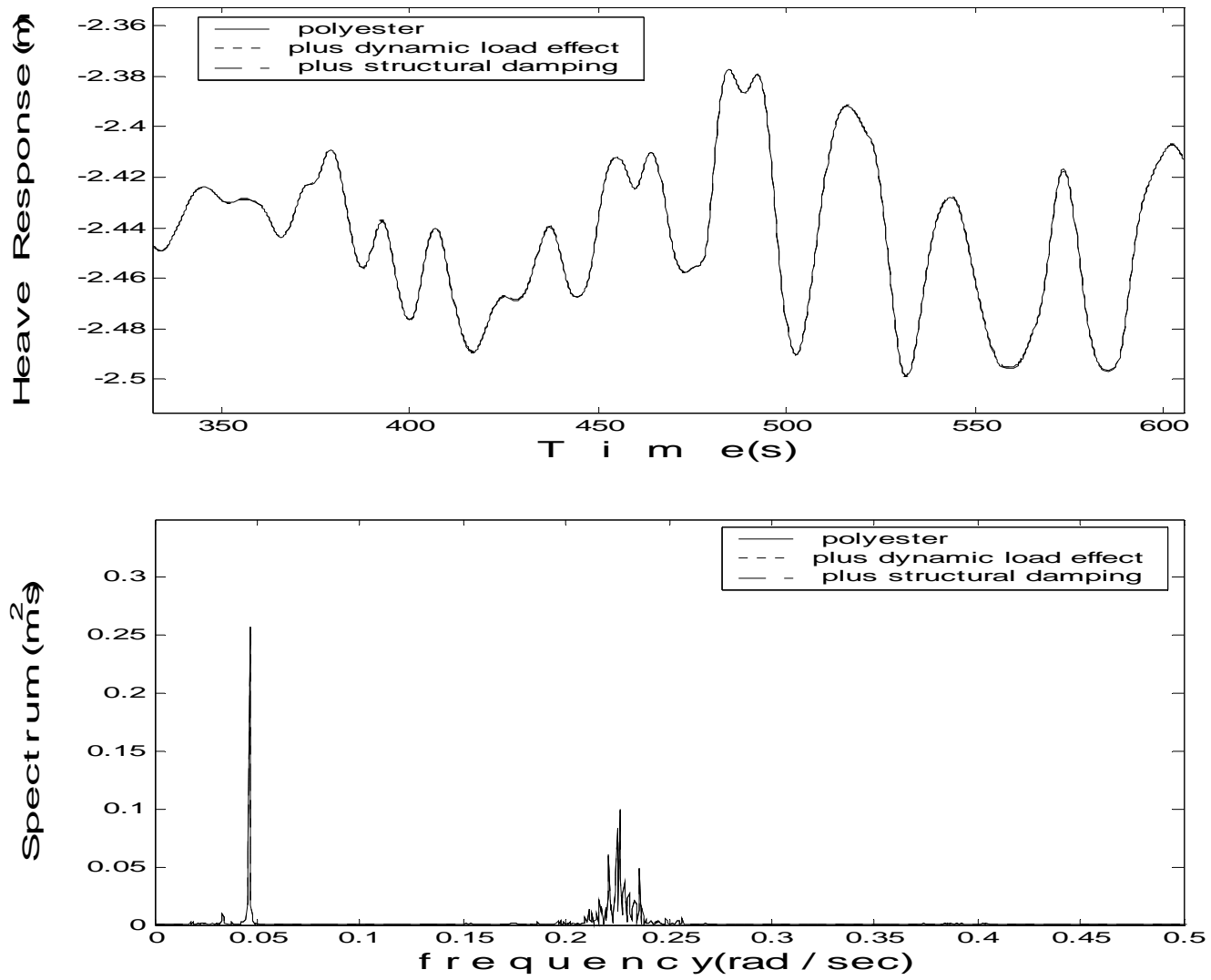

Fig. 39. Heave motions of hybrid polyester mooring systems in loop current condition as a function of a) time and b) frequency 


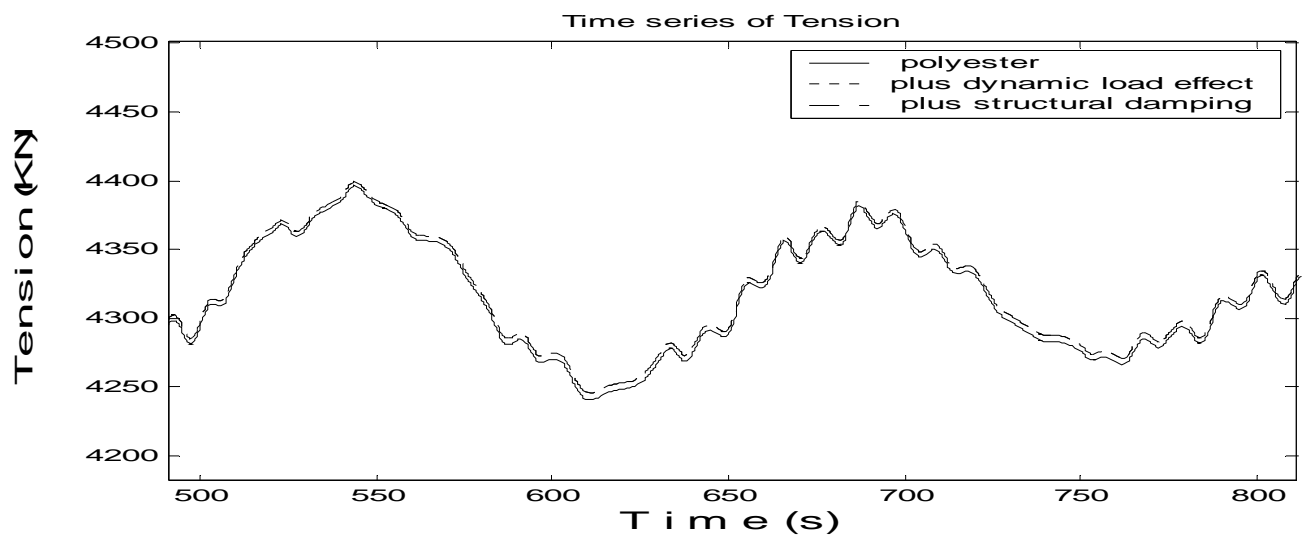

Fig. 40. Tension of hybrid polyester line 8 in loop current condition

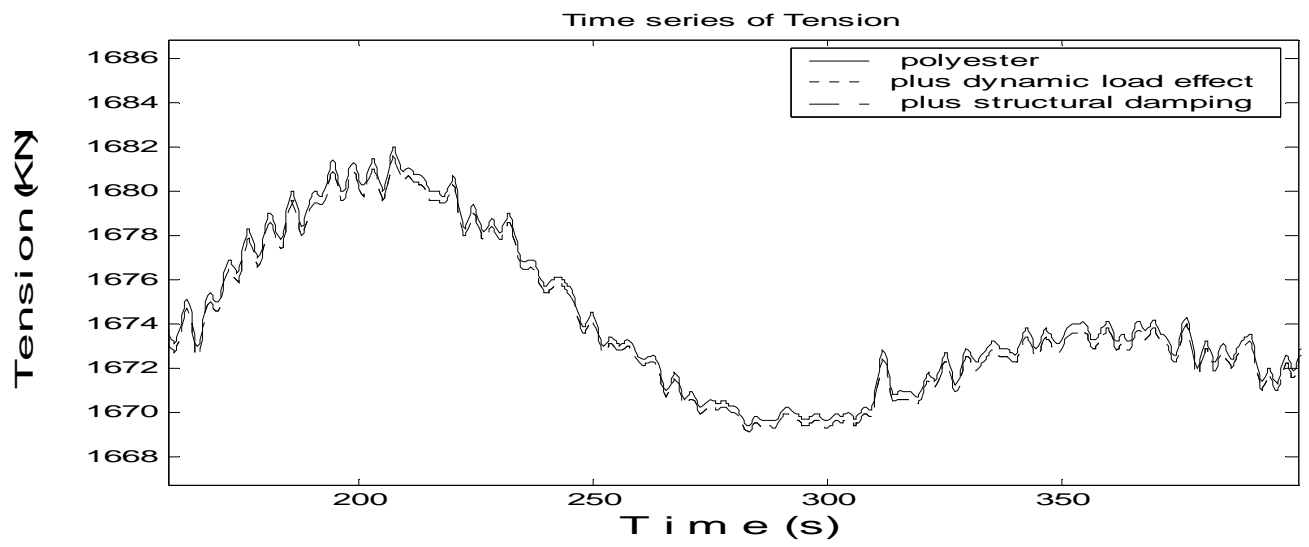

Fig. 41. Tension of hybrid polyester line 1 in loop current condition 
Table 13 Statistics of motions and tensions of polyester mooring systems in loop current condition

\begin{tabular}{|c|c|c|c|c|c|}
\hline Mean load E effects & Surge (m) & Sway (m) & Heave (m) & Line 8 Tension $(\mathrm{KN})$ & Line 1 Tension (KN) \\
\hline Max & 21.7514 & 8.7324 & -2.3228 & $4.4270 \mathrm{E}+03$ & $1.6820 \mathrm{E}+03$ \\
\hline Min & 20.8444 & 1.1972 & -2.5471 & $4.1721 \mathrm{E}+03$ & $1.6662 \mathrm{E}+03$ \\
\hline Mean & 21.3353 & 4.5785 & -2.4441 & $4.3079 \mathrm{E}+03$ & $1.6735 \mathrm{E}+03$ \\
\hline Standard D. & 0.1578 & 1.3628 & 0.0308 & $4.1869 \mathrm{E}+01$ & $2.4671 \mathrm{E}+00$ \\
\hline Dynamic load E effects & Surge (m) & Sway (m) & Heave (m) & Line 8 Tension (KN) & Line 1 Tension (KN) \\
\hline Max & 21.7722 & 8.7510 & -2.3226 & $4.4301 \mathrm{E}+03$ & $1.6816 \mathrm{E}+03$ \\
\hline Min & 20.8743 & 1.2123 & -2.5468 & $4.1772 \mathrm{E}+03$ & $1.6659 \mathrm{E}+03$ \\
\hline Mean & 21.3596 & 4.5950 & -2.4439 & $4.3118 \mathrm{E}+03$ & $1.6732 \mathrm{E}+03$ \\
\hline Standard D. & 0.1559 & 1.3625 & 0.0307 & $4.1412 \mathrm{E}+01$ & $2.4389 \mathrm{E}+00$ \\
\hline $\begin{array}{l}\text { Dynamic load E effects + } \\
\text { Structural damping }\end{array}$ & Surge (m) & Sway (m) & Heave (m) & Line 8 Tension (KN) & Line 1 Tension (KN) \\
\hline Max & 21.7722 & 8.7510 & -2.3226 & $4.4301 \mathrm{E}+03$ & $1.6816 \mathrm{E}+03$ \\
\hline Min & 20.8743 & 1.2123 & -2.5468 & $4.1772 \mathrm{E}+03$ & $1.6659 \mathrm{E}+03$ \\
\hline Mean & 21.3596 & 4.5950 & -2.4439 & $4.3118 \mathrm{E}+03$ & $1.6732 \mathrm{E}+03$ \\
\hline Standard D. & 0.1559 & 1.3625 & 0.0307 & $4.1412 \mathrm{E}+01$ & $2.4389 \mathrm{E}+00$ \\
\hline
\end{tabular}

\subsubsection{Comparison of the polyester mooring system to the steel mooring system}

In this section, the results of numerical simulations of the polyester mooring and steel chain mooring system were compared. The time series and spectra of motions of the SPAR are plotted in Figs. 42 - 44. As shown in surge stiffness curve (see Fig. 9.), the polyester mooing system is softer than the corresponding steel mooring system below 15 $\mathrm{m}$ surge excursion and stiffer above $15 \mathrm{~m}$ surge excursion. Therefore, the static equilibrium position (around $21 \mathrm{~m}$ in surge) of the polyester system is closer to original mean position than that of the steel mooring system.

In the case of loop currents, wave and wind forces are in the y direction, resulting 
in high frequency motions in the sway direction. As plotted in Fig. 43, the sway motion of the SPAR of the steel mooring system is slightly larger than that of the polyester mooring system, because the polyester mooring system is stiffer.

Time series and spectra of heave responses are compared in Fig. 44. The mean draw-down force of the polyester mooring system is much smaller than that of the steel mooring system, because a smaller pretension was applied. As shown in Fig. 44, the heave spectra of the two mooring systems have different trends. The heave pertaining to the polyester mooring system shows larger response at very low frequencies, while that of a steel chain-wire mooring system is greater at relatively high frequencies. As shown in Figs. 45 and 46, mean tensions in polyester mooring lines were significantly lower than those in steel mooring lines but the very low-frequency component of the tension in a polyester rope is grater than the latter. Statistics of numerical simulation are summarized in Table 14. 

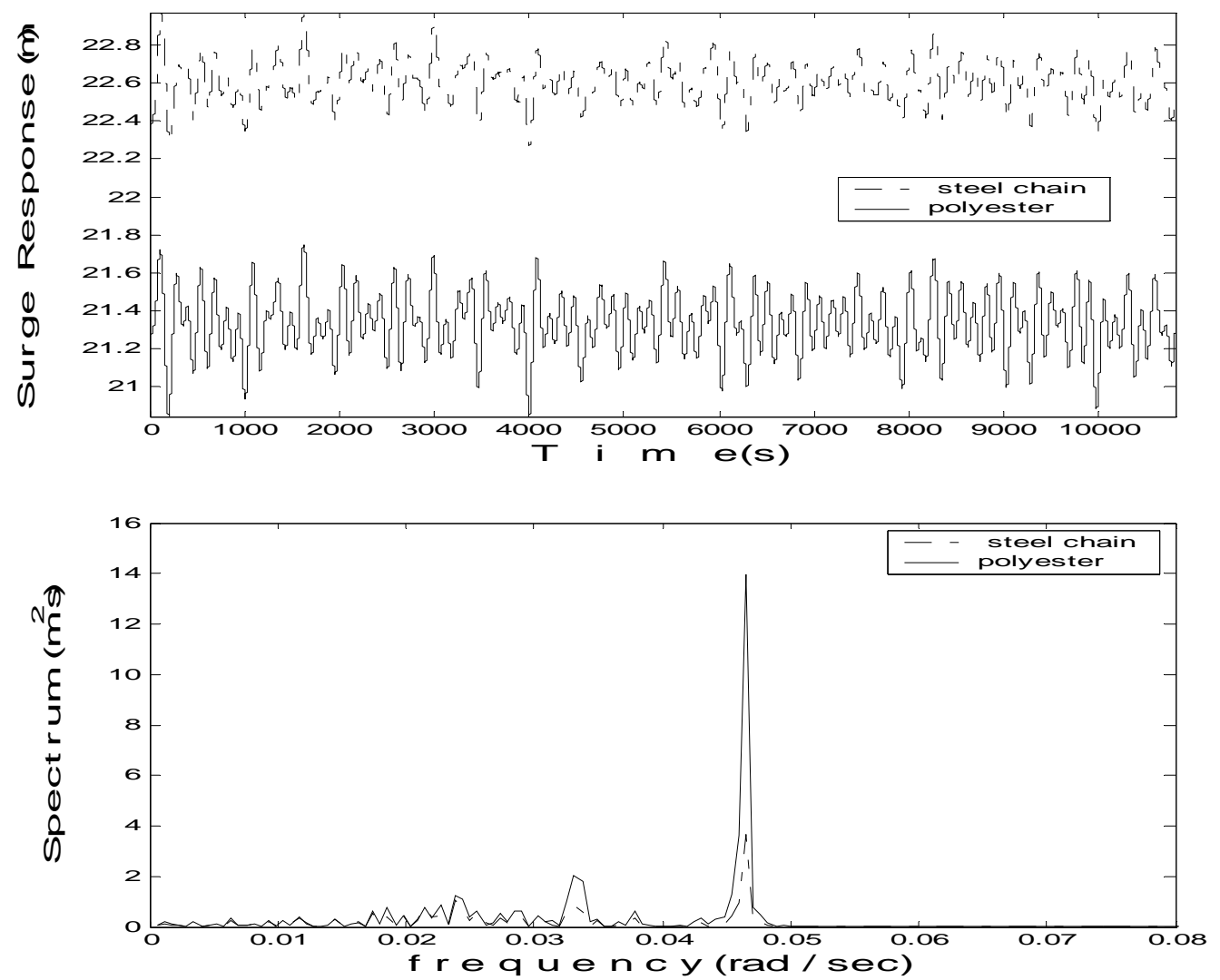

Fig. 42. Surge motions of chain-wire and polyester mooring system in loop current condition as a function of a) time and b) frequency 

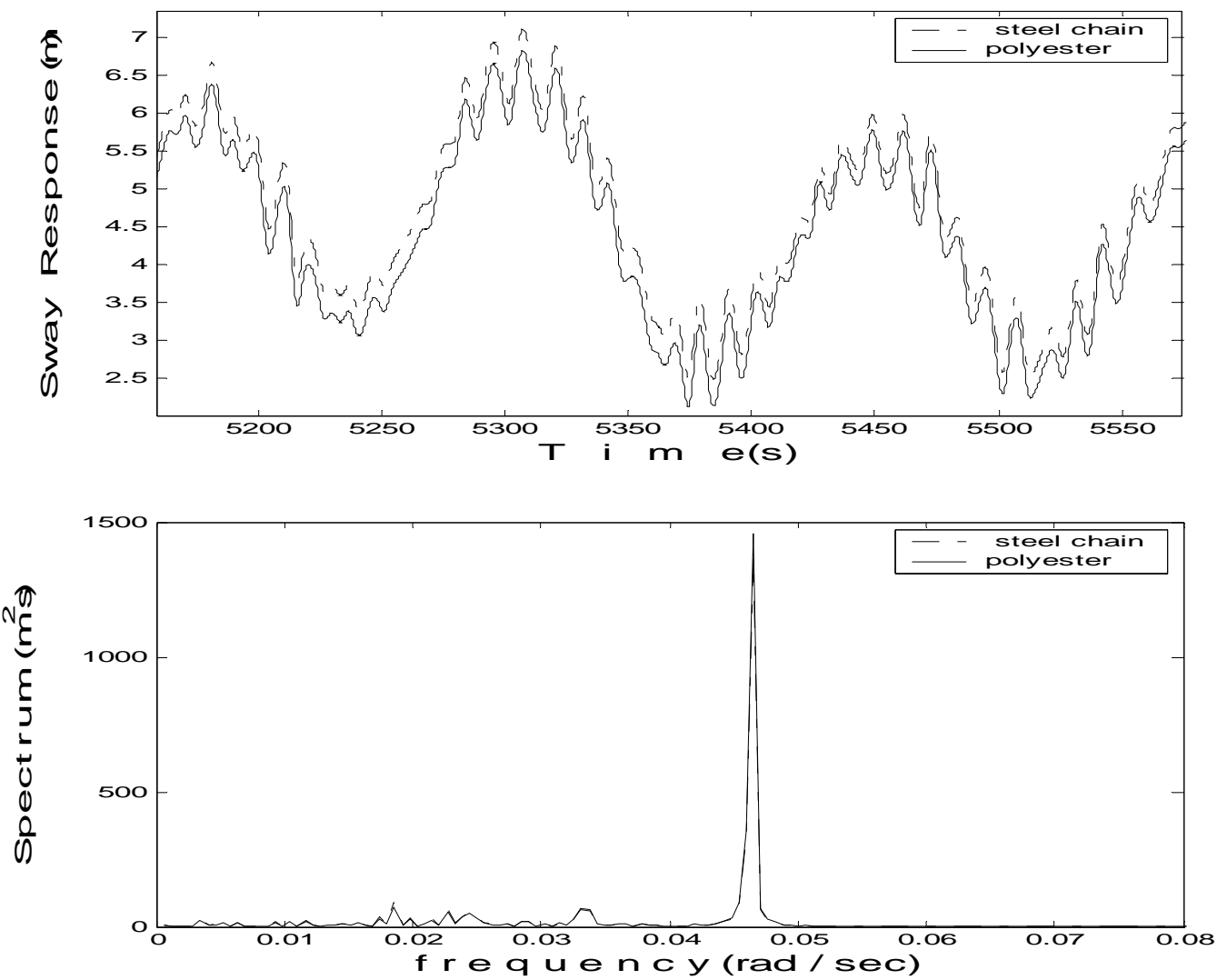

Fig. 43. Sway motions of chain-wire and polyester mooring system in loop current condition as a function of a) time and b) frequency 

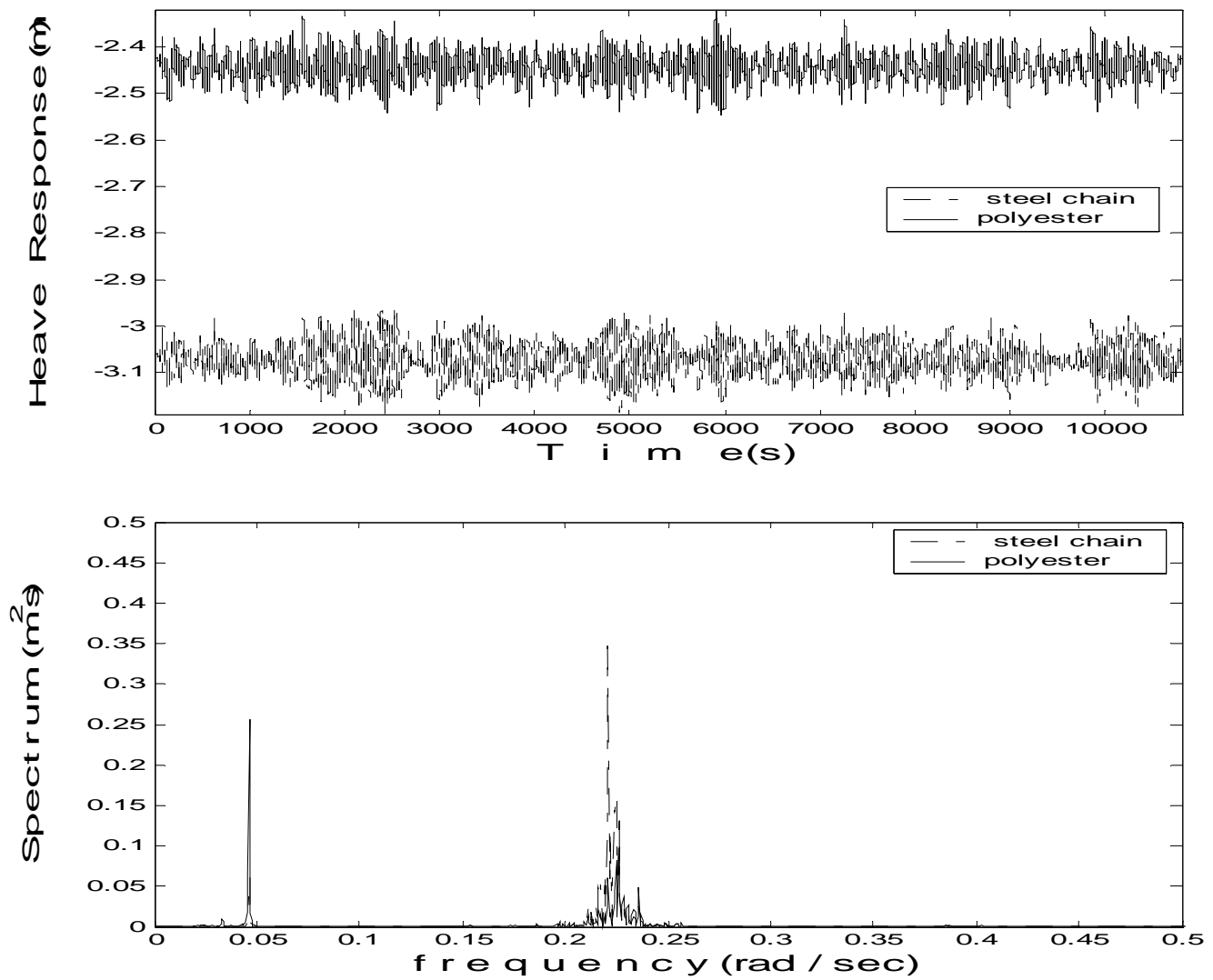

Fig. 44. Heave motions of chain-wire and polyester mooring system in loop current condition as a function of a) time and b) frequency 

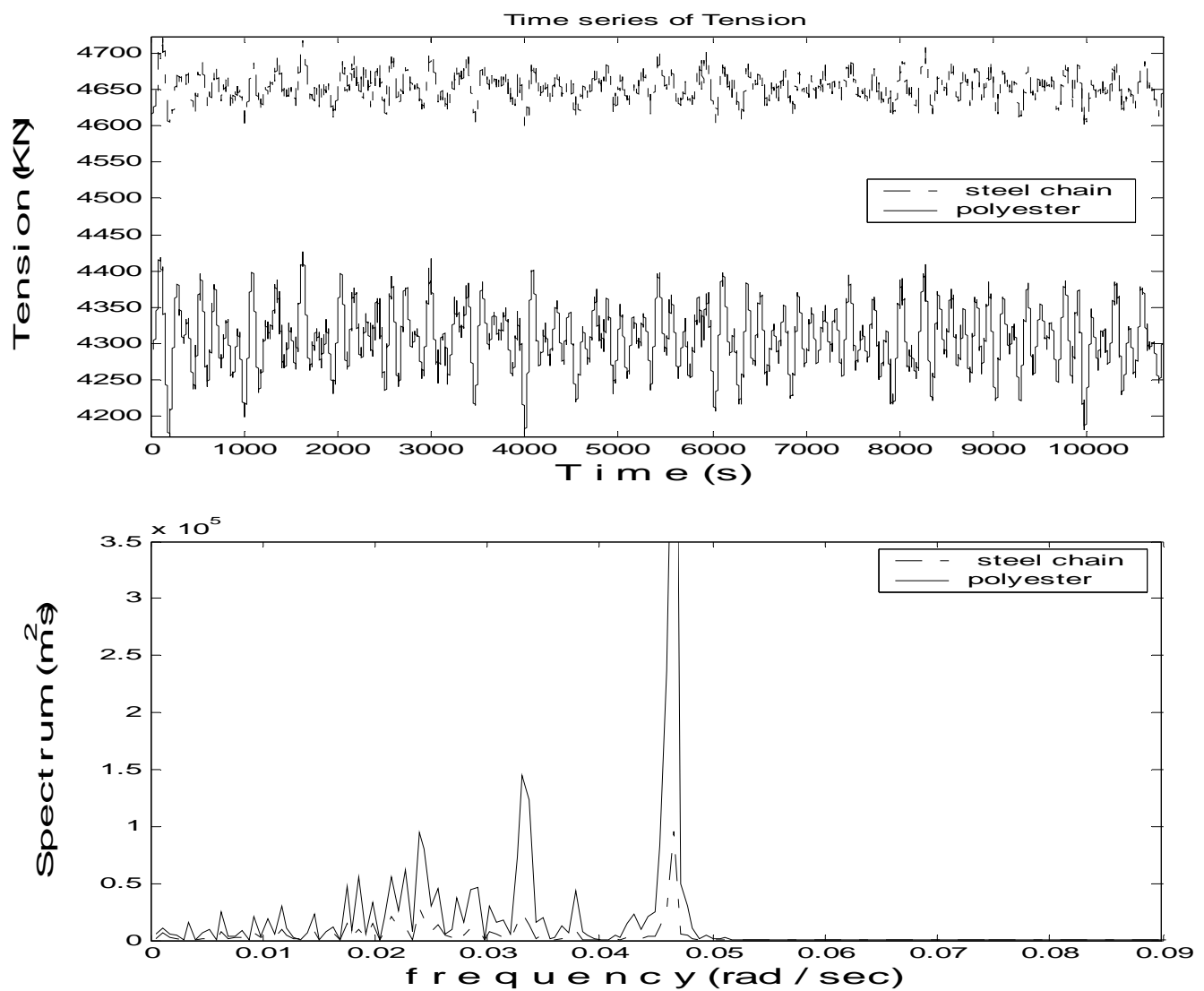

Fig. 45. Line 8 tensions of chain-wire and polyester mooring system in loop current condition as a function of a) time and b) frequency 

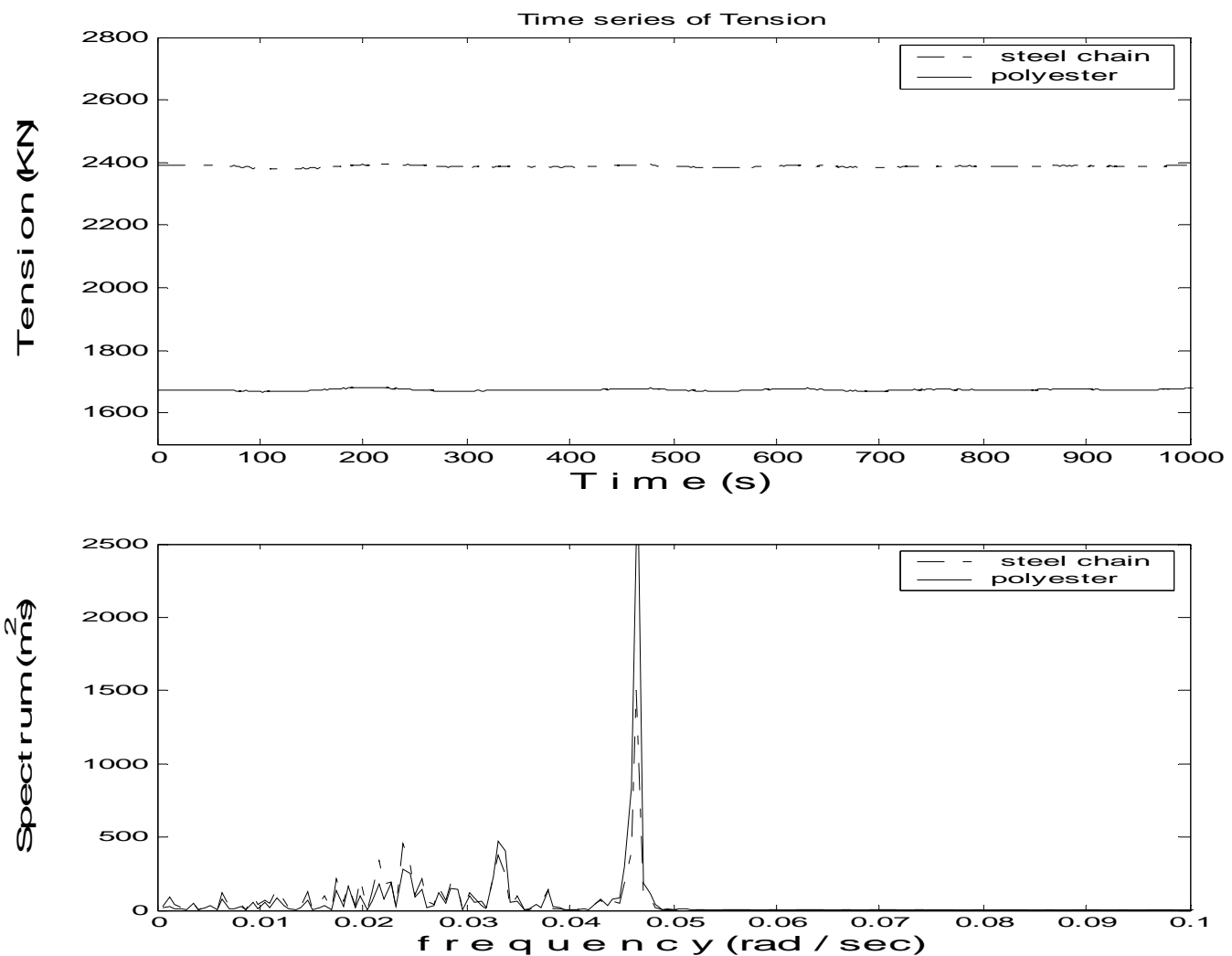

Fig. 46. Line 1 tensions of chain-wire and polyester mooring system in loop current condition as a function of a) time and b) frequency

Table 14 Statistics of steel and polyester mooring systems

\begin{tabular}{|l|c|c|c|c|c|}
\hline Steel chain-wire & Surge (m) & Sway (m) & Heave (m) & Line 8 Tension(KN) & Line 1 Tension(KN) \\
\hline Max & 22.9699 & 9.0925 & -2.9517 & $4.7216 \mathrm{E}+03$ & $2.3962 \mathrm{E}+03$ \\
\hline Min & 22.2702 & 1.4558 & -3.1918 & $4.5949 \mathrm{E}+03$ & $2.3782 \mathrm{E}+03$ \\
\hline Mean & 22.6028 & 4.8886 & -3.0720 & $4.6530 \mathrm{E}+03$ & $2.3875 \mathrm{E}+03$ \\
\hline Standard D. & 0.1100 & 1.3533 & 0.0371 & $1.8607 \mathrm{E}+01$ & $2.4853 \mathrm{E}+01$ \\
\hline polyester & Surge (m) & Sway (m) & Heave (m) & Line 8 Tension (KN) & Line 1 Tension (KN) \\
\hline Max & 21.7514 & 8.7324 & -2.3228 & $4.4270 \mathrm{E}+03$ & $1.6820 \mathrm{E}+03$ \\
\hline Min & 20.8444 & 1.1972 & -2.5471 & $4.1721 \mathrm{E}+03$ & $1.6662 \mathrm{E}+03$ \\
\hline Mean & 21.3353 & 4.5785 & -2.4441 & $4.3079 \mathrm{E}+03$ & $1.6735 \mathrm{E}+03$ \\
\hline Standard D. & 0.1578 & 1.3628 & 0.0308 & $4.1869 \mathrm{E}+01$ & $2.4671 \mathrm{E}+00$ \\
\hline
\end{tabular}




\section{CHAPTER VII}

\section{CONCLUSIONS}

Current trend of the offshore industry is to replace steel wires used in deepwater mooring systems by much lighter and more elastic polyester ropes. A hybrid polyester mooring system is taut and different from a conventional catenary steel mooring system, resulting in a smaller footprint than the latter. However, the behaviors of polyester ropes under either steady or cyclic tensions are quite different from those of steel chain or wires. In addition to the lack of experiences or industrial standards on long-term deployment of polyester ropes as the component of mooring lines in ocean environment, main concern to the designers of a polyester mooring system is nonlinear and nonrepeatable relation between the stress and strain of a polyester rope, which is quite different from that of steel chains and wires.

In this study, we modified a numerical scheme, known as CABLE3D, originally developed for the simulation of dynamics of steel mooring lines so that the large elongation under tension, the dependence of the modulus on both mean and dynamic tensions, and energy dissipation due to hysterisis under cyclic loading of a polyester rope can be accounted. The modified CABLE3D were then integrated into a numerical package, known as COUPLE6D, for computing the interaction between a floating structure and its hybrid polyester mooring system. In this study, we chose the Deepstar Spar to represent the floating structure. The following findings observed from our numerical simulation although limited to the Spar may have implications to the 
numerical simulation of other floating offshore structures interacting with a polyester mooring system.

While the neglect of elongation in steel chains or wires does not significantly change the static offset curve of a steel mooring system, the consideration of elongation in polyester ropes may result in significant changes in the offset curve of a polyester mooring system, that is, about $10 \%$ reduction in restoring force at the mean offset position of the Spar under the impact of 100-year hurricane storm. Hence, it is important to include the effects of elongation of polyester ropes in the numerical simulation. In addition, we also found the inclusion of elongation of polyester rope may effectively eliminate resonant longitudinal vibrations in a coupled dynamic simulation although they can also be eliminated by including the energy dissipation in polyester ropes under cyclic loads.

The empirical formula for modeling dependence of the modulus of polyester ropes on the mean and dynamic tensions can be approximately implemented in time-domain simulations through iterative processes presented in this study. It is found that the effects of the mean loads on the modulus of polyester ropes are much greater than those of the dynamic loads. Hence, the effects of mean loads on the modulus are more important to the response of floating structures. The energy dissipation in polyester ropes under cyclic loading does not play significant roles in the responses of the Spar and tensions in the polyester mooring systems. 


\section{REFERENCES}

API RP2SK, 1996. Recommended Practice for Design and Analysis of Stationkeeping Systems for Floating Structures. American Petroleum Institute, Washington, DC.

API RP 2SM, 1999. Recommend Practice for Design, Manufacture, Installation, and Maintenance of Synthetic Fiber Ropes for Offshore Mooring, American Petroleum Institute, Washington, DC.

Berteaux H. O., 1976. Buoy Engineering, John Wiley \& Sons, Inc, New York.

Bosman, R. L. M., 1996. On the origin of heat build-up in polyester ropes, Oceans Conference Record (IEEE), v1, 332-338

Bosman, R. L. M., Hooker, J., 1999. Elastic modulus characteristics of polyester mooring ropes. In: Proceedings of the Annual Offshore Technology Conference, v3, 139-143.

CERC Technical Memorandum, 1998. Synthetic Fiber Rope Moorings Workshop, Composites Engineering and Application Center for Petroleum Exploration and Production, University of Houston, TX.

Chen, X., 2002. Studies on dynamic interaction between deep-water floating structures and their mooring/tendon systems. Ph.D. dissertation, Ocean Engineering Program, Civil Engineering Department, Texas A\&M University, College Station.

Del Vecchio, C.J.M., 1992. Light weight materials for deep water moorings, Ph D. dissertation, University of Reading, UK. 
Ding, Y., Kim, M., Chen, X., Zhang, J., 2003. A numerical code (COUPLE 6D) for coupled dynamic analysis of moored offshore structures. In: Proceedings of the International Symposium, Deep Water Mooring Systems, Houston, TX, pp. 168 - 182

Fernandes, A. C., Del Vecchio C. J. M., Castro G. A. V., 1998. Mechanical properties of polyester mooring cables, International Journal of Offshore and Polar Engineering, 9(3), 248-254.

Garrett, D.L., 1982. Dynamic analysis of slender rods. Journal of Energy Resources Technology, Transactions of ASME 104, 302-307.

Lee, C.H., 1995. WAMIT Theory Manual. Report No. 95-2, Massachusetts Institute of Technology, Cambridge, MA.

Lo, K. H., H. Xu, 1999. Polyester rope mooring design considerations. In: Proceedings of the 1999 ISOPE Conference, International Society of Offshore and Polar Engineering, Cupertino, CA.

Ma, W., Webster, W.C., 1994. An Analytical Approach to Cable Dynamics: Theory and User Manual. Sea Grant Project R/OE-26.

Meirovitch, L. 1967. Analytical Methods in Vibrations, Macmillan Publishing Co., Inc, New York.

Morton, W. E. 1975. Physical Properties of Textile Fibers $2^{\text {nd }}$, Halsted Press, A Division of John Wiley \& Sons, Inc., New York

Nordgren, R.P., 1974. On computation of the motion of elastic rods. ASME Journal of Applied Mechanics, September, 777-780. 
Paulling, J.R., Webster, W.C., 1986. A consistent large-amplitude analysis of the coupled response of a TLP and tendon system. In: Proceedings of Offshore Mechanics and Arctic Engineering (OMAE), Tokyo, Japan, Vol.3, pp. 126-133.

Van Den Heuvel, C. J. M., Heuvel, H. M., Faassen, W. A., Veurink, J., Lucas, L. J., 1993. Molecular changes of PET yarns during stretching, measured with rheo-optical infrared spectroscopy and other techniques, J Applied Polymer Science, Vol. 49, pp. 925-934

WAMIT, Inc., 1999. WAMIT User Manual Versions 5.4, 5.4PC, 5.3S. Massachusetts Institute of Technology, Cambridge, MA.

Ye, M., 1994. Prediction of unidirectional irregular wave kinematics and evolution. MS Thesis, Ocean Engineering Program, Civil Engineering Department, Texas A\&M University, College Station.

Zhang, J., Chen, L., Ye, M., Randall, R.E., 1996. Hybrid wave model for unidirectional irregular waves - part I theory and numerical scheme. Applied Ocean Research 18, 77-92.

Zhang, J., Prislin, I., Yang, J., Wen J., 1997. Deterministic decomposition and prediction of irregular ocean waves. COE Report No.358, Civil Engineering Department, Texas A\&M University, College Station, Texas. 


\section{APPENDIX A}

\section{ISSUES RELATED TO THE SAFETY FACTOR OF POLYESTER ROPES}

In using polyester ropes, the offshore industry does pay attention to safety factor, life cycle of fatigue, creep strain deformation with respect to time. For instance, regarding conventional steel wire ropes and chain, API recommended factor of safety as 1.67. For polyester ropes, ABS recommended 1.82 for those ropes. That shows $9 \%$ increase in the value of the safety factor in comparison with that of wire. The design safety factor is increased to compensate for the uncertainties in the performance of polyester ropes.

Creep rupture may significantly influence safety, because it is related to high tension load intimately. Prediction of creep rupture life should not be made without experimental verification and the experimental results show that rapid reduction of creep rupture life (time of breaking) can occur at high tension loads. In view of the rapid reduction in the predicted creep rupture life with increasing loads, a design tension limit equals to $60 \%$ of the breaking load of a conventional steel chain might not be suitable for polyester mooring ropes (Van Den Heuvel et al., 1993).

If there were the large variation of the maximum mooring line tension in different environments or considered more severe rope condition (damaged or transient condition), the selection of a relatively more conservative safety factor seems to be reasonable to be applied universally. For example, API RP 2SK (1997) recommended that considerable 
maximum tension limits should be estimated from 55\% under intact condition to $85 \%$ of a breaking strength under transient condition. In contrary, creep deformation did not catch the attention of industry. Because creep deformation is not significantly large, it is not a main concern under normal operating conditions in which mooring system will operate during 20-year service period (Lo et al., 1999).

Another key issue is fatigue life estimation. It is noted that fatigue test results vary with rope construction and end termination. If the average breaking strength of rope is readily available, fatigue life graph in the range of breaking strength must be used to determine the initial size of the mooring rope as the starting point of the design. Unfortunately, the test data that can be used with confidence for the fatigue design of polyester ropes are still quite limited. However, there is sufficient evidence to show that the fatigue life of polyester ropes will be greater than that of the steel wire and chain (CEACTM, 1998).

Although practical guidelines have been presented for the polyester rope design until now based on available data and previous research work in the literature, again, they mentioned that polyester rope stiffness does still remain to be resolved on design issues. Because stiffness estimation requires complicated non-liner model that had not been solved, the variation of polyester rope stiffness that depends on time characteristics like mean tension, load amplitude and load history is difficult to solve. 


\section{VITA}

Min Suk Kim was born in 1974 in Seoul, South Korea. He entered the Department of Naval Architecture and Ocean Engineering at Inha University, Seoul, Korea in 1993. After finishing his military service in Korean Army for two and a half years, he graduated in August 2000 with a B.S. degree in naval architecture and ocean engineering. He enrolled in the Department of Civil Engineering at Texas A\&M University in August 2001. His research focused on dynamic simulation of polyester mooring lines.

Permanent Address:

$539-7$

Pang-Bae Dong, Sucho-Gu

Seoul, South Korea 